Professional Development as a Strategy

for Curriculum Implementation

in Multidisciplinary Science Education.

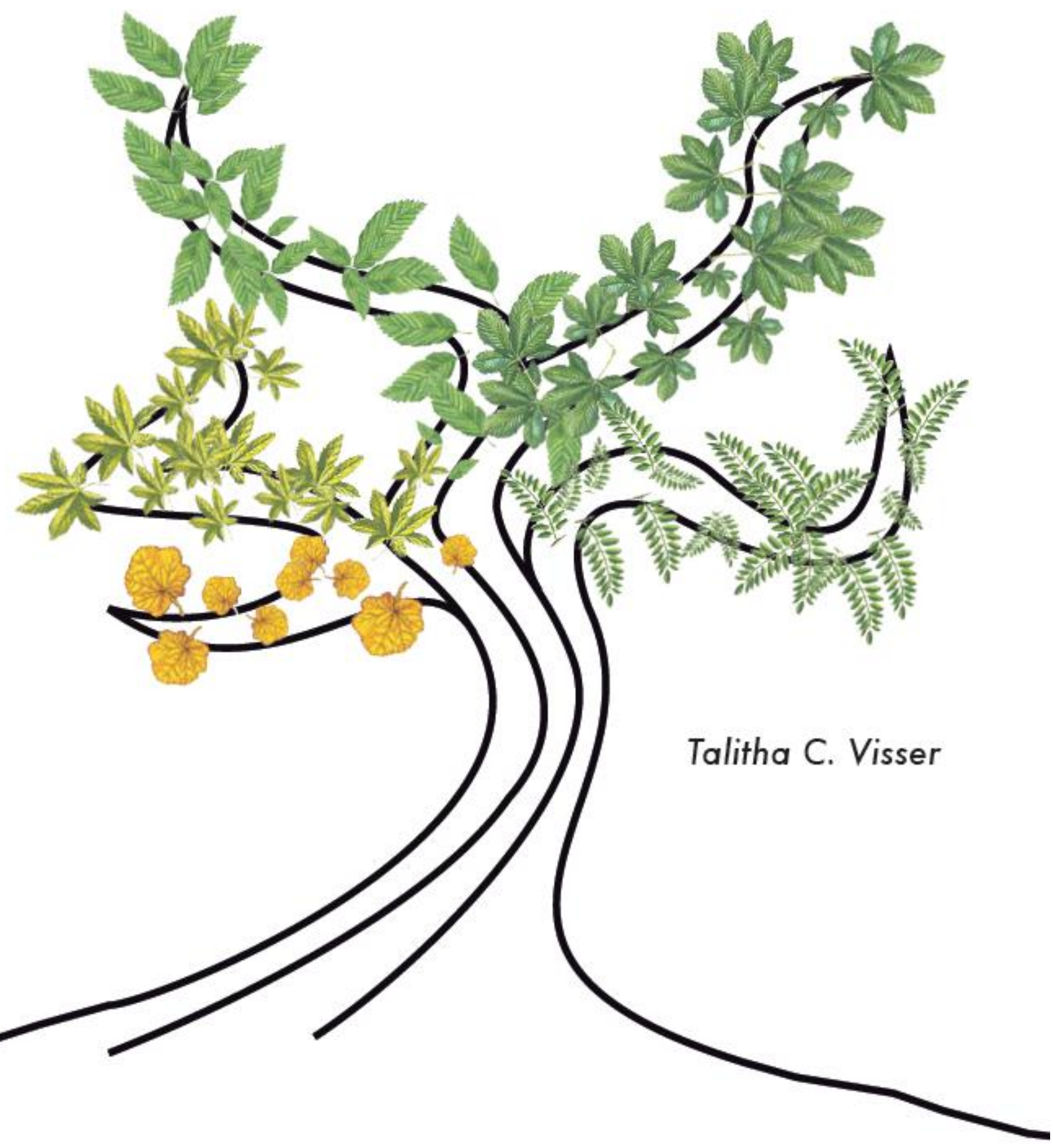




\section{PROFESSIONAL DEVELOPMENT AS A STRATEGY FOR CURRICULUM IMPLEMENTATION IN MULTIDISCIPLINARY SCIENCE EDUCATION}

Talitha C. Visser 
DOCTORAL COMMITTEE

Chair

Prof. Dr. K. I. van Oudenhoven-Van der Zee - University of Twente

Promotor

Prof. Dr. J. M. Pieters - University of Twente

Assistant promotors $\quad$ Dr. C. Terlouw - Saxion University of Applied Sciences

Dr. F. G. M. Coenders = University of Twente

Members

Prof. Dr. J. J. H. van den Akker $\approx$ University of Twente

Prof. Dr. W. R. van Joolingen = University of Twente

Prof. Dr. Tj. Plomp $=$ University of Twente

Prof. Dr. D. Beijaard - Eindhoven University of Technology

Prof. Dr. K. T. Boersma $~=$ University of Utrecht

Dr. J. M. Voogt $=$ University of Twente

\section{UNIVERSITY OF TWENTE.}

This dissertation was supported by the funding from Platform Bèta Techniek, DUDOC programme and facilitated by the Institute for Teacher Education, Science Communication \& School Practices, University of Twente.

Visser, T.C.

Professional Development as a Strategy for Curriculum Implementation in Multidisciplinary Science Education

Thesis University of Twente, Enschede

ISBN 978-90-365-3405-5

DOI 10.3990/1.9789036534055

Cover: Jeanine A. Visser

Layout: Sandra Schele

Press: Ipskamp Drukkers B.V.- Enschede

(C) Copyright, 2012, T.C. Visser

All rights reserved 


\title{
Professional DeVelopment as a StRategy FOR CURRICULUM IMPLEMENTATION IN MUlTIDISCIPLINARY SCIENCE EDUCATION
}

\author{
DISSERTATION \\ to obtain \\ the degree of doctor at the University of Twente, \\ on the authority of the rector magnificus, \\ prof. dr. H. Brinksma, \\ on account of the decision of the graduation committee \\ to be publicly defended \\ on the $25^{\text {th }}$ of October 2012 at 14.45 \\ by \\ Talitha Christine Visser \\ born on the $24^{\text {th }}$ of December 1980 \\ in Dronten
}


Promotor

Assistant promotors
Prof. Dr. J. M. Pieters

Dr. C. Terlouw

Dr. F. G. M. Coenders

This dissertation has been approved by the promotor and assistant promotors. 



\section{TABLE OF CONTENTS}

LIST OF FIGURES AND TABLES $\quad$ v

1. GENERAL INTRODUCTION 1

1.1 Problem statement 1

1.2 Context of the study: Nature, Life, and Technology 5

1.2.1 NLT at the curriculum level 5

1.2.2 NLT at school and class level 8

$\begin{array}{ll}1.3 \text { Conceptual framework } & 10\end{array}$

$\begin{array}{ll}\text { 1.3.1 Curriculum implementation } & 10\end{array}$

1.3.2 Teacher professional development programme 13

1.3.3 Evaluation of the effectiveness of a teacher professional development programme 15

1.4 Research goal, general research questions, and research approach 17

$\begin{array}{ll}1.5 \text { Overview of this study } & 21\end{array}$

2. ESSENTIAL CHARACTERISTICS FOR A PROFESSIONAL DEVELOPMENT PROGRAMME FOR PROMOTING THE IMPLEMENTATION OF A MULTIDISCIPLINARY SCIENCE MODULE 25

2.1 Introduction 26

2.2 Research questions $\quad 28$

2.3 Conceptual framework 28

2.3.1 The 'Evidence-based' approach $\quad 28$

2.3.2 The NLT subject 30

2.3.3 Research about effective implementation 32

2.4 Methods 34

2.4.1 Participants 34

2.4.2 Data collection instruments 34

2.4.3 Procedure 35

2.4.4 Analysis 35 
3. DESIGN AND APPLICATION OF A MODEL FOR A PROFESSIONAL DEVELOPMENT PROGRAMME FOR A MULTIDISCIPLINARY SCIENCE SUBJECT

3.1 Introduction 50

3.2 Towards a model 51

3.2.1 Nature, Life, and Technology 52

3.2.2 Curriculum design phases 53

3.2.3 Essential characteristics for a professional development programme 54

3.3 A generic model for a professional development programme 59

3.4 The generic model applied on a specific NLT module called 'The hydrogen car'

3.5 Expert appraisal $\quad 67$

$\begin{array}{ll}3.6 \text { Discussion } & 69\end{array}$

4. EVALUATING TEACHERS' SATISFACTION ABOUT A PROFESSIONAL DEVELOPMENT PROGRAMME FOR IMPLEMENTATION OF A MULTIDISCIPLINARY SCIENCE SUBJECT

73

4.1 Introduction $\quad 74$

$\begin{array}{ll}4.2 \text { Conceptual framework } & 75\end{array}$

4.2.1 Nature, Life, and Technology $\quad 75$

4.2.2 Professional development programme $\quad 76$

$\begin{array}{lll}4.2 .3 & \text { Evaluation } & 81\end{array}$

4.3 Research question $\quad 82$

$\begin{array}{ll}4.4 \text { Method } & 82\end{array}$

$\begin{array}{lll}\text { 4.4.1 Context } & 82\end{array}$

4.4.2 Participants $\quad 82$

$\begin{array}{lll}\text { 4.4.3 Data instruments and analysis } & 83\end{array}$

4.5 Results 86

4.6 Conclusions and discussion $\quad 92$

4.7 Implications 95 


\section{THE LEARNING EFFECTS OF A MULTIDISCIPLINARY PROFESSIONAL}

DEVELOPMENT PROGRAMME

$\begin{array}{ll}5.1 \text { Introduction } & 97\end{array}$

5.2 Conceptual framework 98

5.2.1 Nature, Life, and Technology 98

5.2.2 Professional development programme 100

5.2.3 Evaluating effectiveness of the professional development programme 104

$\begin{array}{ll}5.3 \text { Research questions } & 106\end{array}$

$\begin{array}{ll}5.4 \text { Methods } & 106\end{array}$

$\begin{array}{lll}5.4 .1 & \text { Participants } & 106\end{array}$

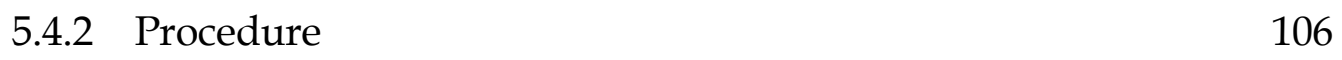

$\begin{array}{lll}5.4 .3 & \text { Data sources } & 108\end{array}$

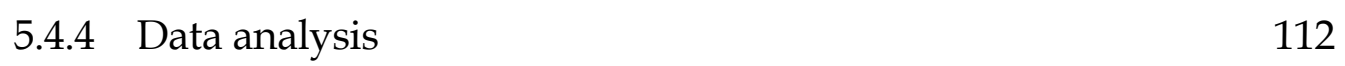

5.4.5 Determination of the reliability 114

$\begin{array}{ll}5.5 \text { Results } & 114\end{array}$

$\begin{array}{ll}5.6 \text { Conclusion } & 130\end{array}$

$\begin{array}{ll}5.7 \text { Discussion } & 131\end{array}$

6. CONCLUSIONS, DISCUSSION, AND RECOMMENDATIONS 135

$\begin{array}{ll}\text { 6.1 Aim and research questions } & 135\end{array}$

6.2 Summarizing the main findings of the previous chapters 137

6.2.1 Results of the first study: Essential characteristics for a professional development programme for promoting the implementation of a multidisciplinary science module

6.2.2 Results of the second study: Design and application of a generic model for a professional development programme for a multidisciplinary science subject

6.2.3 Results of the third study: Evaluating a professional development for the implementation of a multidisciplinary science module and its learning effects

6.3 Reflections on the general research approach and its outcomes 144

6.3.1 Reflection on the analysis of the problem 145

6.3.2 Reflection on the development of potential solutions phase 148

6.3.3 Reflection on the implementation and evaluation 153

6.3.4 Reflection in order to formulate design principles 161

$\begin{array}{ll}6.4 \text { Recommendations for future research } & 165\end{array}$ 
REFERENCES

ENGLISH SUMMARY

NEDERLANDSE SAMENVATTING

DANKWOORD

APPENDIX

189

Questionnaire used for the expert appraisal

CURRICULUM VITAE

191 


\section{LIST OF FIGURES AND TABLES}

\section{FIGURES}

$\begin{array}{lll}1.1 & \text { Four phases of design research } & 18\end{array}$

1.2 Overview of the study 23

2.1 Categories influencing implementation 32

2.2 Flow of the study 36

3.1 Generic model for a professional development programme $\quad 60$

4.1 Generic model for a professional development programme $\quad 76$

5.1 Generic model for a professional development programme 101

6.1 Generic model for a professional development programme $\quad 140$

\section{TABLES}

1.1 Curriculum levels applied to the NLT curriculum 11

2.1 Five-by-five curriculum components and design matrix 29

2.2 Partly filled curriculum components and design matrix 35

2.3 Characteristics that according to the teachers need attention during the selection of a NLT module 39

2.4 Stimulating and hindering characteristics categorized in three groups of professionality $\quad 41$

3.1 Characteristics categorized into three factors of Guskey 56

3.2 Characteristics related to the generic professional development programme model 61

3.3 Collaborative seminar programme including underlying goal and teacher activities 63

3.4 Results of the questionnaire by the three experts 69 
4.1 Collaborative seminar programme including underlying goal and teacher activities

4.2 Overview of the instruments used in the four stages of the professional development programme

4.3 Number of participants rating each question on a 1-5 Likert scale about the contribution of the preparation seminar to ideas (Instrument C)

4.4 Overview of the teaching information and number of responses to the coordinator on the Friday e-mail

4.5 Questions and answers concerning satisfaction regarding the reflection meeting from four teachers participating in the professional development programme of module I

5.1 Characteristics of module instruction per school

5.2 Overview of the data sources used to answer the five research questions

5.3 Operationalization of the questions used to answer research question 1 and 3, contribution to ideas and teacher learning

5.4 Operationalization of the questions used to answer research question 2, class use

5.5 How the preparation seminar contributed to ideas for the different learning areas

5.6 Overview of what teachers used in their classes

5.7 Overview of teacher learning

5.8 Pattern that occur when combining contribution of ideas from

Table 5.5, use in teacher's class from Table 5.6, and teacher learning from Table 5.7

5.9 Assessment results from the students per school 


\section{CHAPTER 1 \\ General introduction}

The first chapter provides a general introduction to the multiple sub-studies reported in this dissertation. The statement of the problem is described, including the focus of the overall study, followed by an overview of the specific context of the research. Highlights of the conceptual framework for the study are given, namely curriculum innovation, professional development, and evaluation, followed by a description of the research design. The chapter ends with an outline of the structure of the dissertation, including the different sub-questions addressed in each sub-study, and an overview of the content of the subsequent chapters.

\subsection{Problem Statement}

Schoolteachers must deal with curriculum innovations during their teaching careers. In recent years, educational innovations have followed one another rapidly, especially in the field of the natural sciences. In 2000, the European Union (EU) agreed to the 'Lisbon Strategy', an action and development plan devised for the economy of the European Union for the period between 2000 and 2010 (European Commision, 2000). Its aim was to make the EU 'the most competitive and dynamic knowledge-based economy in the world capable of sustainable economic growth with more and better jobs and greater social cohesion', by 2010. To pursue this strategy in the Netherlands, the 'Platform Bèta Techniek' got a new directive from the Ministry of Education, Culture and Science in 2003, with the goal of producing $15 \%$ more graduating science students in 2010 than in 2000. Because technology and science have a natural place in overall economic development, 'Platform Bèta Techniek' was established as an organization in which representatives from the Dutch knowledge-based economy can stimulate educational innovations that can change, for the public in general, the negative image of science and ensure 
sufficient numbers of well-trained scientists and engineers. The re-design of the existing science curriculum and the introduction of interesting, new subjects in a science curriculum are means applied in order to reach the before mentioned goals.

The introduction of a new subject into the curriculum of secondary education with its own examination programme is a rare event in the Netherlands, because it requires a rather complex law change. In 2000, the relatively small subject, 'Public Understanding of Science (PUSc)' was introduced (Henze, 2006), with a 120-160 hour study load. The purpose of PUSc was to help students to put science and technology within a wider cultural perspective, and to gain insight into the relation between scientific knowledge and other important aspects of our civilization. PUSc was originally compulsory for all students in upper secondary education, and all schools offered the same content knowledge. Since August 2007, the subject has only been compulsory for certain students in upper secondary education.

In 2005 the Dutch Ministry of Education, Culture and Science set up innovation committees to develop and redesign the curricula for chemistry, biology, physics, and mathematics in secondary education. In addition, in 2006 a steering committee was established with the task of developing a new multidisciplinary subject, 'Nature, Life, and Technology ${ }^{1}$ (NLT)'. NLT differs from the other science subjects in that it is a new school subject for which no curriculum or learning goals had been designed up to that point (Steering Committee NLT, 2007). The purpose of redesigning the curricula and introducing a new subject was to increase the attractiveness of science education and the coherence between the traditional science subjects (Steering Committee NLT, 2010). This is expected to result in new science curricula that better align with recent developments in science, address the current overloaded curricula, and attract more students for science studies.

Each innovation committee decided to use a form of context-based education (Boersma, Eijkelhof, van Koten, Siersma, \& van Weert, 2006), but specified the elements of context-based education differently. Context-based curricula are considered a pedagogical vehicle for increasing the attractiveness and relevance of science and for boosting student motivation. It is argued that recognizable

1 Also known as Advanced Science Mathematics and Technology (ASMaT). 
contexts will appeal to students and built a bridge between the intuitive knowledge that students already have and the concepts intended to be learned. The context is expected to help students give meaning to the concepts they learn. This context-based science education is used in several approaches in different countries, for instance, Salters in the UK (Burton, Holman, Lazonby, Pilling, \& Waddington, 2000) and Chemie im Kontext in Germany (Parchmann et al., 2006). We will come back on the context-based approach later in this chapter.

In the multidisciplinary subject of NLT, students are challenged to become acquainted with contexts that include new, often multidisciplinary or even interdisciplinary developments in science or technology. The issue of multidisciplinarity (combination of disciplinary perspectives, each maintaining their own identity) vs. interdisciplinarity (integration of disciplinary perspectives) and cooperation in multidisciplinary teams are quite common in research, business, and health care. Scientists increasingly cooperate in multidisciplinary groups on topics that cannot be tackled successfully from one specific disciplinary perspective (Black \& Atkin, 1996). For example, multiple perspectives are necessary in studying climate, environment, and health. In their future careers, students must be able to work in multidisciplinary teams to resolve interdisciplinary issues. Newswander and Borrego (2009) report that recent studies suggest that students around the globe are often educated too narrowly, disciplinary, and that certain problems demand an interdisciplinary perspective. Interdisciplinary science has come to be considered an important component of graduate education in the US in recent years (Sa, 2008), Secondary schools in the Netherlands are also increasingly integrating disciplinary perspectives into their programmes, although a multidisciplinary approach predominates. The introduction of a new multidisciplinary or interdisciplinary science subject bears similarities to the implementation of science education reforms in countries such as the UK and the US (National Research Council, 2012; Teaching and Learning Research Programme, 2006).

In this context of science education the next two issues often emerge. First, the discussion about context-based education. As described before, context-based science education is used in several qualities in different countries (Boersma et al., 2006; Burton et al., 2000; Gilbert, 2006; Parchmann et al., 2006). In the next section, we will explain how we used the context-based approach in the context of the multidisciplinary subject NLT. Second, 'interdisciplinary' and 'multidisciplinary' are often topic of debate. By many researchers, different 
definitions are used for both approaches dependent upon the application in various domains and contexts (Borrego \& Newswander, 2008; Campbell \& Henning, 2010; Şahin, Sarı, Demir, Demirci, \& Usta, 2010). In dealing with context-based science education, interdisciplinarity may be prevalent in the problems students are confronted with, i.e. in a coherent and integrative way. As an interdisciplinary approach science problems will be analyzed and solved through the use of an own integrated theoretical, conceptual, and even paradigmatic identity. In a multidisciplinary approach these problems will be analyzed and solved from different angles, using different disciplinary perspectives, with no integration of different theoretical perspectives and disciplinary findings. In a learning environment for context-based education, the disciplinary concepts will be integratively acquired and constructed in the learning environment, from the multidisiciplinary perspective, whereas from an interdisciplinary perspective integration will be effective after learning has been achieved through transfer to different problems and task environments.

The introduction of a new subject such as NLT can be considered a curriculum innovation. It is widely acknowledged that teachers play an important role during the implementation of a curriculum innovation, as they must enact the new curriculum in their classes (Fullan, 2007; Geijsel, Sleegers, Van Den Berg, \& Kelchtermans, 2001). The success of the implementation of a new curriculum depends among other factors on the active involvement of teachers in the curriculum design process, their feeling of ownership of this curriculum, and teacher professional development opportunities (Borko, Jacobs, \& Koellner, 2010; Hargreaves, 1994; Penuel, Fishman, Yamaguchi, \& Gallagher, 2007; Rousseau, 2004; Wikeley, 2005). Preparing teachers for a new curriculum can be seen as a mutual adaptation and learning process, in which the teachers bring their knowledge, skills, and beliefs into alignment with the new curricular demands and vice versa (Kezar, 2012; Lotan \& Navarrete, 1986; McLaughlin, 1976; Voogt et al., 2011). These general implementation characteristics such as taking teachers' prior knowledge and beliefs as a starting point, providing opportunities to practice, reflecting on own practice, creating ownership, and collaboration have proven to be applicable in context-based science teaching (Coenders, 2010; De Putter-Smits, 2012; Stolk, Bulte, de Jong, \& Pilot, 2009). To prepare teachers for an educational reform such as NLT and context-based science teaching, various professional development activities can be developed and carried out. This study focuses on the design and implementation of a 
professional development programme consistent with school practices (Hill \& Cohen, 2005; Waslander, 2007), in order to assist and support teachers of NLT before, during, and after class use of a multidisciplinary science module. The effects of this programme in terms of teacher learning, class use and student learning are examined.

\subsection{CONTEXT OF THE STUDY: NATURE, LifE, AND TECHNOLOGY}

In this section we describe the subject NLT, first at the curriculum level and second at school and class level.

\subsubsection{NLT at the curriculum level}

NLT was introduced into the science curriculum of the upper level of secondary education in the Netherlands in August 2007. Schools interested in offering NLT had to register at the National Steering Committee responsible for the development and implementation of this subject (Steering Committee NLT, 2007).

The objectives for introducing NLT into the school curriculum are the following (Steering Committee NLT, 2007):

1. to enable a broader and more in-depth educational programme for study of science and mathematics;

2. to enable students to become familiar with a wide range of higher education options and professions;

3. to allow students to experience the importance of multidisciplinary coherence in the development of science and technology;

4. to create a closer connection between science education and new developments in society, science, and technology;

5. to offer more choices to teachers and students within the educational science programme at school; and

6. to make a permanent contribution to innovation in science education.

Students in the upper level of secondary education in the Netherlands choose their study programme. This programme consists of three parts: general common subjects; 'profile' subjects; and elective subjects. The general common subjects are identical for all students, such as, for example, Dutch and English. For the 
elective part, students can fill in their study programme by selecting subjects of their choice. For the remainder of their study programme, students must choose one of four profiles, with characteristic subjects for each profile. They can choose from: Nature \& Technology, Nature \& Health, Economy \& Society, and Culture \& Society. NLT is an elective subject, and schools therefore have the freedom to offer it (or not). NLT can be offered within the two Nature profiles, 'Nature \& Technology' and 'Nature \& Health'. NLT has a study load of 320-440 hours, comparable to compulsory courses such as chemistry or biology.

While NLT differs from other traditional science subjects, they nonetheless share certain properties. In accordance with the direction chosen by the committees for the separate science disciplines, NLT also uses the contextbased approach. The innovation committees for the science subjects each specified various definitions of the context-concept approach to use (Boersma et al., 2006). Gilbert (2006) organizes context-concept approaches according to four models. The first model refers to 'context' as the direct application of concepts. The second model brings opportunities for a 'context' by taking the reciprocal between concepts and applications. The third model assumes 'context' to be provided by personal mental activity. Finally, the fourth model considers 'context' as a social circumstance. Based on Van Oers (1998), Gilbert makes a distinction between two interpretations of the fourth model: (a) 'a context as social surrounding' and (b) 'a context as social activity'. The Dutch approach is an elaboration of the interpretation of 'context as social activity'. Within this framework of 'context as social activity', several Dutch authors focus on authentic practices as a starting point for science learning (Bulte, Westbroek, Jong, \& Pilot, 2006; Prins, 2011).

The definitions of the function of contexts differed across the innovation committees. The committees identified four types of contexts: social, vocational, practical, and theoretical (Goedhart, 2004). In each case, it is important to select contexts with interrelated relevant concepts, and to ensure that students are able to acquire the intended concepts from the selected contexts.

Unlike the other science subjects, NLT was context-based from its inception. In the context-concept approach formulated for NLT by the National Steering Committee (2007), potential contexts for NLT are practical situations of everyday life, professional practices, or knowledge development in specific 
areas of science and technology. NLT has a modular structure, integrating elements from physics, chemistry, biology, mathematics, and physical geography within its modules. The two modules implemented in this research, 'The hydrogen car' and 'The brain and learning', both have the context of a practical situation from everyday life. The topic of 'hydrogen cars' often appears in the newspaper. Fossil fuels are running out and fuel is getting more and more expensive. Students investigate whether hydrogen is a suitable alternative for fossil fuels. This question addresses concepts from different disciplines and therefore its answer must build upon multidisciplinary and even interdisciplinary perspectives. Aspects from different disciplines will be taught in most cases by one or two teachers with a Master's degree in one of the relevant mono-disciplines. In this module, aspects such as: an electrochemical cell (chemistry), catalysts (chemistry), properties of molecules (chemistry), climate change and depletion of fossil fuels (geography), and calculation of mathematical and physical forces on a car will be dealt with. Through this integrative, interdisciplinary character of NLT modules, their content goes beyond being just the sum of the contents of the traditional science subjects, although the individual teachers each bring their mono-disciplinary backgrounds. The introduction of NLT with a context-based approach and an interdisciplinary perspective offers an environment in which there is need for adequate professional development and the opportunity to create an interdisciplinary approach. However, although the subject itself is committed to interdisciplinarity, the instruction delivered by the teachers is conducted in a multidisciplinary way. Therefore, throughout this dissertation the multidisciplinary perspective will be addressed.

The examination programme for NLT describes the requirements students must meet to complete NLT as an examination subject. The examination programme for NLT, unlike those for the other science subjects, does not include historical basic concepts. The NLT examination programme consists of nine different domains, worked out between 2006 and 2007 in collaboration between schools and other (educational) institutions (higher education, business companies). The starting point was that every mono-disciplinary domain of science and technology in higher education should be able to identify itself with at least one of the newly created nine domains. For students, NLT is assessed in a school examination and it does not have a central nationwide final exam. Therefore there is relatively substantial freedom in how NLT is implemented. Each of the 
nine domains consists of different modules to choose from. The advantage of the modular structure is that schools have more autonomy in offering this subject. It gives teachers the opportunity to select modules according to their interests and expertise and in relation to their students' interests and prior knowledge.

A minimum of 6-7 modules must be taught, and The National Steering Committee constraints the choices of modules. From the nine domains (labeled A-I), schools must cover the entire skills domain A and one module from content domain B, two modules from content domains C-E, and two-three modules from content domains F-I.

A teaching module consists of a situated practice from everyday life (for example, MP3-players or Molecular gastronomy) together with professional practices (for example, Forensic research or Medical Imaging) or knowledge development in specific areas of science and technology (for example, Biosensors or Nuclear fusion) in which specific concepts traditionally belonging to physics, chemistry, biology, mathematics, and physical geography are explored. Because each domain includes several modules, teachers can select modules according to their own preferences. The following examples illustrate this. In the domain 'Language of science', students learn to use relevant concepts and techniques from mathematics and/or computer science and apply these to scientific or technological issues. Here schools can choose among modules such as 'Dynamic models,' 'Make the difference,' and 'Measuring and interpreting.' Within the domain 'Biomedical technology and biotechnology', modules to choose from include 'Technical design in biomedical technology,' 'Food and fuel,' and 'Artificial kidney and membranes'.

\subsubsection{NLT at school and class level}

At the school level, the implementation of NLT has several specific features (Steering Committee NLT, 2007). Firstly, the interdisciplinary nature of NLT requires at least teachers from the different science disciplines (physics, chemistry, biology, mathematics, and physical geography) to cooperate in a multidisciplinary team (a group of at least three teacher with different background disciplines) in order to implement this new subject. Secondly, teachers of NLT have a Master's degree in one of the five relevant monodisciplinary subjects, although they are not specifically trained for this new interdisciplinary subject. Thirdly, the multidisciplinary team of teachers at the 
school has the freedom to select the modules for each examination domain, and decides on the order in which the modules will be taught. Finally, the school administration, in close consultation with the team of teachers, determines which and how many teachers will be teaching a specific module. Selecting a particular module not only determines the topic and the content, but also to a large extent the teaching methods and the assessment strategies and tools. Because teacher teams make different choices on these topics, implementation varies from school to school.

At the class level, NLT has five particular characteristics (Steering Committee NLT, 2007). Firstly, given the modular and context-based character of NLT, instructional strategies are more diverse than those used in the monodisciplines. Students mostly work in small groups and do a lot of practicals and research projects. Secondly, students are not obliged to take biology, physics or geography, which means that students in NLT can have different levels of prior knowledge for these three subjects that are integrated in NLT. Thirdly, teachers have the freedom to make changes to the subject content, for instance as a result of new developments, lack of time, overloaded modules, or items that appear in the news. Fourthly, as a consequence of the learning goals and the context-based approach, the assessment methods and instruments are more diverse than those used in the mono-disciplines. Examples of possible assessment methods are: a portfolio, an oral presentation, a report, a paper and pencil test, or combinations of some of these. Fifthly, one of the objectives of NLT is to inform students about and to bring them in contact with a broad range of higher education studies and possible careers through organizing field trips and guest lectures.

NLT teachers collaborate in a multidisciplinary team with colleagues from their own school (see below for examples). Besides the NLT team, they also participate in their own mono-disciplinary team, such as the biology department. Most teachers choose a NLT module to teach according to their interests and expertise. A teacher can also teach a module with a co-teacher or co-teachers in their own school. They together prepare the module and thereafter distribute the tasks according to their own interests and expertise. Teachers should cooperate with their own NLT team to use each other's expertise and to improve the implementation of NLT in their school. Teachers who collaborate with colleagues from other schools support each other by sharing materials, experiences, and ideas (cf. Borko, 2004; Penuel et al., 2007). 
Co-teaching NLT and preparing the whole module together, sharing materials, experiences, information, ideas and joining a professional network of NLT teachers at other schools would be ideal for teachers and could support multidisciplinary collaboration across schools and disciplines.

\subsection{CONCEPTUAL FRAMEWORK}

Three central elements in our conceptual framework are discussed: curriculum implementation (1.3.1.), teacher professional development programme (1.3.2.), and evaluation of effectiveness of a teacher professional development programme (1.3.3.).

\subsubsection{Curriculum implementation}

A curriculum is a formal academic plan for the learning experiences of students. Denzure (2003) defined the term curriculum broadly as:

... includes goals for student learning (skills, knowledge and attitudes), the content (the subject matter in which learning experiences are embedded), the sequence (the order in which concepts are presented), the learners, the instructional methods and activities, the instructional resources (materials and settings), the evaluation (methods used to assess student learning as a result of these experiences), and the adjustments to teaching and learning processes, based on experience and evaluation. (p. 510)

This definition is broad enough to include changes in the curriculum due to an innovation that pertains to the involvement of instructional methods, sequencing, and assessment, that together with instructional goals and content have been implemented in order to improve learning. Five different system levels can be distinguished to define the curriculum, according to Van den Akker (2003). In Table 1.1 we show these curriculum levels can be applied to the curriculum innovation of NLT. The division into these five levels will prove to be useful for understanding the coherence of objectives at the supranational and macro level with the realization of curriculum materials on the micro and nano level, and it will contribute to the implementation and evaluation of the NLT modules. 
Table 1.1 Curriculum levels (Van den Akker, 2003) applied to the NLT curriculum

\begin{tabular}{|c|c|c|}
\hline Level & Description & Applied to NLT curriculum \\
\hline SUPRA & International & $\begin{array}{l}\text { European Union plan 'Lisbon Strategy' to increase } \\
\text { knowledge and skills in science and technology } \\
\text { aimed at a competitive knowledge-based economy. }\end{array}$ \\
\hline MACRO & System, national & $\begin{array}{l}\text { Plan for coherent and multidisciplinary integration } \\
\text { of science and technology in authentic contexts to } \\
\text { create a closer connection between science education } \\
\text { and new developments in society, science, and } \\
\text { technology and produce more graduates students in } \\
\text { science. }\end{array}$ \\
\hline MESO & School, institute & $\begin{array}{l}\text { School programme, modularly structured, on } \\
\text { Nature, Life, and Technology. }\end{array}$ \\
\hline MICRO & $\begin{array}{l}\text { Classroom, } \\
\text { teacher }\end{array}$ & $\begin{array}{l}\text { NLT module, for instance Molecular gastronomy or } \\
\text { MP3 player. }\end{array}$ \\
\hline NANO & Pupil, individual & Adaptive materials and individual assignments. \\
\hline
\end{tabular}

However, the relationships from macro via meso to micro are relatively loose for the subject of NLT. Schools are not obliged to implement the subject; teachers and pupils also have a relatively large amount of curricular freedom because of the modular structure. This study concerns the lowest three curriculum levels, with a focus on the micro- and nano-level the NLT module and adaptive materials. Because of the specific NLT features and characteristics mentioned earlier, we consider implementing NLT to be a complex curriculum innovation for the teachers involved.

Fullan (2007) described three broad phases to the innovation process. Phase 1, variously labeled as initiation, mobilization, or adaptation, consists of the process that leads up to include a decision to adopt change. Phase 2, the implementation or initial use (usually the first two to three years of use), involves the first experiences of attempting to put an idea or reform into practice. Phase 3, called continuation, incorporation, routinization or institutionalization, refers to whether the change gets built in as an ongoing part of the system or disappears by way of a decision to discard or through attrition.

Previous experiences with curriculum development in the Netherlands and elsewhere have shown that a new subject is fragile to the already existing 
subjects, especially when they have an interdisciplinary nature (Eijkelhof \& Kruger, 2009). Interdisciplinary activities, with an integrated theoretical and conceptual identity, are yet not common in Dutch schools, the school organization is not tailored to such interdisciplinary teaching, and the monodisciplinarily trained teachers can mainly approach these activities from a multidisciplinary perspective. Additionally, the newly introduced NLT curriculum is assessed in a school examination and does not have a central nationwide final exam. For these reasons, teachers are critical about the quality of the curriculum innovation and mainly the quality of testing in determining differences between schools (Folmer, Ottevanger, Bruning, \& Kuiper, 2011).

Many conditions must be fulfilled to make a curriculum implementation successful (Fullan, 2007; Van den Akker, 2003), a crucial one is the role of the teachers. Teachers need to be actively involved in shaping and adapting curriculum materials for their students and in bringing about change and reform in educational practice. In this study, we particularly focus on the role of teachers in the process of curriculum implementation as part of the curriculum innovation. Implementing a new subject that can be considered a curricular innovation means that teachers must be introduced to the new subject domain, must adopt the innovation, must understand the elements of the innovation, and must acquire new knowledge, skills, and routines needed to adequately teach the new subject (Bergen \& Van Veen, 2004; Van den Akker, 1999). These characteristics are to be incorporated in a programme, aimed at shaping and adapting the curriculum, in which teachers are actively involved, and that implicitly directs teachers' learning and professional development (Garet, Porter, Desimone, Birman, \& Yoon, 2001; Loucks-Horsley, Love, Stiles, Mundry, \& Hewson, 2003; Penuel et al., 2007). Professional development programmes often have a deductive and solution- based orientation and are mainly designed on the basis of the content characteristics described in research literature. Less focus and analysis is devoted to school practices when designing a professional development programme. Successful curriculum implementation is more likely when a professional development programme is consistent with school practices and has an inductive and problem based orientation (Hill \& Cohen, 2005; Waslander, 2007). Therefore, in our study, the programme must be connected to everyday school practice of individual teachers, and must prepare teachers before and assist them during the implementation of a NLT module at the micro curriculum level. 


\subsubsection{Teacher Professional Development Programme}

Professional development is an important aspect of educational life of teachers (Avalos, 2011; Duffee \& Aikenhead, 1992). Additionally, professional development is a necessary component in all educational improvement efforts. In every attempt to reform, restructure or transform education the role of the teacher as the main stakeholder in bringing about needed changes is emphasized. Teachers therefore need to be professionally prepared. One of the challenges in science education is to design professional development programmes for teachers that can lead to fundamental changes in their practice (Loucks-Horsley et al., 2003). Various conceptual approaches provide tools such as different development strategies for designing such professional development programmes, with a focus on changes in teacher practice or on changes in teachers' professional content knowledge, their attitudes and beliefs (Bell \& Gilbert, 1996; Coenders, 2010; Jeanpierre, Oberhauser, \& Freeman, 2005; Loucks-Horsley et al., 2003; Luft, 2001; Stolk, De Jong, Bulte, \& Pilot, 2011).

Guskey (2000) defined professional development as "those processes and activities designed to enhance the professional knowledge, skills and attitudes of educators so that they might, in turn, improve the learning of students" (p. 16). According to this author, there are three important factors that influence the quality of professional development: context, process and content. Context characteristics refer to the 'who', 'when', 'where' and 'why' of professional development. Process variables refer to the 'how' of professional development. Content characteristics refer to the 'what' of professional development. Similar components have also been described by Loucks-Horsley et al. (2003,), in their design framework for professional development for teachers of Science and Mathematics, and by Garet et al. (2001) in their analysis of characteristics of professional development that focuses on 'structural features' and 'core features'.

The distinction drawn in the previous section between deductive and inductive activities aligns with the views of Richter (2011), who defined professional development as an uptake of formal and informal learning opportunities that deepen and extend teachers' professional competences. This definition distinguishes between formal and informal learning opportunities (Desimone, 2009). Formal learning opportunities are defined as structured learning environments with a specified curriculum, such as workshops, courses, or fullor half-day activities. Informal learning opportunities, in contrast, do not follow a specified curriculum and are not restricted to certain environments. They 
include individual activities such as reading books or classroom observations, along with collaborative activities such as conversations with colleagues and parents, mentoring activities, teacher networks, and study groups (Desimone, 2009; Mesler \& Spillane, 2010). Moreover, informal learning opportunities are often embedded in the classroom or school context (Putnam 2000). In interviews, teachers themselves indicate that they learn everyday (Kwakman, 1999). Teachers report that even when learning is not supported, all sorts of activities they undertake during work are inducing learning (Hoekstra, Brekelmans, Beijaard, \& Korthagen, 2009; Kwakman, 2003). Learning in the workplace is integrated into the work process and occurs through engagement in work-related activities (Eraut, 2004). Learning in the workplace can be understood as a process that is part of everyday work practices. Teachers indicate that they learn through the activity of teaching itself (Kwakman, 2003; Lohman \& Woolf, 2001). In several studies in which informal teacher learning was studied by means of interviews, logbooks, and questionnaires, teachers indicated the kind of activities they learn from in the workplace (Kwakman, 2003; Lohman \& Woolf, 2001; Meirink, Meijer, \& Verloop, 2007). There are four major categories of activities: a) learning by experimenting, b) learning by considering own teaching practice, c) learning by getting ideas from others, and d) learning by doing.

In literature on workplace learning it is stated that learning in the workplace may be incidental, and may even take place beneath learners' awareness (Eraut, 2004). Teachers themselves typically refer to such learning as 'learning by doing' or 'learning from experience', without specifying how this process takes place. The literature on teachers' activities in the workplace does not provide further empirical evidence regarding the type of activities involved in learning by doing. Eraut (2004) theorizes about possible reactive activities such as noting facts and observing effects of actions and possible implicit activities such as unconscious expectations and implicit linkage of past memories with current experience. The study by Meirink (2007) gives greater insight into teachers' learning by doing. An important learning activity in the teachers' learning process during teaching occurred when teachers realized that their behavior or teaching method did not have the expected consequence. Teachers were either happily surprised by the enthusiasm and activity of the students or it happened that their 'good idea', or usual teaching behavior, did not work out as they expected. Teachers thus became aware of a discrepancy between what they 
expected and what they perceived to happen. In this study this awareness is referred to as realizing the need 'to do something different next time'.

In addition to what is stipulated above, research has shown that professional development is most effective when it is long-term, collaborative, and schoolbased. It should focus on the learning of all students, be linked to teachers' daily school practices, and connected to teachers' prior knowledge as well as to the curriculum guidelines teachers need to keep an eye on. Adjusting the professional development programme to participants' diversity of behaviors and beliefs increases its effectiveness (Borko, 2004; Desimone, 2009; Garet et al., 2001; Hunzicker, 2011; Lieberman \& Pointer Mace, 2010; Vescio, Rossa, \& Adams, 2008). It is challenging to design such a programme in the context of the complex curriculum innovation NLT that will satisfy all participants. In chapter 2 , teachers' professional development will be further elaborated and conceptualized.

\subsubsection{Evaluation of the effectiveness of a teacher professional development programme}

Evaluation of the effectiveness of teacher professional development programmes is an essential condition for programme improvement and renewal, for long-term success (Rovai, 2003), and eventually for student learning (Fishman, Marx, Best, \& Tal, 2003; Jeanpierre et al., 2005; Luft, 2001; Stolk et al., 2011). In our study we presume that the effectiveness of a professional development programme is also related to the success of the implementation of the curriculum innovation. Teachers who are actively involved in the implementation of a curriculum innovation, by (re) designing and adapting curriculum materials will implicitly learn and eventually develop professionally. Evaluation of a professional development programme that aims to engage teachers in the implementation needs to focus on the immediate learning of teachers and on the near and far transfer of their competencies as well. However, many evaluations of professional development of teachers only assess the participants' satisfaction and/or their opinions of their professional development experience (Lowden, 2005). In order to assess the teachers' acquired competencies from professional development, evaluations must be based on an effort to better understand the influence of professional development on teachers and to document its eventual impact on student learning. The role of the teacher in the implementation process is an integral part of the evaluation approach, and therefore Guskey's (2002) approach fits 
very well. Guskey (2002) developed a five-level model for evaluating the effectiveness of a teacher professional development programme. The levels in this model are hierarchically arranged, with each level building on the ones before. The levels are, in order: (a) Participants' reactions, (b) participants' learning, (c) organizational support, (d) participants' use of new knowledge and skills, and (e) student learning outcomes.

Participants' reactions, level 1, focuses on participants' satisfaction with the programme. Points of interest at this level are 'basic human needs' such as quality of food and comfort of the rooms, and whether participants 'like' the experience, whether the materials and presentations 'make sense' and whether presenters seem 'knowledgeable and helpful'. In our study, participants' evaluative reactions are described as a measure of 'satisfaction', in particular consumer satisfaction, and its defining components are: awareness of concerns, addressing these concerns, contributing ideas, usefulness, and creating self-confidence.

Participants' learning, level 2, focuses on what knowledge and skills the teachers have acquired. Guskey warns against using merely a 'standardized form' and advises instead 'that indicators of successful learning' should be designed to fit specific local needs. Evaluation results can help with improving the content, format, and organization of the programme or activities.

Organizational support, level 3, focuses on organizational factors that can hinder or facilitate the success of improvement efforts. Any professional development effort can fail if there is a lack of organizational support. This suggests that organizational policies can undermine implementation efforts and thereby any gains made at previous levels might be lost.

Participants' use of new knowledge and skills, level 4, focuses on whether or not teachers apply the newly acquired knowledge and skills in their professional practice. This kind of information needs to be gathered within a reasonable time following the completion of the programme, in order to give participants enough time to enact the knowledge and skills.

Student learning outcomes, level 5, attends to student learning. The 'expected' learning outcomes depend on the goals of the specific professional development programme, and they can include cognitive as well as affective and psychomotor indicators. 
Levels 1, 2, and 4 directly relate to outcomes of the professional development programme for the individual teacher. Level 3 is considered as a condition for success of the professional development programme rather than a result. Our focus is primarily on the learning outcomes of the professional development programme, but we will report level 3 and 5 as well but separately.

\subsection{RESEARCH GOAL, GENERAL RESEARCH QUESTIONS, AND RESEARCH APPROACH}

The overarching goal of this study is to determine essential characteristics for developing a professional development programme in order to improve the implementation of a multidisciplinary module, to design such a programme while taking these characteristics into account, to implement the programme for two different NLT modules, and to evaluate this programme with respect to teachers' satisfaction and to its effectiveness in terms of teacher learning, in-class use of what teachers learned, and impact on student achievement. This has led to the following overall research question for this dissertation:

'What is the effectiveness of a professional development programme as a strategy for improving the implementation of a multidisciplinary science curriculum?'

The overall research question can be answered by the following four subresearch questions described successively in chapters 2 to 5 :

1. Which characteristics are essential for a professional development programme to promote the implementation of a multidisciplinary science module?

2. How does a generic model for a professional development programme to prepare and assist teachers for a multidisciplinary NLT module look like, and how can this be translated into a programme suitable for a specific NLT module?

3. How do participating teachers evaluate the professional development programme in terms of satisfaction?

4. How effective is the multidisciplinary professional development programme in achieving teacher learning and in successful enacting in class?

The research approach used in this dissertation is inspired by design-based research. Design-based research was initially introduced as a methodology for designing and evaluating educational solutions. This methodology has for some 
time been advocated as a research methodology that can effectively bridge the gap between research and practice in formal education (Anderson \& Shattuck, 2012; McKenney \& Reeves, 2012). Design-based research is also commonly known as design-research (Oha \& Reeves, 2010), development research (Conceição, Sherry, \& Gibson, 2004; Oha \& Reeves, 2010), and design studies/experiments (Van den Akker, Gravemeijer, McKenney, \& Nieveen, 2006), although these terminologies all indicate that a systemically conducted analysis, design, and evaluation of an educational solution together with a carefully created implementation in which all stakeholders are involved can lead to a scientifically-based and evidence-informed solutions in practice. The added value of this carefully organized design and research process is the production of design principles. It is also an interactive research process which Reeves (2006) described as four connected phases, see Figure 1.1.

\section{Design Research}

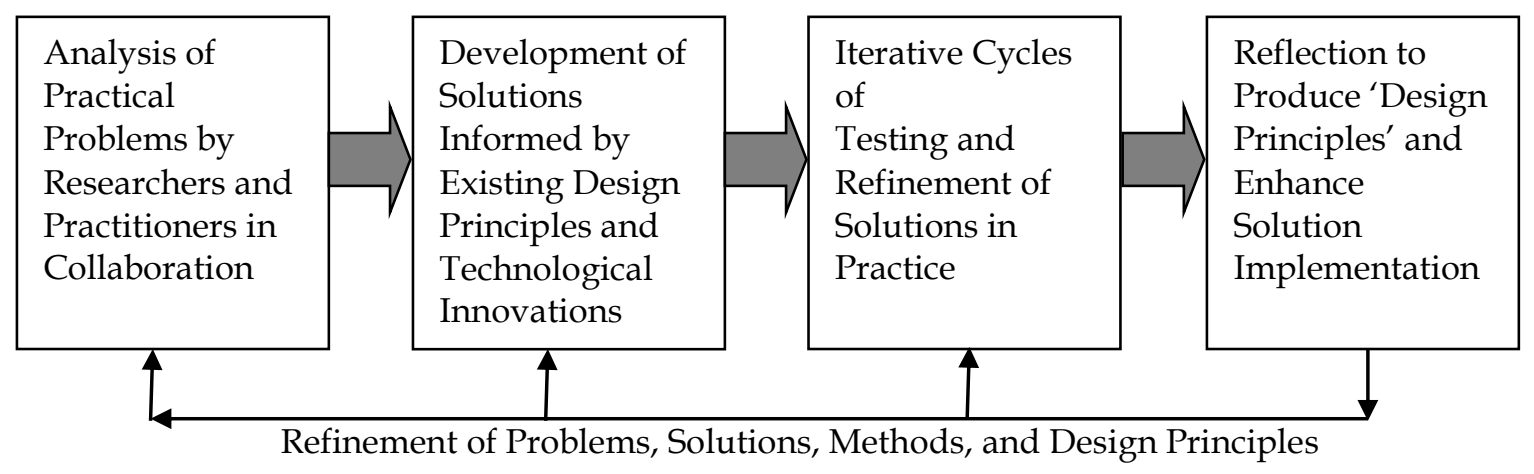

Figure 1.1 Four phases of design research (Reeves, 2006, p. 59)

The four connected phases are: analysis, development of solutions, iterative cycles of testing and refining solutions, and reflection and production of design principles (Reeves, 2006). In this dissertation these phases are enacted to design and implement a professional development programme for teachers based on essential characteristics for the implementation of a multidisciplinary module. The strength of the design-based research approach is its explicit focus on improving practice by designing in close contact with practice, and by understanding the messiness of real-world practice. Further, design-based research involves flexible design revisions (cyclic process of (re)designing) and multiple dependent variables (including the context variables of collaboration and availability among participants, and the outcomes variables of learning of content, transfer, and sustainability). It also involves capturing social interaction 
(involving different participants in the design). The design-based research approach is appropriate for this study because it entails a situated educational practice context and teachers who are actively involved in the design, implementation, and evaluation of the professional development programme through several phases.

Phase 1 Analysis of the problem

During this phase, the researcher clearly articulates the problem and investigates what work has already been done in the same or related fields. In order to prepare teachers adequately for the implementation of the new multidisciplinary subject NLT, it is essential to set up a professional development programme. We therefore focus on the identification of characteristics for such a programme. We used a three-step approach. The first step was evidence produced in the school and classroom settings, where teachers were interviewed. As a second step, specific curriculum features of NLT were taken into account. The third step consisted of evidence generated by curriculum implementation literature pertaining to characteristics associated with effective implementation of an innovation. This three-step approach facilitated the identification of the essential characteristics for a professional development programme from different angles.

\section{Phase 2 Development of potential solutions}

Phase 2 of the design research approach focuses on designing and developing solutions to the problem. During this phase a more targeted literature review was conducted. Relevant theories, design principles and existing frameworks were explored in depth to develop a framework for the design of the programme (Herrington, Reeves, \& Oliver, 2010). The aim was to design a model for a professional development programme to prepare and assist teachers during the implementation of a multidisciplinary science module. Three sources important for the design of such a programme have been elaborated: multidisciplinary science features including school practices (specific NLT features and characteristics), the curriculum design phases (applying the general curriculum design phases (Marsh \& Willis, 2003; Verhagen, Kuiper, \& Plomp, 1999) to NLT at school), and professional development characteristics (derived from phase 1). We combined these three sources with three factors influencing the quality of professional development, namely, context, process, and content (Guskey, 2000). These sources and factors 
have been translated into a generic model for a professional development programme including four learning episodes to prepare and assist teachers. A learning episode is a defined period of time during which teacher learning is planned by one or more activities. The four learning episodes are, in order, individual preparation, preparation seminar, online support, and reflection meeting.

\section{Phase 3 Implementation and evaluation}

In phase 3 , the professional development programme developed in phase 2 is implemented and evaluated to determine the effectiveness of the programme. The generic module including the four learning episodes is translated into a professional development programme for two specific multidisciplinary modules from NLT, 'The hydrogen car' and 'The brain and learning'. Both professional development programmes are evaluated, based on Guskey's fivelevel model of evaluation (2002). Quantitative and qualitative data were collected during this phase and used in a mixed-method approach. In the context of NLT, the design of the generic model for a professional development programme took place as a single case-study (Yin, 2003). The application of the designed professional development programme to two different NLT modules was seen as an embedded case study design in this dissertation (Yin, 2003). Different schools participated in the professional development programme, divided between the two different NLT modules. The results were analyzed by taking the individual teacher as the unit of analysis. Both the designed and the applied professional development programme were assessed, as well as the individual teachers' personal growth and student learning outcomes.

\section{Phase 4 Reflection and report}

Phase 4 of the overall study is where the researcher reflects on the entire project and disseminates information to the broader educational community. The culmination of this dissertation is final design principles comprising evidencebased heuristics that can inform future efforts at designing a professional development programme for multidisciplinary science modules. 


\subsection{OVERVIEW OF THIS STUDY}

The present study can be characterized as a design-based study, and it includes three sub-studies. Figure 1.2 shows an overview of the study. We broke down the general research question in order to address it in three sub-studies: first, essential characteristics for a professional development programme (chapter 2); next, the design and application of a model for a teacher professional development programme (chapter 3); and finally, the evaluation of the effectiveness of the implemented teacher professional development programme (chapter 4 and 5).

The aim of study 1 is to theoretically and empirically identify essential characteristics for a professional development programme that promotes the acquisition of teacher competences required for the implementation of a NLT module. Three specific sub-questions are distinguished: (a) Which characteristics are important during the selection of a NLT module according to the 'evidence based' approach, (b) Which of these characteristics from the first sub-question belong to what kind of professionality? And (c) which characteristics from the second sub-question stimulate the effective implementation of a NLT module, according to teachers and according to the curriculum implementation literature? This study is reported in chapter 2.

The aim of study 2, reported in chapter 3, is to design a generic model for a professional development programme and to apply this to a programme suitable for a specific NLT module. Two sub-questions are addressed: (a) How does a generic model for a professional development programme to prepare and assist teachers for a multidisciplinary science module look like and what are its specific characteristics? And, (b) how can this generic model be translated into a professional development programme to prepare and assist teachers with the implementation of a specific multidisciplinary science module?

Study 3 aims to evaluate the professional development programme that prepares and assists teachers with the implementation of a multidisciplinary science module, based on Guskey's five-level model for evaluation (2002). In the sub-study described in Chapter 4, the professional development programme is evaluated in terms of satisfaction, the first level of Guskey's five-level model (2002). Four specific sub-questions have been formulated: (a) How do 
participating teachers evaluate the individual preparation? (b) How do participating teachers evaluate the preparation seminar? (c) How do participating teachers evaluate the online support? (d) How do participating teachers evaluate the reflection meeting?

Chapter 5 contains the sub-study aiming to evaluate the effects of the multidisciplinary professional development programme using Guskey's other four levels. Levels 2 and 4 directly relate to outcomes of the professional development programme for the individual teacher. Two research questions have been formulated for level 2: one to assess the influence on teacher learning of the 'before teaching phase', and one to assess the overall impact of the programme. Evaluation on level 4, with a research question, pertained to the application of learning in the classroom. Level 3 is a condition for the professional development programme rather than a result, and because our interest was primarily on the learning outcomes of the professional development programme for teachers, we will report level 3 and 5 at the end.

The five sub-questions addressed are: (a) How did the 'before teaching phase' contribute to pedagogical and curricular intentions of participating teachers (Level 2)? (b) What new learning outcomes from the seven learning areas did teachers apply in their classes (Level 4)? (c) What did teachers in general learn from the entire professional development programme (Level 2)? (d) Did organizational factors hinder the success of the professional development programme (Level 3)? And, (e) what are the student learning outcomes from the modules addressed in the professional development programme (Level 5)? 


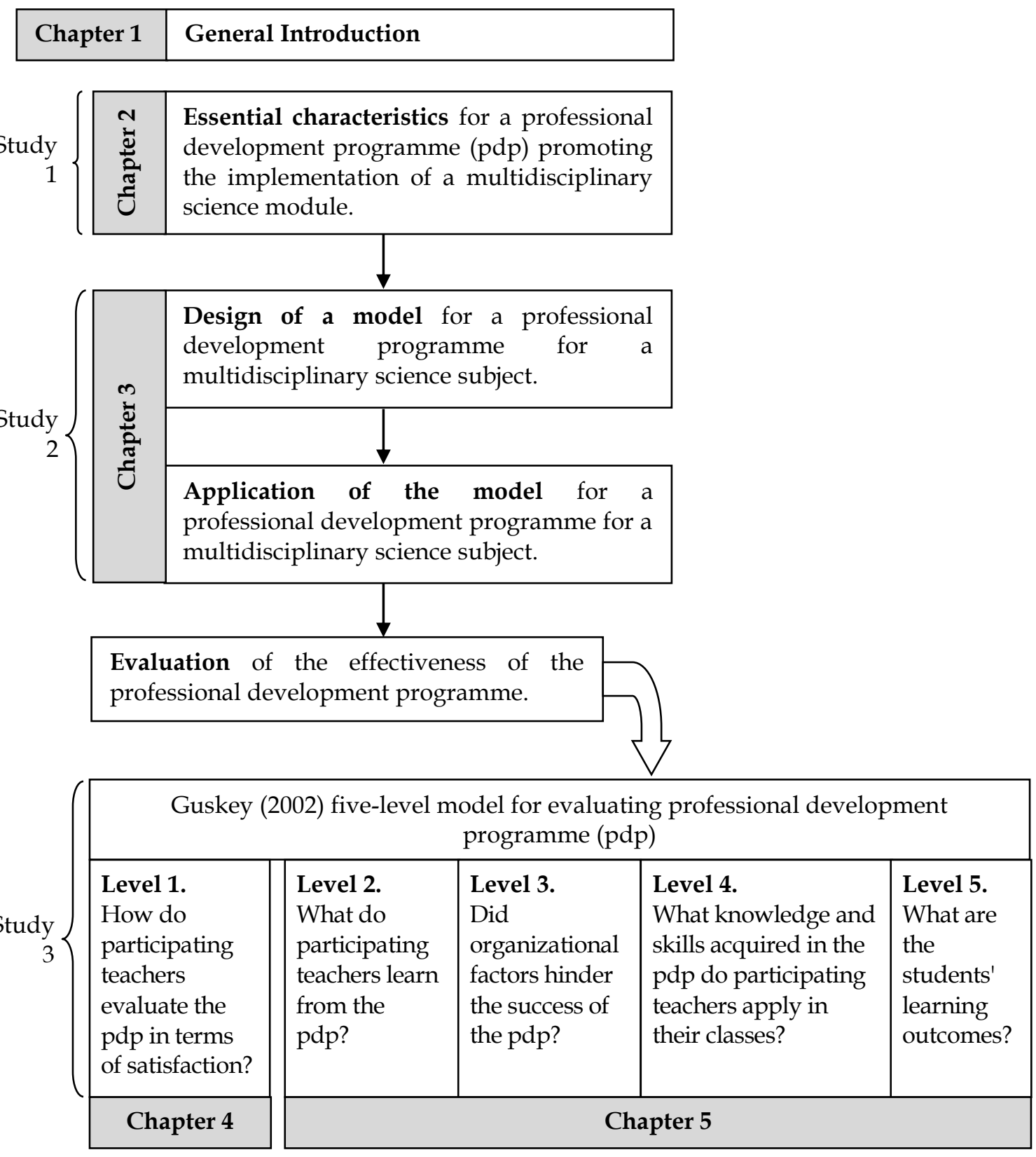

\section{\begin{tabular}{l|l} 
Chapter 6 & Conclusions, discussion, and recommendations
\end{tabular}}

Figure 1.2 Overview of the study 


\title{
CHAPTER 2
}

\section{Essential characteristics for a professional development programme for promoting the implementation of a multidisciplinary science module ${ }^{2}$}

\begin{abstract}
Teachers involved in the implementation of a curriculum innovation can be prepared for this task through a professional development programme. In this article, we describe essential characteristics (identified empirically and theoretically) for such a professional development programme that promotes the acquisition of competences by teachers involved in the implementation of a curriculum innovation. The innovation deals with the introduction of modules from a new multidisciplinary subject called Nature, Life, and Technology (NLT), in which elements from physics, chemistry, biology, mathematics, and physical geography are integrated. A three-step approach was used to identify the essential characteristics: evidence from classroom practice, characteristics of the new subject, and theoretical and empirical evidence from curriculum implementation studies. Analysis of the data showed that five characteristics need particular attention in a professional development programme. These essential characteristics are knowledge acquisition by teachers, teachers' cooperation, teachers' networking, modules' appropriateness, and teachers' preparedness.
\end{abstract}

2 This chapter is based on the article published as: Visser, T. C., Coenders, F. G. M., Terlouw, C., \& Pieters, J. M. (2010). Essential characteristics for a professional development program for promoting the implementation of a multidisciplinary science module. Journal of Science Teacher Education, 21(6), 623-642. 


\subsection{INTRODUCTION}

The success of the implementation of a new curriculum at the secondary school level depends among other factors on the active involvement of teachers in the curriculum design process, their feeling of ownership of this curriculum, and the further preparation by these teachers (Hargreaves, 1994; Rousseau, 2004; Wikeley, 2005). Implementing a new subject can be considered a curricular innovation means that teachers have to be introduced to the new subject domain, have to understand the elements of the innovation, have to adopt the innovation, and have to acquire the new knowledge, skills, and routines needed to adequately teach the new subject (Bergen \& Van Veen, 2004; Shulman, 1987; Van den Akker, 1999). This may be achieved by means of a professional development programme in which teachers are actively involved (Garet et al., 2001; Loucks-Horsley et al., 2003; Penuel et al., 2007). Such a programme can take various forms: (a) workshops and seminars, (b) teacher communities that carry out research and design activities, and (c) work with professionals experienced in both the domain and in teaching. Active teacher participation in a professional development programme influences the quality of the lessons and eventually students' achievements (Fishman et al., 2003).

Professional development programmes are often only designed on the basis of characteristics described in research literature. Less focus and analysis is specifically devoted to the creation of a professional development programme where the starting point begins with school practice. A successful implementation is more likely when a professional development programme is consistent with this practice (Hill \& Cohen, 2005; Waslander, 2007). Therefore, the characteristics of the professional development programme have to be connected to the everyday school practice of individual teachers, if not the result is a gap between the programme and practice.

In this study, we focus on identifying essential characteristics of such a programme to support teachers involved in the introduction and implementation of a new multidisciplinary science module in their classroom. The essential characteristics identified can later be used to design a suitable professional development programme consistent with the school practice. 
The new science subject dealt with in this article is called Nature, Life, and Technology (NLT), and was introduced in the science curriculum of the upper level of secondary education in the Netherlands in August 2007. NLT is a multidisciplinary subject, integrating elements from physics, chemistry, biology, mathematics, and physical geography, and has a modular structure. Objectives for introducing this subject in the school curriculum are as follows: (a) it enables students to become familiar with a wide range of higher education options and professions; (b) it lets students experience the importance of interdisciplinary coherence in the development of science and technology; (c) it creates a closer connection between science education and new developments in society, science, and technology; and (d) it encourages cooperation with higher education and research institutes.

The multidisciplinarity of the subject requires schoolteachers from different science departments (physics, chemistry, biology, mathematics, and physical geography) to cooperate in a multidisciplinary team in order to implement this new subject. The implementation of NLT at the school level has several specific features. Firstly, teachers involved in the teaching of NLT have a degree in one of the mono-disciplinary subjects listed above, but have not been specifically trained for this new multidisciplinary subject. Secondly, the multidisciplinary team of teachers has the freedom to select the modules, and the order in which the modules will be taught. Thirdly, the team of teachers also decides which and how many teachers will be teaching a specific module. By selecting a particular module, not only is the topic and the content determined, but also to a large extent the teaching methods and the assessment strategies and tools. Because teacher teams make different choices, implementation varies from school to school.

The essential characteristics of a professional development programme to support NLT teachers in developing expertise in specific fields for an effective implementation of a NLT module, will be identified in a three-step approach. First an evidence-based approach in school contexts to identify implementation characteristics from existing classroom practices is employed. Secondly, specific features of the subject NLT are used. Finally, the third step consists of evidence from the curriculum implementation literature. 
To begin with, the research questions will be explained followed by the conceptual framework in which this three-step approach will be explained.

\subsection{RESEARCH QUESTIONS}

This study aims to theoretically and empirically identify essential characteristics for a professional development programme that promotes the acquisition of teachers' competences involved in the implementation of a NLT module. The general research question is 'Which characteristics are essential for a professional development programme to promote the implementation of a NLT module?' Three specific sub-questions are distinguished: (a) Which characteristics are important during the selection of a NLT module according to the 'evidencebased' approach? (b) Which of these characteristics from the first sub-question belong to what kind of professionality? (c) Which characteristics from the second sub-question stimulate the implementation of a NLT module according to teachers and according to the curriculum implementation literature?

\subsection{CONCEPTUAL FRAMEWORK}

\subsubsection{The 'Evidence-based' Approach}

Connecting the characteristics of the professional development programme to the everyday school practice, teachers' prior knowledge, beliefs, and skills must be taken into account in order to make a professional development programme successful (Davis, 2003; Lieberman, 1995; Schwab, 1973). Professional development programmes should also be adjusted to the diversity of behaviors and beliefs of their participants (Cotton, 2006; Luft, 2001), and should support the professional growth as the outcome of a complex process (Clarke \& Hollingsworth, 2002). Two aspects are of vital importance when thinking in terms of class implementation of implementing an innovation that takes into account the school's practice: (a) the curriculum design phases and (b) the curriculum components. A framework based on these two aspects is used to collect and organize the implementation characteristics. The curriculum design phases are based on the general process components of a generic model for curriculum design (Marsh \& Willis, 2003; Verhagen et al., 1999; Visscher- 
Voerman, 1999; Visscher-Voerman \& Gustafson, 2004). The curriculum components have their roots in the curricular 'spider web' proposed by Van den Akker (2003).

The generic model that reflects the process of designing a curricular innovation has been applied to the NLT module, resulting in the following five phases. Firstly, the 'Module Selection' phase - teachers have the freedom to determine which modules will be offered, in line with the modular structure of the NLT subject. During this selection phase, teachers select the module they are going to teach. Secondly, the 'Module Preparation' phase-this encompasses all the steps before the module is actually delivered, such as drawing up a study programme for students, dividing tasks among teachers, and trying-out experiments. Thirdly, the 'Module Teaching' phase - this phase focuses on the teaching and actual classroom delivery, for example on changes made in the study programme, the teaching methods used, and the cooperation between teachers. Fourthly, the 'Effect of the Module' phase - this shows the degree to which goals are achieved after finishing the module. The fifth and final phase is 'Reflection on the Module.' In this phase, the teacher reflects on the module to determine strong aspects and elements that need to be adapted (See the columns in Table 2.1).

The curriculum components we used are based on the need for creating balance and consistency between the various curriculum components. Van den Akker (2003) proposed a framework of ten components addressing ten specific questions about the planning of student learning. He visualized these ten curriculum components as a spider's web, not only to illustrate the numerous interconnections, but also to underline its vulnerability.

Table 2.1 Five-by-five curriculum components and design matrix

\begin{tabular}{|c|c|c|c|c|c|}
\hline \multirow[b]{2}{*}{$\begin{array}{l}\text { Curriculum } \\
\text { components }\end{array}$} & \multicolumn{5}{|c|}{ Curriculum design phases } \\
\hline & $\begin{array}{l}\text { Module } \\
\text { Selection }\end{array}$ & $\begin{array}{c}\text { Module } \\
\text { Preparation }\end{array}$ & $\begin{array}{l}\text { Module } \\
\text { Teaching }\end{array}$ & $\begin{array}{l}\text { Effect of the } \\
\text { module }\end{array}$ & $\begin{array}{c}\text { Reflection on } \\
\text { the module }\end{array}$ \\
\hline \multicolumn{6}{|l|}{ 1. Aim } \\
\hline \multicolumn{6}{|l|}{ 2. Content } \\
\hline \multicolumn{6}{|l|}{ 3. Pedagogy } \\
\hline \multicolumn{6}{|l|}{ 4. Conditions } \\
\hline 5. Assessment & & & & & \\
\hline
\end{tabular}


As this study is about the teachers' implementation of a NLT module in the classroom, for pragmatic reasons the ten curricular components were reduced to five: aim, content, pedagogy, conditions, and assessment (See the rows in Table 2.1). 'Aim' is used to describe the rationale, aims, and objectives of a module. 'Content' describes what is actually taught in class. 'Pedagogy' is about learning activities, materials and resources, the teacher's role, and student grouping. 'Conditions' encompass location and time, and 'Assessment' refers to both learning progress and learning outcomes.

Combining the five curriculum design phases and the five curriculum components leads to a five-by-five matrix (Table 2.1). As this matrix covers all the main strategic elements that are relevant to curriculum implementation, it will be used as the data-organizing instrument to present the evidence from the interviews focusing on the implementation in schools.

\subsubsection{The NLT subject}

NLT is a new optional science subject that was introduced in upper secondary education in the Netherlands in August 2007. Schools interested in offering NLT had to register at the National Steering Committee responsible for this subject. While NLT is different from other traditional science subjects, it is linked to them at the same time. The NLT curriculum is different because it is based on contexts and has a modular structure. A teaching module consists of a situated practice (for example, using forensic technology, MP3-players, or holography) in which specific concepts traditionally belonging to physics, chemistry, biology, mathematics, and physical geography are explored. Through its interdisciplinary character, the content of the NLT modules goes beyond the sum of the contents of the traditional science subjects. Teachers usually have a degree in one of the traditional science subjects. Therefore, teaching the NLT modules is challenging, because the modules not only deal with their own disciplines, but also involve content from other science disciplines at a high level. The advantage of the modular structure is that schools have more freedom in offering this subject. It gives teachers the opportunity to select modules according to their interests and expertise and to their students' interests and prior knowledge. In order to encourage schools to offer high quality education in this new subject, the National Steering Committee has formulated a number of criteria that schools should fulfill to become an officially registered implementation school. A criterion that schools 
have to fulfill is selecting the modules following the examination programme. The NLT examination programme consists of nine different domains. The following examples illustrate this. The domain 'Biomedical technology and biotechnology' is about developments in biomedical technology and biotechnology. Modules in this domain that schools can choose from are for instance 'Technical design in biomedical technology,' 'Food and fuel,' and 'Artificial kidney and membranes.' A different domain is called 'Language of science' where students learn to use relevant concepts and techniques from mathematics and/or computer science and apply these on science or technological issues. Modules that cover this domain are 'Dynamic models,' 'Make the difference,' and 'Measuring and interpreting.'

Another important criterion is that a team of teachers consisting of at least three teachers with different Master's degrees (physics, chemistry, biology, mathematics, or physical geography) should be responsible for teaching NLT (Steering Committee NLT, 2007).

As described earlier, NLT is a subject with several specific features. Therefore, NLT teachers implementing this subject must possess a broad knowledge base and good classroom skills. Hoyle and John (1995) made a distinction between what they termed as restricted professionality and extended professionality. In restricted professionality, the focus is on teachers' own classroom practice. Extended professionality refers to a broader range of knowledge and skills, going beyond the individual classroom. Extended professionality is largely acquired through participation in a wide range of professional development activities, including attending in-service courses, reading professional literature, visiting other institutions, and collaborating with colleagues. NLT is a broad, interdisciplinary subject in which teachers have to collaborate with each other in school, research institutes, and industry, in a sustainable manner. For students, a team of teachers is an example of interdisciplinary collaboration among subject experts. Contacts beyond school enable students to become familiar with a wide range of higher education options and professions. Therefore, a professional development programme for NLT must promote the extended professionality of the teachers. The distinction of Hoyle and John (1995) will be taken into account when analyzing the characteristics developed for the professional development programme. 


\subsubsection{Research about effective implementation}

A completed matrix, as shown in Table 2.1, contains the implementation characteristics for a NLT module for a particular school: the choices made by the teachers and their considerations. To determine which characteristics need to be covered by a professional development programme, the elements for effective implementation as identified in research are relevant. In the process of curriculum implementation, many aspects play a role that can be either stimulating or hindering. Factors influencing the implementation of a curriculum can be categorized into four areas (Figure 2.1; (Van den Akker, 1998)). Each area will be briefly explained below.

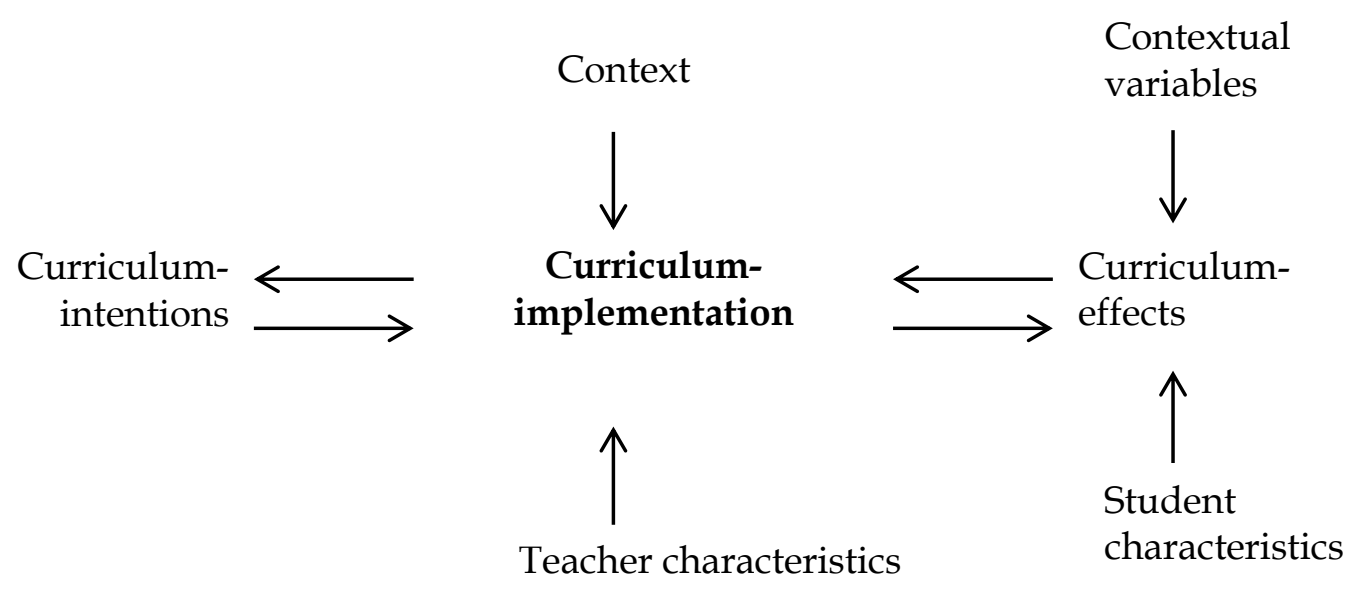

Figure 2.1 Categories influencing implementation (from Van den Akker (1998)

\section{Curriculum Intentions}

During the introduction of a new subject, teachers will especially find support from specific student learning material (Desimone, 2002; Van den Akker, 1998; Waslander, 2007). The learning material largely determines the content, knowledge, and skills students acquire at school. The quality and the usability of the learning material therefore are important for teachers and students alike. Learning materials guide teachers in their teaching but this does not mean that teachers use the materials exactly as the developers had in mind. Teachers adapt and supplement learning materials to their own situation and needs, and this promotes ownership. Teacher ownership is necessary to change teachers routines in order to try something new (Bergen \& Van Veen, 2004). Several studies show that teachers' sense of ownership is a stimulating condition for implementation (Ogborn, 2002; Wikeley, 2005). There are indications that 
teachers' sense of ownership contributes to higher student achievement (Caprara, Barbaranelli, Steca, \& Malone, 2006).

\section{Curriculum Effects}

Curriculum effects include student experiences and learning outcomes. Student characteristics such as capacity and motivation determine curriculum implementation effectiveness and learning outcomes (Lepper, Corpus, \& Iyengar, 2005). Contextual variables such as the home situation, media, and friends also affect student achievement through informal learning (Van den Akker, 1998).

\section{Context}

The context includes policy, school organization, and external support for the curriculum. Policy entails the decisions about testing programmes and the attainment targets for the subject. Cooperation between teachers and coordination within departments are part of the school organization. Collaboration between colleagues is a stimulating condition for the implementation of an innovation. Usually teachers only cooperate with colleagues in their own departments (Van Wessum, 1997). Multidisciplinary collaboration can provide motivation and introduce teachers to a broader variety of ideas and teaching methods (Leliveld, Van Tartwijk, Verloop, \& Bolk, 2008; Meirink, 2007). Teachers can assist colleagues by sharing information and experiences whereby new knowledge can be developed (Ball \& Cohen, 1996). The teachers who implement the innovation must be given time and feel supported by the school management (Geijsel et al., 2001; Wikeley, 2005). The external support includes collaborative activities between colleagues in the same school and between schools. This can be stimulated in a professional development programme (Andrews \& Lewis, 2002; Desimone, 2002; Waslander, 2007).

\section{Teacher Characteristics}

Various studies report and discuss the important role that teachers play in the implementation (Fullan, 2007; Geijsel et al., 2001; Kwakman, 2003). Teachers' knowledge and beliefs are determined by their education and experiences. Beliefs about what is feasible and valuable for their students, preferences for certain teacher roles, and preferences for teaching methods will influence any implementation (Beijaard, Meijer, \& Verloop, 2004; Pajares, 1992; Van den Akker, 1998; Van Veen \& Sleegers, 2006). 


\subsection{METHODS}

\subsubsection{Participants}

A written invitation to participate in this research was sent to thirteen teachers at thirteen different officially registered implementation schools in the eastern part of the Netherlands. One teacher did not respond at all, while four teachers had not yet started implementing NLT modules; the remaining eight teachers all participated in this study. All participating teachers were heads of their NLT departments and active NLT teachers. Three were chemistry teachers, two biology teachers, two physics teachers, and one mathematics teacher. Six of the participants were male and two female. All had more than 6 years' teaching experience. The eight schools that participated in this study were among the first schools to implement the subject NLT and started teaching NLT modules in August 2007. They developed their own strategies for implementation without assistance or examples from other schools.

\subsubsection{Data collection instruments}

To investigate the implementation process of a NLT module in the school we used semi-structured interviews in which teacher have to take the last module taught in mind. For each cell of the five-by-five matrix shown in Table 2.1 a question was formulated. Table 2.2 shows the designation of the different cells in Table 2.1 and an example of the answers we found for the question formulated for cell 1: For which aim was the module selected? This question involved a combination of the first curriculum component (Aim) and the first curriculum design phase (Module Selection). With a completed matrix, we had an overview of how a NLT module was implemented in a specific school. After these 25 questions, the following open question was phrased: What is stimulating and what is hindering you during the implementation of a NLT module? This question provided additional information about what teachers experienced as stimulating or hindering aspects during the implementation. 
Table 2.2 Partly filled curriculum components and design matrix

\begin{tabular}{|c|c|c|c|c|c|}
\hline \multirow[b]{2}{*}{$\begin{array}{l}\text { Curriculum } \\
\text { components }\end{array}$} & \multicolumn{5}{|c|}{ Curriculum design phases } \\
\hline & $\begin{array}{l}\text { Module } \\
\text { Selection }\end{array}$ & $\begin{array}{l}\text { Module } \\
\text { Preparation }\end{array}$ & $\begin{array}{l}\text { Module } \\
\text { Teaching }\end{array}$ & $\begin{array}{l}\text { Effect of the } \\
\text { module }\end{array}$ & $\begin{array}{l}\text { Reflection on } \\
\text { the module }\end{array}$ \\
\hline 1. Aim & Cell 1 & Cell 6 & Cell 11 & & \\
\hline & $\begin{array}{r}\text { - Student } \\
\text { interest }\end{array}$ & & & & \\
\hline & - Feasibility & & & & \\
\hline 2. Content & Cell 2 & Cell 7 & Cell 12 & & \\
\hline 3. Pedagogy & Cell 3 & Cell 8 & Etc. & & \\
\hline 4. Conditions & Cell 4 & Cell 9 & & & \\
\hline 5. Assessment & Cell 5 & Cell 10 & & & \\
\hline
\end{tabular}

\subsubsection{Procedure}

The first author of this article conducted a semi-structured interview with each of the eight participants who had started teaching NLT from the beginning of the school year 2007-2008. The semi-structured interviews were conducted between January and April 2008. All interviews took place in a location chosen by the teacher (e.g., the teacher's classroom or a small office) and the conversation was recorded. Each interview took about $40 \mathrm{~min}$. All the interviews were transcribed.

The transcripts were returned to the teachers for verification and approval. In these transcripts, the core elements of the answers were identified and translated into keywords. For example, an answer given by a teacher in cell 1 (For which aim was the module selected?) was 'We selected our module because we thought it would interest our students and we assessed the feasibility of the module'. The keywords for this answer were 'student interest' and 'feasibility' (See Table 2.2, cell 1). Quite often multiple keywords were identified and included in the matrix. Each cell was populated in this way.

\subsubsection{Analysis}

In this section, we discuss how the research data were analyzed (a) to describe important characteristics during selection (Research Sub-question 1), (b) to classify characteristics into kinds of professionality (Research Sub-question 2), and (c) to indicate stimulating characteristics for implementation (Research Sub-question 3). 
The flow of the study is visualized in Figure 2.2.

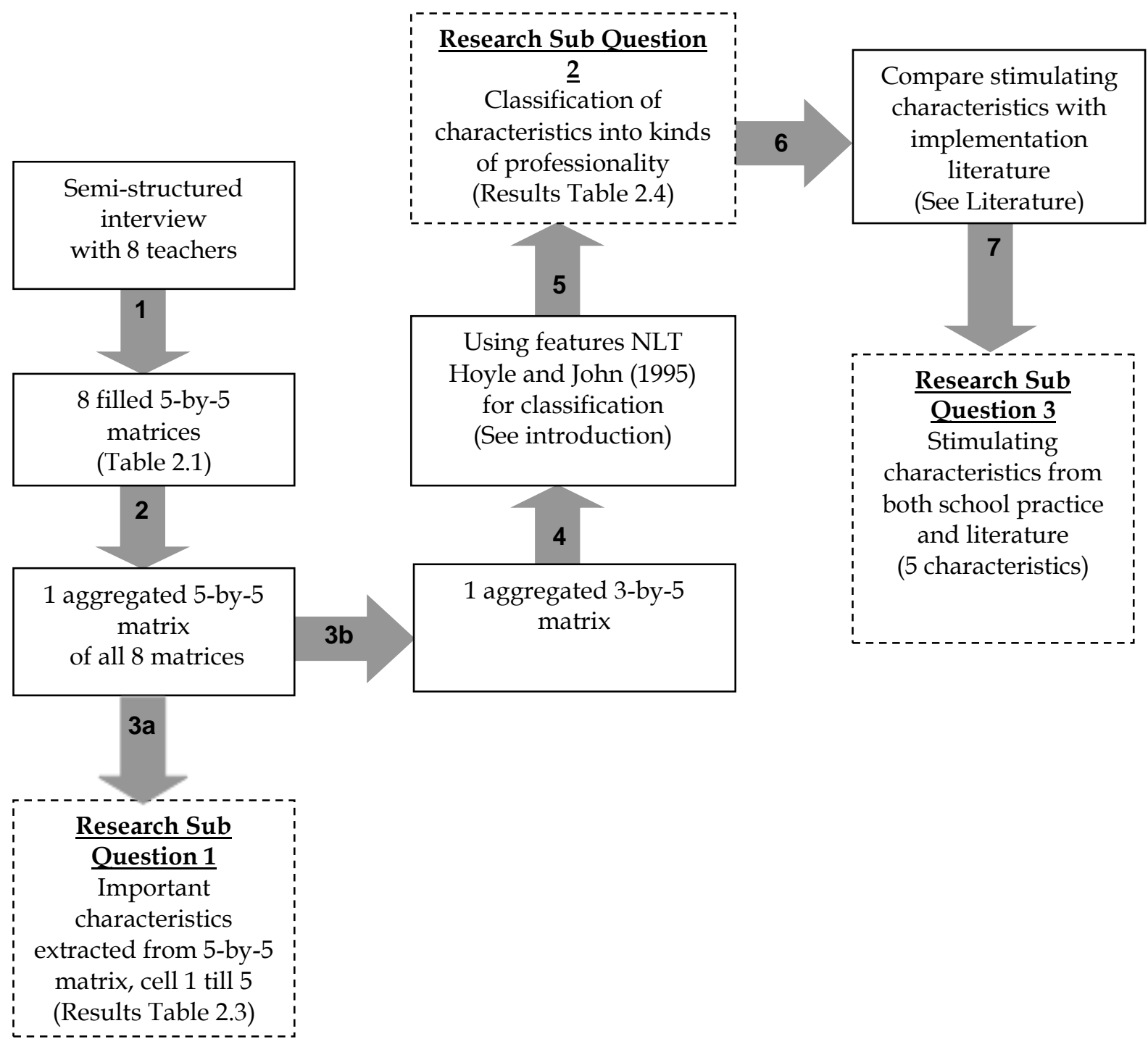

Figure 2.2 Flow of the study

Research Sub-Question 1: Important Characteristics during Selection

The eight matrices from the different schools were combined into one new matrix. For instance, all the keywords in cell 1 from the eight matrices were aggregated in one new cell 1 of the new matrix. The keywords of the open question: 'What is stimulating and what is hindering you during the implementation of a NLT module?' were also added. The resulting matrix was very comprehensive with many keywords.

To ensure the reliability of the keywords, a researcher not previously involved in this research was asked to check whether the keywords represented the key 
points of the sentences and whether these were consistently used for similar fragments. This resulted in $86 \%$ immediate agreement; the other findings were discussed until a consensus was reached.

To answer research question one, cells 1 to 5 were needed. Similar keywords from these cells were collapsed. The important keywords are therefore mentioned twice or more, or were also mentioned in the additional question. These important remaining keywords were transformed back to the original sentences as answered by the teacher as accurately as possible. We call these characteristics.

\section{Research Question 2: Classification of Characteristics into Kinds of Professionality} The first two curriculum design phases (Module Selection and Preparation) from the original five curriculum design phases occurred before the actual implementation of a NLT module. The third and fourth curriculum design phases (Module Teaching and Effect of the module) took place during the implementation. The last curriculum design phase (Reflection on the module) occurred after the implementation. Therefore, the five curriculum design phases were collapsed into three curriculum design phases: one phase before, one during, and one after implementation.

Similar characteristics from these cells were collapsed. Characteristics mentioned less than twice were removed unless they were also mentioned as stimulating or hindering in the additional question. The characteristics of this three-by-five matrix were classified according to Hoyle and John (1995), into the restricted professionality characteristics (e.g., focus on classroom practices) and the extended professionality characteristics (e.g., cooperation with colleagues) where similar characteristics were clustered. While doing this it became clear that some characteristics (those with comments about the quality of the module, for instance) did not fit these two classes. For these characteristics, we created a third group, namely 'neither restricted nor extended professionality.'

\section{Research Question 3: Stimulating Characteristics for Implementation}

In this sub-question only the stimulating characteristics from sub-question 2 were used. Stimulating characteristics are identified from the answer of the open question after the semi-structured interview and were also mentioned in the semi-structured interview. These stimulating characteristics were compared 
with research literature findings about elements for effective implementation. When a stimulating characteristic according to the teachers also was found in literature for effective implementation, this characteristic becomes a stimulating characteristic for implementation; if not it was eliminated.

\subsection{RESULTS}

Important Characteristics during Selection

The implementation process of a new NLT module into classroom practice consists of different phases. The first phase is the 'Module Selection' phase, important because of the modular structure of NLT. In this phase, teachers have the freedom to determine which modules they are going to teach. They may base their decision on the content, the teaching methods, assessment, or some combination of these.

The characteristics that teachers mentioned as needing attention in the selection of a module are shown in the left column of Table 2.3. These characteristics were deduced from the results in the first column of Table 2.2 of the semistructured interview. The semi-structured interview ended with the open question: 'What is stimulating and what is hindering you during the implementation of a NLT module?' The results from this question are reported in the right column of Table 2.3. The teachers' answers were related to both students and teachers; this division is shown in the rows of Table 2.3. An answer one teacher gave was 'I feel enthusiastic when I notice the coherence between different mono-disciplines in a NLT module. For example in the topic $E A R$, biology and physics are related very well. When I notice this I am excited to teach it to my students.' 
Table 2.3 Characteristics that according to the teachers need attention during the selection of a NLT module

\begin{tabular}{|c|c|c|}
\hline & $\begin{array}{l}\text { Characteristics that were } \\
\text { mentioned during the interview. }\end{array}$ & $\begin{array}{l}\text { Characteristics that were both mentioned } \\
\text { during the semi-structured interview and } \\
\text { during the open question after the semi- } \\
\text { structured interview. }\end{array}$ \\
\hline $\begin{array}{l}\text { Related } \\
\text { to } \\
\text { students }\end{array}$ & $\begin{array}{l}\text { The module should: } \\
\text { - Connect to students' prior } \\
\text { knowledge } \\
\text { - Offer sufficient in-depth } \\
\text { knowledge } \\
\text { - Broaden the knowledge of } \\
\text { students } \\
\text { - Provide variation in skills and } \\
\text { - pedagogy } \\
\text { - Be correct, clear, and structured } \\
\text { - Show interrelationships } \\
\text { between content of the mono- } \\
\text { disciplines } \\
\text { - Have a social meaning and } \\
\text { prepare students for follow-up } \\
\text { studies }\end{array}$ & $\begin{array}{l}\text { The module should fit: } \\
\text { - The interest of the students } \\
\text { - Permit students to work independently } \\
\text { with it }\end{array}$ \\
\hline $\begin{array}{l}\text { Related } \\
\text { to } \\
\text { teachers }\end{array}$ & $\begin{array}{l}\text { The module should: } \\
\text { - Have some freedom to include } \\
\text { (creative) suggestions from the } \\
\text { teacher } \\
\text { - Be realizable and practicable for } \\
\text { the teacher }\end{array}$ & $\begin{array}{l}\text { The module should: } \\
\text { - Fit the interest and knowledge of the } \\
\text { teacher } \\
\text { - Include materials and facilities that are } \\
\text { easy to achieve } \\
\text { - Have a good teacher's guide }\end{array}$ \\
\hline
\end{tabular}

\section{Classification of Characteristics into Kinds of Professionality}

The characteristics of the three-by-five matrix were classified into three groups based on Hoyle and John (1995): the restricted professionality, the extended professionality, and the 'neither restricted nor extended professionality' group. The characteristics are shown in Table 2.4. Teachers' intentions with respect to these characteristics are explained below. The characteristics under A to E and $\mathrm{O}$ to $\mathrm{R}$ are mentioned both in the semi-structured interview and during the open question after the interview ('What is stimulating and what is hindering you during the implementation of a NLT module?'). The characteristics A to E were mentioned as a stimulating characteristic during implementation; $\mathrm{O}$ to $\mathrm{R}$ were mentioned as hindering. Some teacher statements included: 
It is very stimulating to experience other knowledge, outside the regular daily programme in my own classroom. I also learn things from other subjects. Beside that, the cooperation with the university and research institutes is meaningful and stimulating too (Open Question, Teacher 1).

The cooperation with other teachers is very stimulating and necessary for successfully implementing NLT (Open Question, Teacher 1).

When I am well prepared for the lessons I have to teach, the lessons are going better and it feels stimulating (Open Question, Teacher 2).

Below we explain the characteristics from the restricted professionality group:

- Modules' appropriateness. Teachers find it stimulating when the content connects to students' prior knowledge and when the module is attractive and interesting for students.

- Teachers' preparedness. Teachers want to prepare and organize their lessons extensively but often time is a limiting factor. Teachers find it stimulating when after intensive preparation they experience that everything ran smoothly.

- Teachers' ownership. Teachers prefer curricular innovations in which they have freedom to follow their own preferences. Selecting and adapting teaching material to suit their situation and needs promotes teachers' ownership. Link to teachers' prior knowledge. NLT is a multidisciplinary subject having a modular structure; the content of the NLT modules goes beyond the more traditional science subjects (physics, chemistry, biology, mathematics, and physical geography). NLT teachers have a degree in one of the science subjects and naturally prefer to teach content related to their subject.

- Pedagogy. The teachers prefer to use various teaching methods (e.g., individual work, student group work), practicals (e.g., practical demonstrations, student research), and assessment methods (e.g., portfolios, presentations).

- Evaluation and reflection. Teachers want to evaluate and reflect on each module in their own class, but there is not always enough time for this.

- Teachers' assistance. Teachers prefer the availability of a good teachers' guide of the module as this can provide guidance and answers to questions. The availability of an experienced lab technician saves teachers' time as a lab technician can prepare and perform trial lessons. 
- Student independent work. Teachers find it important that the module provides sufficient guidance in class for students to work independently so they do not need teacher assistance all the time. When students often need help, teachers experience this as a hindering aspect.

Table 2.4 Stimulating and hindering characteristics categorized in three groups of professionality (Hoyle E John, 1995)

\begin{tabular}{|c|c|c|c|c|c|c|}
\hline \multirow{5}{*}{ Stimulatinga } & \multicolumn{2}{|c|}{$\begin{array}{l}\text { Restricted } \\
\text { professionality }\end{array}$} & \multicolumn{2}{|c|}{$\begin{array}{l}\text { Neither restricted nor } \\
\text { extended } \\
\text { professionality }\end{array}$} & \multicolumn{2}{|c|}{$\begin{array}{l}\text { Extended } \\
\text { professionality }\end{array}$} \\
\hline & A & $\begin{array}{l}\text { Modules' } \\
\text { appropriateness }\end{array}$ & \multirow{10}{*}{ K } & \multirow{10}{*}{$\begin{array}{l}\text { Student } \\
\text { achievement }\end{array}$} & $\mathrm{C}$ & $\begin{array}{l}\text { Knowledge } \\
\text { acquisition by }\end{array}$ \\
\hline & \multirow[t]{3}{*}{ B } & Teachers' & & & & teachers \\
\hline & & preparedness & & & $\mathrm{D}$ & $\begin{array}{l}\text { Teachers' } \\
\text { cooperation }\end{array}$ \\
\hline & & & & & $\mathrm{E}$ & $\begin{array}{l}\text { Teachers' } \\
\text { networking }\end{array}$ \\
\hline \multirow[t]{6}{*}{ Neutral $^{b}$} & $\mathrm{~F}$ & Teachers' ownership & & & $\mathrm{L}$ & Teachers' \\
\hline & G & Link up to teachers' & & & & competences \\
\hline & & prior knowledge & & & $\mathrm{M}$ & Evaluation \\
\hline & $\mathrm{H}$ & Pedagogy & & & $\mathrm{N}$ & Mono- \\
\hline & $\mathrm{I}$ & $\begin{array}{l}\text { Evaluation and } \\
\text { reflection }\end{array}$ & & & & $\begin{array}{l}\text { disciplinary } \\
\text { coherence }\end{array}$ \\
\hline & $\mathrm{J}$ & Teachers' assistance & & & & \\
\hline \multirow[t]{3}{*}{ Hindering $\mathrm{c}$} & \multirow[t]{3}{*}{$\mathrm{O}$} & \multirow[t]{3}{*}{$\begin{array}{l}\text { Student independent } \\
\text { work }\end{array}$} & $\mathrm{P}$ & $\begin{array}{l}\text { Responsibility } \\
\text { National Steering } \\
\text { Committee }\end{array}$ & & \\
\hline & & & Q & $\begin{array}{l}\text { Modules' } \\
\text { suitability }\end{array}$ & & \\
\hline & & & $\mathrm{R}$ & School facilities & & \\
\hline
\end{tabular}

Note: aStimulating: Mentioned as a stimulating characteristic, answered in the open question after the semi-structured interview and also mentioned in the semi-structured interview. ${ }^{b}$ Neutral: These characteristics were not mentioned in the open question after the semistructured interview but only during the semi-structured interview.

cHindering: Mentioned as a hindering characteristic, mentioned in the open question after the semi-structured interview and also in the semi-structured interview.

Below we explain the characteristics from the 'neither restricted nor extended professionality' group:

- Student achievement. Student motivation and learning results were lower than teachers had initially anticipated and hoped for. 
- Responsibility National Steering Committee. When teachers experience problems preparing or teaching a module, they want to get assistance. If the National Steering Committee does not respond quickly to questions that teachers have, teachers experience this as a hindering aspect.

- Modules' suitability. Teachers find it hindering when the NLT module does not have the correct size, when the structure is not clear, or when there are inaccuracies in the content.

- School facilities. Teachers find it hindering when equipment and materials needed to teach a module (e.g., computers) are not sufficiently available at school. Teachers want to prepare their lessons in cooperation with colleagues and the school organization therefore must be flexible with respect to timetable requests such as parallel scheduling, block scheduling, and collective consultations with colleagues.

Explanation of the characteristics from the extended professionality group

- Knowledge acquisition by teachers. Teachers find it stimulating when they acquire new knowledge in the form of science content, instruction, and assessment methods. This knowledge can be obtained by consulting colleagues, experts, and literature.

- Teachers' cooperation. Teachers find it motivating and stimulating to work with colleagues from different disciplines. They learn from each other by discussing ideas, teaching methods, and content. When team-teaching a module with colleagues from different subjects, teachers can assist each other and share information and experiences.

- Teachers' networking. Teachers find it stimulating when they participate in a well-organized network meeting where teachers from different schools participate in collaborative activities.

- Teachers' competences. Teachers think that not every teacher makes a good NLT teacher. The NLT teacher should have qualities such as a broad interest in science, broad employability, being socially competent with students, and a willingness to spend time and energy on the new subject.

- Evaluation. Teachers not only find it important to evaluate and reflect on each module in their own classroom (see I), but also appreciate evaluation and reflection in collaboration with colleagues.

- Mono-disciplinary coherence. Students and teachers experience and create coherence between the mono-disciplines because of the integrated character of the NLT module. 
Research Question 3: Stimulating Characteristics for Implementation

The results from research question 2 are characteristics classified into three groups. The characteristics in the first row from Table 2.4, A to E are experienced as stimulating by the teachers. The characteristics in the last row, $\mathrm{O}$ to $\mathrm{R}$ were experienced as hindering.

Characteristics that stimulate implementation of a NLT module should be incorporated into a professional development programme. Hindering characteristics should be neutralized or avoided wherever possible. The question that now arises is: are the stimulating characteristics that teachers mentioned also described in the literature?

The characteristic 'Modules' appropriateness (A)' can be linked to the category 'Curriculum effect' of Van den Akker (1998). Capacity and motivation of the students are two aspects that influence the effectiveness of curriculum implementation. When students study a module in which the content links to their prior knowledge, and they experience the module as both pleasant and interesting, it will promote the implementation. The characteristic 'Teachers' preparedness (B)' can be found in 'Teacher characteristics'. Teachers' knowledge, skills, attitudes, experiences, preferences for teacher roles, and teaching methods all influence the effectiveness of the implementation (Beijaard et al., 2004; Pajares, 1992; Van den Akker, 1998; Van Veen \& Sleegers, 2006). For example, when a teacher has positive experiences with a situation, and this situation turns out to be part of the module, the implementation will be stimulated. The characteristic 'Knowledge acquisition by teachers (C)' and 'Teachers' cooperation (D)' can be linked to the category 'Context' from Van den Akker (1998). Cooperation between colleagues is a stimulating condition for implementation of an innovation, especially in multidisciplinary collaboration. It can provide motivation and introduce teachers to a broad variety of ideas and teaching methods (Leliveld et al., 2008; Meirink, 2007). Teachers can assist colleagues by sharing information and experiences through which new knowledge can be developed (Ball \& Cohen, 1996). The characteristic 'Teachers' networking (E)' is also linked to the category 'Context' from Van den Akker (1998). Collaborative activities in which teachers from different schools participate are effective strategies for teacher learning (Andrews \& Lewis, 2002; Desimone, 2002) and teacher learning is important for successful implementation. 
All the stimulating characteristics from the evidence-based approach, shown in the first row of Table 2.4, are also considered to be stimulating according to the curriculum implementation literature.

\subsection{CONCLUSION}

Professional development programmes are often designed only on the basis of characteristics described in research literature. Taking school practice as a starting point to the creation of a professional development programme, a successful implementation is more likely (Hill \& Cohen, 2005; Waslander, 2007). Effectively implementing a new multidisciplinary subject such as NLT is in particular a complex endeavor, because teachers do not have specific prior training for this new subject, and they are not familiar with cooperating with colleagues from other science disciplines. In order to prepare teachers adequately for NLT it is essential to set up a professional development programme. This study focused on the identification of characteristics for such a programme. The general research question in this research was as follows: 'Which characteristics are crucial for a professional development programme to promote the implementation of a NLT module?'

In this study we discussed the empirical basis for a professional development programme directed towards the implementation of new multidisciplinary modules in secondary education in the Netherlands. We identified and investigated a three-step approach. The first step was evidence produced in the classroom settings of the schools. Teachers were interviewed about the procedure followed and the decisions made to implement a module in their school, and the adaptations made to tailor the module to their particular classroom setting. As a second step, specific curriculum features of the NLT subject were taken into account. Hoyle and John (1995) and relevant national curriculum documents were used to analyze and categorize the information from the teachers interviewed. The third step consisted of evidence generated by curriculum implementation literature pertaining to effective characteristics of implementing an innovation. These three steps approached the problem of identifying the essential characteristics for a professional development programme from different angles. We started with teachers and their practices in order to develop the characteristics of the professional development programme, connected these 
characteristics to the features of NLT, and linked them up to what has been described as successful curriculum implementation in the research literature. The combination of these three steps can be regarded as an effective and efficient method of triangulation, resulting in a number of systematically obtained characteristics for a professional development programme.

The answers to the three sub-research questions filled a database with possible ingredients for a professional development programme. The first sub-question was about selecting an appropriate NLT module. Teachers mentioned selection characteristics that were related to students and to teachers. Students' prior knowledge, their interest and motivation, and the instructional strategy used, were considered important. Practical issues pertaining to teachers - the quality and availability of materials, and teachers' interest in the topic-surfaced. Five characteristics were mentioned during the semi-structured interview and again during the open question after the semi-structured interview, and are therefore considered especially important when selecting a module. These characteristics are as follows: (a) the module should fit the interest of the students; (b) the module should permit students to work independently of a teacher; (c) the module should connect to the knowledge and interest of the teacher; and (d) the module should include materials and facilities that are easy to obtain; and the module should have a high-quality teacher's guide.

The answer to the second sub-research question contains characteristics from the existing school practice related to the professional features of NLT. The characteristics were classified into three groups based on the work of Hoyle and John (1995): (a) the restricted professionality, (b) the extended professionality, and (c) the 'neither restricted nor extended professionality' group. Extended professionality refers to knowledge and skills going beyond the individual classroom. For a subject like NLT, with its multidisciplinary nature requiring teachers from different subjects to collaborate, the characteristics of the extended professionality group are therefore considered especially important when it comes to the implementation of a NLT module.

To answer our third sub-question, characteristics stimulating implementation were distilled from the existing school practice and these were compared to the curriculum implementation literature. The stimulating characteristics found in our study were also described as stimulating in literature. 
A professional development programme like the one this study suggests and we aim to design needs to incorporate characteristics that stimulate implementation and avoid ones that hinder it. For instance, the hindering characteristics 'student independent work' and 'modules' suitability' can be avoided by incorporating a session in the professional development programme in which participants can adapt and supplement the module.

Three characteristics stimulate implementation and belong to the extended professionality group. These are considered of special importance for a professional development programme. These three characteristics are as follows: knowledge acquisition by teachers, teachers' cooperation, and teachers' networking. Two other characteristics-'Modules' appropriateness' and 'Teachers' preparedness' - are also considered stimulating and important for each curriculum, (Desimone, 2002; Van den Akker, 1998; Waslander, 2007) and are therefore also taken into account.

Five characteristics that address the general research question were, this way, identified as essential characteristics that should be incorporated into a professional development programme to promote the implementation of a NLT module. In the actual design of the professional development programme, these essential characteristics can be interpreted as follows:

- Teachers should develop their knowledge. Teachers should be given ample opportunities to acquire new knowledge and skills, for example science content, instructional strategies, and assessment methods. Experts, colleagues, and specific literature can provide this knowledge.

- Teachers should cooperate with colleagues. Teachers should first be given opportunities to exchange and discuss experiences and ideas with colleagues.

- Discussion topics can be teaching methods and content, but also practical issues such as how to use a specific activity in class. Cooperation can be intensified by having teachers develop additional material or assessment instruments.

- Teachers should network. The result of the professional development programme should be a well-organized network in which teachers from different schools participate in collaborative activities.

- The module should be made relevant and attractive for students. Teachers can design stimulating curricular elements to increase students' interest and motivation. 
- Teachers should be well prepared and organized for their lessons. In the professional development programme, teaching and learning difficulties can be discussed, and good practices exchanged. How to prepare practical activities and where to obtain certain equipment and materials also needs to be addressed. 


\title{
CHAPTER 3
}

\section{Design and application of a model for a professional development programme for a multidisciplinary science subject ${ }^{3}$}

\begin{abstract}
Schools are increasingly integrating multidisciplinary education into their programmes. The Minister of Education, Culture and Science introduced a new, integrated science subject in secondary education in the Netherlands. The aim of this study is to design a model for a professional development programme to prepare teachers for and assist them during the implementation of a multidisciplinary science module. The following two research questions will be addressed: How does a generic model for a professional development programme to prepare and assist teachers for a multidisciplinary science module look like and what are its specific characteristics? How can this generic model be translated into a programme for a specific multidisciplinary science module? Three sources important for the design of such a programme have been elaborated: multidisciplinary science features including school practices, the curriculum design phases, and professional development characteristics. We combine these three sources with three factors influencing the quality of the professional development context, process, and content. These sources and factors have been translated into a generic model for a professional development programme to prepare and assist teachers. Following that, this generic module is translated into such a programme for a specific multidisciplinary module, called 'The hydrogen car'.
\end{abstract}

3 This chapter is based on the article published as a Research Note: Visser, T. C., Coenders, F. G. M., Terlouw, C., \& Pieters, J. M. (2012). Design of a model for a professional development programme for a multidisciplinary science subject in the Netherlands. Professional Development in Education, 1-4. 


\subsection{INTRODUCTION}

Teachers are crucial for a successful implementation of a new curriculum as they have to enact the new curriculum in their classes. Preparing teachers for a new curriculum can be seen as a learning process in which the teachers bring their knowledge, skills, and beliefs in line with the new curricular demands and partly vice versa. Concurrently the teachers learn to make use of the new curricular materials, the pedagogy, and the assessment strategies. This creates teacher ownership of the new curriculum and the curriculum materials facilitating implementation (Hargreaves, 1994; Rousseau, 2004; Wikeley, 2005). A professional development programme to prepare teachers for a new curriculum, to create ownership, and to assist teachers during implementation should engage teachers actively before and during the implementation (Garet et al., 2001; Loucks-Horsley et al., 2003; Penuel et al., 2007). Such a professional development programme will take time as it is a process, not an event (Fullan, 2007). Different kinds of professional development programmes for teacher learning for curricular reform have been described in literature. Coenders et al. (2008) summarize in their paper two kinds of professional development programmes. The first is based on the premise that teachers need to experience for themselves the learning in which they want to engage their students (Jeanpierre et al., 2005; Loucks-Horsley et al., 2003). Such a programme therefore contains numerous opportunities for practice. The second is about the use of curriculum materials to support teacher learning (Ball \& Cohen, 1996; Schneider, Krajcik, \& Blumenfeld, 2005).

In research, business, and healthcare, cooperation in multidisciplinary teams is quite common. An increasing number of scientists are working in multidisciplinary groups on topics which cannot be tackled successfully from one specific perspective (Black \& Atkin, 1996). For example, the fields of climate, environment, and health must be approached from multiple perspectives. Multidisciplinary education is therefore encouraged by the Minister of Education, Culture and Science in the Netherlands. In their future careers, students must be able to work in multidisciplinary teams to solve multidisciplinary issues. Therefore, schools are increasingly integrating multidisciplinary education into their programmes. The Minister of Education, Culture and Science has introduced a new, integrated science subject called Nature, Life, and Technology (NLT) in secondary education. Multidisciplinary 
education creates more coherence and cooperation between the different monodisciplines in schools and will improve communication, promoting a more collaborative approach to issues, and increasing insight into the work of other experts. Science is a discipline quickly developing by the contributions of a large number of researchers.

Due to this multidisciplinary education context it is theoretically and practically important to design a professional development programme to prepare and assist teachers during the implementation of the multidisciplinary science subject NLT. Different kinds of professional development programmes are described but none in the context of a multidisciplinary science subject.

The aim of this study is to design a model for a professional development programme to prepare teachers with and assist them during the implementation of a multidisciplinary science module. The following two research questions will be addressed: (a) How does a generic model for a professional development programme to prepare and assist teachers for a multidisciplinary science module look like and what are its specific characteristics? (b) How can this generic model be translated into a professional development programme to prepare and assist teachers with the implementation of a specific multidisciplinary science module?

\subsection{TOWARDS A MODEL}

Professional development activities in the Netherlands are normally organized during school weeks, not during holidays. The willingness of teachers toward professional development depends on availability of time, money, and encouragement of management (Beijaard, Meijer, Morine-Dershimer, \& Tillema, 2005; Fullan, 2007; Hewson, 2007). Within these Dutch school culture constraints, we have to design a professional development programme to prepare teachers for and assist them during the implementation of a multidisciplinary science subject (Hill \& Cohen, 2005; Waslander, 2007). For the design of such a professional development programme within a multidisciplinary science context three sources have to be taken into account. First of all, the programme must be consistent with the multidisciplinary science subject features including school practices and particular school specific constraints. We will describe these in a 
section below. Secondly, the crucial phases in curriculum design are equally important for designing the process of an effective implementation of the curriculum innovation, in particular creating ownership and actively involving teachers (Visser, Coenders, Terlouw, \& Pieters, 2010). Thirdly, in a previous study, we identified five essential characteristics that must be taken into account for a professional development programme to promote the implementation of a multidisciplinary science module (Visser et al., 2010).

Guskey (2000) defined professional development as those processes and activities designed to enhance the professional knowledge, skills and attitudes of educators so that they might, in turn, improve the learning of students'. According to this author three factors influencing the quality of professional development are important: Context characteristics refer to the 'who', 'when', 'where' and 'why' of professional development; Process variables refer to the 'how' of professional development; Content characteristics refer to the 'what' of professional development. Similar components have also been described by Loucks-Horsley et al. (2003), in their design framework for professional development for teachers of Science and Mathematics, and by Garet et al. (2001) in their analysis of characteristics of professional development focused on "structural features" and "core features". The three factors context characteristics, process variables, and content characteristics from Guskey (2000) are especially suitable to use in the multidisciplinary science context of the new subject NLT with its specific characteristics.

In the next sections, we first elaborate on the earlier mentioned three sources important for a programme within the multidisciplinary science context. To create a high quality professional development programme we then describe how these three sources relate to the three factors described by Guskey (2000).

\subsubsection{Nature, Life, and Technology}

Students in the upper level of secondary education in the Netherlands have to choose their school programme based on four streams: Science \& Technology, Science \& Health, Economy \& Society, and Culture \& Society. A profile consists of a number of subjects: a common part that is identical for all profiles, a profile part that characterizes each profile, and a free part. Since August 2007, the new subject NLT is introduced in the two Science streams. NLT is not a compulsory subject; schools have the freedom to offer it. The general objective of NLT is to 
make the natural sciences and technology more attractive to students and to show the relationships between the different science subjects. NLT has a modular structure, integrating elements from Physics, Chemistry, Biology, Mathematics, and Physical Geography. The NLT examination programme consists of nine different domains; from each domain at least one module has to be taught. Within each domain the teacher can choose from several modules. A module consists of a situated practice (for example, forensic technology, robotics, or holography) in which specific concepts traditionally belonging to Physics, Chemistry, Biology, Mathematics, and Physical Geography are explored.

At the school level, the implementation of NLT has several specific features (Steering Committee NLT, 2007). Firstly, the multidisciplinarity of NLT requires teachers from the different science disciplines mentioned above to cooperate in a multidisciplinary team. Secondly, the teachers involved in the teaching of NLT have a Master's degree in one of the aforementioned mono-disciplinary subjects, but have not been specifically trained for this new multidisciplinary subject. Thirdly, the multidisciplinary team of teachers at school has the freedom to select the modules for each examination domain, and decides on the order in which the modules will be taught. Finally, the school administration, in close consultation with the team of teachers, determines which and how many teachers will be teaching a specific module. Because teacher teams make different choices, implementation varies from school to school.

At the class level, NLT has three specific characteristics. Firstly, students are not obliged to take up all the subjects integrated in NLT, meaning that some students do not take Biology, Physics or Geography. Therefore not all the students have similar prior knowledge. Secondly, teachers have the freedom to change parts of the subject matter, for instance as a result of current developments or items that appear in the news. Thirdly, given the specific character of NLT, the assessment methods and instruments differ from those used in the mono-disciplines.

Implementing a new subject with a complex and multidisciplinary nature such as NLT, is therefore seen as a curriculum innovation for the teachers involved.

\subsubsection{Curriculum design phases}

Taking into account the before mentioned characteristics of NLT curriculum innovation it is valuable for curriculum design for teachers. In curriculum design, different phases can be distinguished (Marsh \& Willis, 2003; Verhagen 
et al., 1999). For NLT the following five curriculum design phases are important (Visser et al., 2010). The first is the 'Module Selection' phase in which teachers have to determine which modules will be offered at their school and in which order these will be taught. The second is the 'Module Preparation' phase, which encompasses all the steps before the module is actually delivered, such as drawing up a study programme for students, dividing tasks among teachers, and trying out experiments. The third one is the 'Module Teaching' phase, which focuses on the teaching and actual classroom delivery, such as, for example, the teaching methods used and the cooperation between teachers. The fourth is the 'Effect of the module' phase that shows the degree to which student learning goals are achieved after finishing the module. The fifth and final phase is 'Reflection on the module', where the teacher reflects on the module to determine strong aspects and elements that need to be adapted. The first two curriculum design phases (Module Selection and Preparation) occur before the actual implementation of a NLT module. The third and fourth curriculum design phases (Module Teaching and Effect of the module) take place during the implementation. The last curriculum design phase (Reflection on the module) occurs after the implementation. Therefore, in the design of the professional development programme the five curriculum design phases can be combined into one phase before, one during, and one after implementation. A professional development programme should assist and support teachers during these phases.

\subsubsection{Essential characteristics for a professional development programme}

To be successful, a professional development programme should not only be designed on the basis of characteristics described in literature, but also be consistent with school practices. In a previous study (Visser et al., 2010), the focus was on the identification of characteristics for a professional development programme that promoted the implementation of a multidisciplinary science (NLT) module. A 3-step approach was used to identify these essential characteristics: (a) evidence from classroom practice, (b) characteristics of the new subject, and (c) theoretical and empirical evidence from curriculum implementation studies. 
This resulted in five essential characteristics for a professional development programme to promote the implementation of a multidisciplinary science (NLT):

1. Teachers should develop their knowledge. Teachers should be given ample opportunities to acquire new knowledge and skills, with respect to for example science content, instructional strategies, and assessment methods. Experts, colleagues, and specific literature can provide this knowledge;

2. The module should be made relevant and attractive for students. Teachers can design stimulating curricular elements to increase students' interest and motivation;

3. Teachers should be well prepared and organized for their lessons. In the professional development programme, teaching and learning difficulties can be discussed, and good practices exchanged. How to prepare practical activities and where to obtain certain equipment and materials also need to be addressed;

4. Teachers should cooperate with colleagues. Teachers should first be given opportunities to exchange and discuss their own experiences and ideas with colleagues. Discussion topics can be instructional strategies and content, but also practical issues such as how to use a specific activity in class. Cooperation can be stimulated through teacher activities like the development of lesson plans, of additional materials, or of assessment instruments;

5. Teachers should network. The result of the professional development programme should be a well-organized network in which teachers from different schools participate in collaborative activities. A professional development programme for teachers based on these five characteristics should result in acquired knowledge and skills, a relevant and attractive module for students, and teachers being well prepared and organized for their lessons. All this should be in cooperation with colleagues in a wellorganized network.

We elaborate the three multidisciplinary science sources and its characteristics. How these characteristics A till N relate to Guskey's (2000) factors of professional development can be seen in Table 3.1 and will be explained below. 


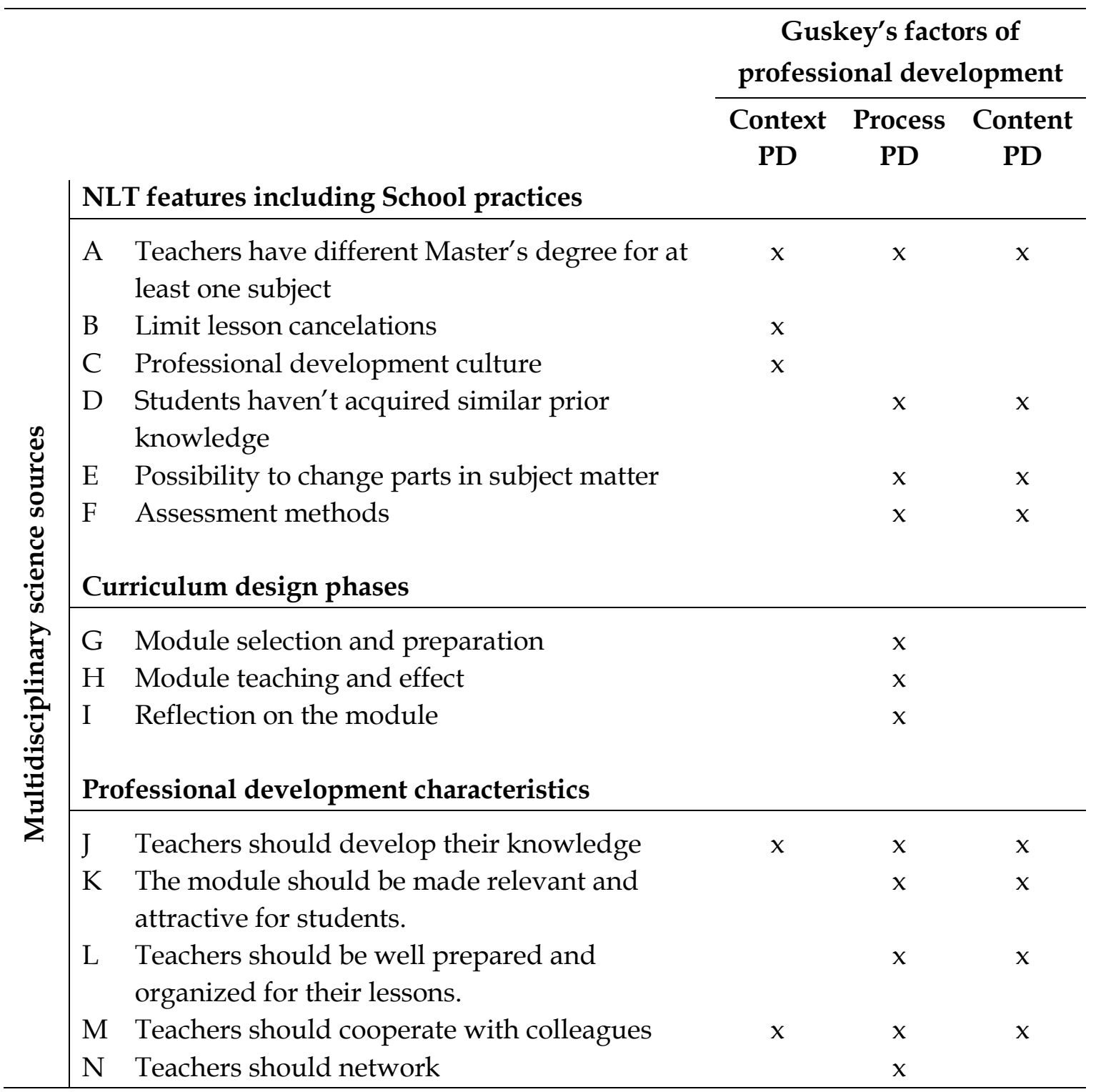

\section{Context of the Professional Development}

Context characteristics refer to the 'who', 'when', 'where' and 'why' of professional development. They include the organization, the system, and culture in which professional development takes place and where the new understandings will be implemented (Guskey, 2000).

NLT teachers from different schools are the participants of the professional development programme. These teachers have at least one Master's degree in one of the following mono-disciplines: physics, chemistry, biology, mathematics, or physical geography (Table 3.1; A). Science experts in the content area or with other specific relevant expertise from universities or 
companies can be requested for specific input in the professional development programme (Table 3.1; J). The professional development programme has to prepare teachers with and assist them during the implementation. To prevent lesson cancelation (Table 3.1; B, and C), on a normal school day, face-to-face meetings will be organized after classes. When the participating teachers have no teaching obligations it can take place during the day.

Professional development can in principle be organized in teachers' school and in face-to-face meetings at a location with laboratory facilities easily accessible for all participants involved.

Implementing a new subject with a complex and multidisciplinary nature, such as NLT, is seen as a curriculum innovation for the teachers involved. The success of the implementation of an innovation depends among other factors on the active involvement of teachers (Garet et al., 2001; Loucks-Horsley et al., 2003; Penuel et al., 2007). Therefore, teachers are encouraged to participate in professional development programmes. The professional development must be linked to the curricula teachers have to teach, collaborative, and should be effective with respect to time - outcome (Table 3.1; C, J, and M)(Hunzicker, 2011).

\section{Process of the Professional Development}

Process variables refer to the 'how' of professional development, not just the type and form of professional development activities; it also refers to the way those activities are planned, organized, carried out and followed up (Guskey, 2000; Loucks-Horsley et al., 2003). The curriculum design phases will form the foundation of the process of the professional development programme. Three professional development phases are distinguished. The first phase is scheduled before the actual implementation of a NLT module. Here module selection and first familiarization with the module will take place (Table 3.1; G). The second phase, module teaching and effect of the module, takes place during the implementation of the module (Table 3.1; H). The third phase, reflection on the module, occurs after the implementation of a module (Table 3.1; I). In each phase different activities are planned and carried out to prepare and assist the teachers optimally.

Teaching usually does not take place in an interdisciplinary setting. Moreover, teachers are not always used to working in teams, sharing experiences, and following good practices. Because of its interdisciplinary character, NLT 
teachers have to work in a multidisciplinary teacher team. The content of NLT modules goes beyond the content of the traditional science subjects. Teachers usually have a teacher qualification in one of the traditional science subjects (Table 3.1; A). Therefore, teaching NLT modules is challenging, because the modules not only deal with their own discipline but also involve content from other science disciplines at a high level (Table 3.1; J). To deal with this challenge, it is important to be well prepared and collaborate with colleagues from different backgrounds and with assistance from external experts (Table 3.1; L, and M). This collaboration can be organized in a professional network (Table 3.1; N). Several studies discuss the potential role of professional learning and working communities (networks) for teacher professional development and school development. A professional learning and working community is seen as a stimulating context for teacher learning (Witziers, Sleegers, \& Imants, 1999), improving professional practice, and developing collective knowledge (Grossman, Wineburg, \& Woolworth, 2001; Hammerness, Darling-Hammond, \& Bransford, 2005; Little, 2003). Professional development of teachers is promoted when teachers work in a professional learning community in which a culture of collaboration between colleagues and experts exists, and collective responsibility prevails (Geijsel \& Meijers, 2005). Teachers themselves also see the interaction with colleagues as a useful experience for their professional development (Kwakman, 1999). Another aspect of professional development is teachers' willingness to take risks with new approaches and their confidence that they can react meaningfully to unknown outcomes (Mitchell \& Mitchell, 2005). Dealing with the three specific characteristics of NLT at the class level is new and therefore teachers have to try something new and must take risks (Table 3.1; D, E, and F). If teachers try something new in their classroom, they need to feel that they will not be penalized for imperfect attempts and unexpected student learning outcomes. They also need a reasonable degree of freedom to capitalize on unexpected class events such as students asking interesting questions. Putting new approaches into action and reacting with flexibility to unpredictable events require curriculum flexibility. A rigid curriculum and prescriptive assessment instruments hamper professional growth (Mitchell \& Mitchell, 2005). Because NLT has a flexible curriculum, it is possible to act on differences in students' prior knowledge, to adapt the subject matter, and to use different assessment methods. These three specific NLT factors can be used in trying to make the module relevant and attractive for students (Table 3.1; K). 


\section{Content of Professional Development}

Content characteristics refer to the 'what' of professional development. They concern the new knowledge, skills, and understanding that are the foundation of any professional development effort (Guskey, 2000; Loucks-Horsley et al., 2003). An interdisciplinary subject like NLT, where teachers typically have one Master's degree for one of the science subjects, requires teachers to develop their knowledge (Table 3.1; A and J). To prepare and organize the lessons, teachers must take students' prior knowledge into account, change parts in the subject matter, decide which assessment methods will be used, and make the module relevant and attractive for the students (Table 3.1; D, E, F, K, and L). When teachers cooperate with colleagues from different science subjects, ideas, experiences, and good practices will be exchanged. They can use each other's knowledge and experiences to expand their prior knowledge and make useful decisions in preparing the module (Table $3.1 ; \mathrm{J}, \mathrm{K}, \mathrm{L}$, and $\mathrm{M}$ ).

\subsection{A GENERIC MODEL FOR A PROFESSIONAL DEVELOPMENT PROGRAMME}

The three factors - context, process, and content, including the characteristics $\mathrm{A}$ till $\mathrm{N}$ from Table 3.1 - have been translated into a generic model for the professional development programme shown in Figure 3.1. In this Figure, the context of the professional development is shown as the white box, the factor process of the professional development is grey and the factor content of the professional development is represented by the black boxes.

The model shown in Figure 3.1 is a practice oriented theory generic model (Terlouw, 2009). This model can be used for all the NLT modules in the Netherlands. The joint elements in a module are the following: the topics of the NLT modules are often from the interface of the different disciplines - Physics, Chemistry, Biology, Mathematics, and Physical Geography. The modules deal with the integration of concepts in contexts: both the application of disciplinary concepts and the acquisition of new knowledge and skills. The modules contain a knowledge component and a skill component, integrated as much as possible. 


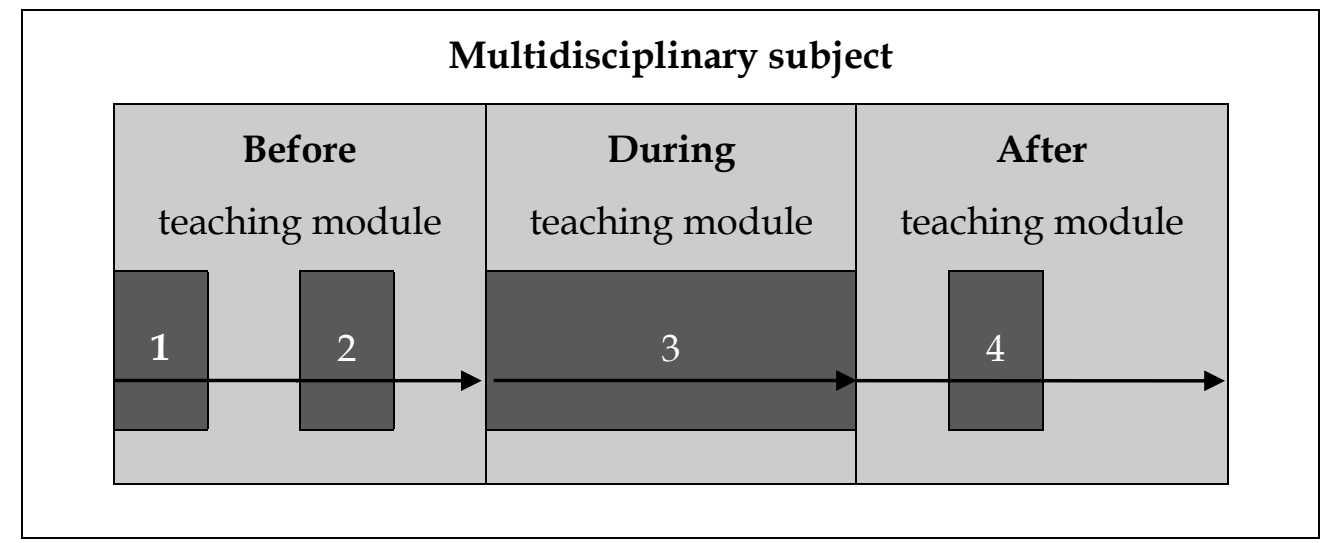

$\mathbf{1}$ individual preparation

2 preparation seminar

3 online support

4 reflection meeting

Figure 3.1 Generic model for a professional development programme

Elements that differ in a module are as follows: (a) The balance between a systematic structure and the possibility for teacher and student to choose their own directions while working on the module; (b) The teaching methodology underlying the subject matter; (c) The relation between concept and context in the module; and (d) The role of ICT and distance learning. The following practical constraints of the modules are embedded in the generic model for a professional development programme: The acquisition of background knowledge, the presentation of results and distance learning, the consultation of experts, video conferencing, data processing, simulation and conducting virtual research on a site.

The professional development programme assists and supports teachers before, during, and after implementation of a multidisciplinary science module. A coordinator is necessary to chair this professional development programme. Before teaching, teachers are requested to read the material (Figure 3.1, number 1) and just before teaching, a seminar with all stakeholders is held (Figure 3.1, number 2). During teaching, regular support between all teachers is organized (Figure 3.1, number 3). After evaluation of student learning outcomes, a reflection meeting with all teachers is held (Figure 3.1, number 4). The three different phases of this programme are described in more detail, in the next section.

How the multidisciplinary characteristics A till $\mathrm{N}$ are integrated in Figure 3.1 is shown in Table 3.2. Every characteristic has a certain focus in one of the three 
phases. For instance, characteristic $\mathrm{E}$ is the possibility to change parts in subject matter. This characteristic will be tackled before teaching, during the preparation seminar, as it is important to exchange ideas for changes to be made. Minor adaptations are also made during teaching, because of lack of time or because of newsworthy and relevant items for the topic at hand. After the module is taught, during the reflection meeting, weaknesses of the module can be changed and changes made earlier can be reflected and adapted.

Table 3.2 Characteristics related to the generic professional development programme model

\begin{tabular}{|c|c|c|c|c|c|c|c|c|c|c|c|c|c|c|}
\hline \multirow[t]{2}{*}{ Phases } & \multicolumn{14}{|c|}{ Characteristics } \\
\hline & $\mathrm{A}$ & $\mathrm{B}$ & $\mathrm{C}$ & $\mathrm{D}$ & $\mathrm{E}$ & $\mathrm{F}$ & $\mathrm{G}$ & $\mathrm{H}$ & $\mathrm{I}$ & $\mathrm{J}$ & K & $\mathrm{L}$ & $\mathrm{M}$ & $\mathrm{N}$ \\
\hline Before & $\mathrm{x}_{2}$ & $x_{2}$ & $\mathrm{x}_{1}$ & $x_{2}$ & $x_{2}$ & $x_{2}$ & $x_{1,2}$ & & & $x_{1,2}$ & $\mathrm{x}_{2}$ & $x_{2}$ & $x_{1,2}$ & $\mathrm{x}_{2}$ \\
\hline During & & & & & & & & $x$ & & $x$ & & $x$ & $x$ & $x$ \\
\hline After & & & & & $x$ & $x$ & & & $x$ & $x$ & & & & $x$ \\
\hline $\begin{array}{l}x=\text { focus } \\
1=\text { indiv } \\
2=\text { prep }\end{array}$ & $\begin{array}{l}\text { par } \\
\text { mir }\end{array}$ & ion & $\mathrm{ph}$ & & & & & & & & & & & \\
\hline
\end{tabular}

\section{Before teaching}

A professional development programme is more successful when it connects everyday school practice and teachers' prior knowledge, and also adjusts to the diversity of behaviors and beliefs of their participants (Cotton, 2006; Luft, 2001). Therefore, this stage consists of an individual and a collaborative part.

Individual preparation (See Figure 3.1, number 1)

Well before teaching the teachers are asked by an e-mail from the coordinator of the professional development programme to examine the module and consider issues like: (a) What knowledge and skills do I want my students to acquire in this module? (b) What kind of assessment methods and instruments do I intend to use in this module? (c) What questions do I have for the preparation seminar?

As the delivery time of equipment for practical activities can be long, teachers are advised to find out what materials their school already has and what needs to be purchased or borrowed. 
Preparation seminar (See Figure 3.1, number 2)

A preparation seminar is organized shortly before teaching the NLT module at schools. Professional development is most relevant when it focuses on class implementation and existing needs; therefore, teachers' personal needs form the starting point of the seminar (Dunne, 2002; Erickson, Brandes, Mitchell, \& Mitchell, 2005; Lieberman \& Pointer Mace, 2008). This creates a strong sense of ownership (Ogborn, 2002; Van den Akker, 1998; Vermunt, 2006; Wikeley, 2005) and encourages active learning by using teachers' own input for the interaction with colleagues (Day, 1999; Garet, Birman, Porter, Desimone, \& Herman, 1999). Immediately after opening the seminar, teacher questions from their individual preparation are collected, categorized and included in the seminar programme. Questions can be related to content, planning or equipment (Table 3.3, II).

Thereafter, teachers must get an overview of the structure and operationalization of the entire module. Issues that deserve attention are: learning goals, motivation, prior knowledge, and assessment methods and instruments. Through discussion and exchange of experiences, ideas, and good practices these issues will be tackled (Table 3.3, III).

The substantive aspects to be addressed next are experiments, module outline, and additional learning material. The breadths and depths of these aspects depend on the topic and content of the module. Try-out experiments play a role in being well prepared for the lessons; it prevents surprises in class and enhances the possibility of solving arising problems in advance. In the preparation seminar programme, therefore, time (and space) to try-out the experiments is created. In the Netherlands, it is compulsory to have a (module) outline for each subject, serving both the teacher and the students. It consists of a timetable which indicates per week what sections will be taught, what exercises and homework need to be done, possible excursions, and assessment moments and methods. For teachers, it also serves as a good stepping stone towards the elaboration of a lesson plan. In the seminar, teachers exchange ideas, experiences, and good practices. Teachers can use these ideas to make thoughtful decisions to outline the module for their own class use (Borko, 2004). Given the specific character of NLT, there is a need to develop additional learning materials, assessment methods, and instruments. Discussion of these aspects with colleagues saves time. Furthermore, ideas from one teacher can act as inspiration for the others. After this discussion, teachers should know what materials have to be elaborated. 
Reflection on the programme and making appointments for the next phase conclude the seminar. This seminar is an important first step to the creation of a network. Interaction with teachers of different schools in an interactive process can create a network (Clement \& Vandenberghe, 2000).

Table 3.3 Collaborative seminar programme including underlying goal and teacher activities

\section{Outline of the}

Collaborative Seminar

Programme

Goal

What teachers do

I. Opening

II. Soliciting teachers' questions to be included in the programme

To create strong sense of ownership with the programme.

III. Discussion of the overall module

IV. Substantive aspects of the module

- Experiments

- Module outline

- Design materials

V. Appointments
To familiarize with alternative ideas, and to form a clear picture of the overall module.
Teachers mention personal questions.

Discuss and exchange experiences, ideas, and good practices.
To handle practicalities, and discuss solutions for practical problems.

To prepare module and lesson outline.

To develop additional learning materials.

To organize support during teaching and organize field trips and guest lectures.
Try-out experiments from the module.

Outline the module for own class use.

Discuss additional learning materials, assessments methods and instruments.

Reflect on the professional development programme and make appointments.

VI. Closure

During teaching; Online support (See Figure 3.1, number 3)

The period of teaching a module varies per school, as it depends on the number of lessons per week. Teachers need support during the teaching phase, especially when they have to implement new approaches in their classes (Dede, Ketelhut, Whitehouse, Breit, \& McCloskey, 2009). Because time constraints 
complicate organizing face-to-face meetings during teaching, an online component can provide such support (Berger, Eylon, \& Bagno, 2008; Owston, Sinclair, \& Wideman, 2006). As a simple tool enabling all teachers to participate in the online exchange, e-mail is preferred and selected (Berger et al., 2008). Owsten (2006) suggests that short weekly postings of teachers' reflections may stimulate others to participate in the exchange. During the teaching phase of the NLT module teachers are regularly asked to describe in an e-mail their individual good practices and problematic experiences with the module for that week, and can post requests for assistance or guidance with aspects of the module. All responses are summarized by the coordinator of the professional development programme and returned by e-mail to all participating teachers a few days later. The coordinator of the professional development programme makes sure all teachers' questions are addressed.

\section{After teaching; Reflection meeting (See Figure 3.1, number 4)}

The final phase of this professional development programme is the collaborative reflection meeting which takes place after the NLT module is finished. All participating teachers should have enough time to collect the assessment results. Issues to be discussed in the refection meeting are: strengths and weaknesses, assessment methods, learning goals, teaching methods, and module outline. Joint reflection is an important learning activity (Meirink, 2007), as strengths and weaknesses of the teaching-learning process emerge and are described for future use. Such a collaborative process builds confidence for the next module.

\subsection{THE GENERIC MODEL APPLIED ON A SPECIFIC NLT MODULE CALLED 'THE HYDROGEN CAR'}

Above, we described a generic model for a professional development programme for multidisciplinary science modules. We now apply this model to a specific NLT module called 'The hydrogen car'. In this module, students immerse themselves in the core of the hydrogen car: the fuel cell. Questions to feature in the module are: How to stock sufficient hydrogen in the fuel tank? What storage option is the most promising? How much fuel is needed for a car with a certain speed? In the final chapter, student groups work on a chosen challenge in the field of fuel storage or car design. 
Through a written invitation teachers are invited to participate in this professional development programme.

\section{Before teaching}

Individual preparation (See Figure 3.1, number 1)

Participating teachers are requested by e-mail, well before teaching the module, to examine the module and consider the three earlier mentioned issues: (a) What knowledge and skills do I want my students to acquire in this module? (b) What kind of assessment methods and instruments do I intend to use in this module? (c) What questions do I have for the preparation seminar?

This module contains three lab experiments. For these experiments, special equipment is needed. At least one hydrogen fuel cell and one Hofmann electrolysis apparatus must be present. The teachers are asked to check whether these are available in their schools. Depending on budget and class size the teacher determines the number of devices that must be purchased or borrowed.

Preparation seminar (See Figure 3.1, number 2 and Table 3.3)

The preparation seminar will take place shortly before teaching the module. The programme starts with an introduction of all the participants. The participants of the seminar are as follows: the coordinator who will chair the seminar; an expert; a representative from the regional NLT information centre who knows the possibilities for organizing excursions; the teachers who will teach the module 'The hydrogen car' next period; and the school lab assistants.

After the introduction, all issues teachers have in relation to the content, planning, or equipment will be collected and included in the programme (Table 3.3, II).

To develop an overview of the module, teachers will discuss and exchange ideas and good practices with respect to learning goals, motivation, prior knowledge, and assessment methods and instruments. (Table 3.3, III). We will now describe some of these aspects with a few possibilities and ideas that can come along in the discussion and exchange.

What are the possibilities regarding the subject matter of this module?

The total module is too large to teach in the 40 study hours that are available for it. Therefore, teachers have to decide which content is important for every student and which content is optional. Motivation and prior knowledge can 
play a role in this choice. Differentiation between students is an option. Students can choose between two chapters, or the teacher can make a classification due to prior knowledge. To motivate students for the module it is possible to start with a small study, which students must explore.

How can we cope with variation between students' prior knowledge in this module? Most of the elements from the module 'The hydrogen car' came from Physics. Because Physics is not obligatory for students, the module can be difficult for some of them. When preparing the module it is useful to know the prior knowledge of the students. Depending on how many students there are who have not been taught in Physics, the teacher has different options. He or she can give more attention and explanation during the lessons about the physics content to these students. These students can do additional exercises to make their knowledge adequate at least, or the teachers can differentiate with the teaching material.

What kind of assessment methods and instruments are most suitable for this module? The module consists of a practical, theoretical, and research part. The assessment method must assess the core elements of the module. To assess the exercises and experiment reports, the students can keep a portfolio. A theoretical test with or without their own portfolio, a presentation, and an article are possibilities for assessing the theoretical and research part. After discussing these issues, the teachers will be more familiar with the operationalization of the module.

The substantive aspect to be addressed next is a try-out of the experiments (Table 3.3, IV). In a lab, the experiment with the fuel cell from the module will be available. A chemical engineering student will guide the teachers and lab assistants with the experiment.

Teachers should now have an overview of the module and can use all the information to elaborate a first version of an outline of this module. The modules' outline shall differ for each school because of teacher choice concerning subject matter, prior knowledge, assessment methods, and lesson schedules.

The teacher guide of the module contains no theoretical test; therefore, during the seminar the teachers will be asked to consider some key topics for exercises that can be used in a theoretical test. The complete exercises for the theoretical test can be made at home and will be exchanged later by e-mail. 
At the end of the seminar, the coordinator will reflect on the programme and make appointments for the next phase. The issue of weekly mail contact needs to be discussed. Additionally, content-what information each participant wants to receive and provide - and organizational aspects - who is doing what and when-need attention. The reflection meeting date will be chosen, shortly after the last teacher finishes teaching the module.

\section{During teaching; Online support (See Figure 3.1, number 3)}

The period of teaching a module varies per school. Teachers will receive an email from the coordinator during the teaching period of the NLT module. Depending on the agreements they made about the content and organization of the e-mails, the teachers could be asked to describe their individual good practices and problematic experiences with the module for each week. They can also post requests for assistance or guidance referring to the module in the email. A summary of the experiences will be returned to all participating teachers.

During the seminar teachers consider key topics for exercises of a theoretical test. The coordinator collects all the developed exercises for the test and sends them in one file to all the participating teachers well before the test is assessed.

\section{After teaching; Reflection meeting (See Figure 3.1, number 4)}

The reflection meeting will take place soon after the last teacher is finished teaching the module. The programme of this meeting will be partly open to accommodate teachers' contributions and requests. The teachers will discuss the following issues in the refection meeting: strengths of the module, weaker points of the module, assessment methods, differences next year, and different learning goals. After the reflection of the module, teacher requests will be discussed.

\subsection{EXPERT APPRAISAL}

Three experts, all familiar with NLT, evaluated our model for a professional development programme. All have a different expertise to make an informed judgment on the design. Expert one is a teacher trainer and was involved in the development of NLT modules. Expert two is Biology and NLT teacher and involved in a regional NLT information centre. Expert three is a Chemistry and NLT teacher. 
The professional development model and an explanation of the model, together with a questionnaire with thirteen questions on a five points Likert scale were sent to the experts (see Appendix 1). The experts were asked to score the professional development programme model on thirteen different factors. A score of 1 means that a certain factor was not sufficient available in the model and a score 5 means that it is sufficient available in the model. A score above 3.0 means, that this factor is adequately available in the professional development model according to the experts. From experts' mean scores on the questionnaire (Table 3.4) it can be seen that the experts are sufficient congruent in their judgment of the model. The mean score of the experts is 4.0. Professional development culture of Dutch school (Appendix 1, question 2), student's prior knowledge (question 3), change subject matter (question 4), assessment methods (question 5), selection and preparation phase (question 6), teaching and effect phase (question 7), and reflection on the module (question 8), all these facts are adequately taken into account in the generic model by the experts. Furthermore, the generic model gives teachers ample opportunities to acquire new knowledge and skills (question 9), to make the module relevant and attractive for students (question 10), adequately prepare and organize teachers for their lessons (question 11), exchange and discuss experiences and ideas with colleagues (question 12), and the model could lead to a well-organized network in which teachers from different schools participate (question 13).

The experts judged all aspects of the model sufficient or better, except for the possibility to work on content knowledge deficiencies (question 1, mean score 2.3). 
Table 3.4 Results of the questionnaire (Appendix 1) by the three experts

\begin{tabular}{ccccc}
\hline Question & Expert 1 & Expert 2 & Expert 3 & Mean \\
\hline 1 & 3 & 2 & 2 & 2.3 \\
2 & 5 & 3 & 3 & 3.7 \\
3 & 4 & 4 & 4 & 4.0 \\
4 & 5 & 4 & 5 & 4.7 \\
5 & 4 & 4 & 5 & 4.3 \\
6 & 4 & 3 & 5 & 4.0 \\
7 & 4 & 5 & 5 & 4.7 \\
8 & 4 & 5 & 5 & 4.7 \\
9 & 3 & 4 & 5 & 4.0 \\
10 & 5 & 3 & 4 & 4.0 \\
11 & 5 & 4 & 3 & 4.0 \\
12 & 4 & 4 & 5 & 4.3 \\
13 & 3 & 3 & 5 & 3.7 \\
\hline Mean & & & & 4.0 \\
\hline
\end{tabular}

\subsection{DiscUSSION}

Overall, the experts were positive in their judgment of the model for a generic professional development programme. They were however critical about the issue of whether the model offers sufficient possibilities for participants to familiarize themselves with new content knowledge. Teachers have a Master degree for one science subject and are therefore non specialists in other science subjects. We acknowledge the notion that teachers might have deficiencies in specific content knowledge. The solution for NLT however can be found in the idea that teacher teams would be responsible for teaching it, as it is almost impossible for teachers to acquire the knowledge of the other science disciplines at the required level in the short time span available. Teacher teams at schools must therefore consist of at least three teachers with different Master's degrees (physics, chemistry, biology, mathematics, and physical geography) (Steering Committee NLT, 2007). In the professional development programme we want to focus on class use of modules in relation to pedagogical content knowledge, planning, and equipment. On top of this, explicit attention is paid to student prior knowledge; classroom activities and instruction can link to students' prior knowledge. 
The first question pertained to the effective characteristics of a generic model for a professional development programme that could prepare and assist teachers in teaching a multidisciplinary science module. The second question focused on the translation of the generic model to implement a specific multidisciplinary science module.

The model introduced and discussed in this paper can effectively prepare teachers with and assist them during the implementation of a multidisciplinary science module. Additional effective characteristics were incorporated, ownership of the innovation, and active involvement in the implementation, in which school culture and practical constraints are also explicitly taken into account (Hill \& Cohen, 2005; Waslander, 2007). Three sources important to the design of such a professional development programme have been elaborated and further incorporated. These sources have been identified in a previous study as essential NLT design and implementation characteristics, including school practices, curriculum design phases, and professional development characteristics (Visser et al., 2010). In this study, these three sources have been combined with the three factors, identified and introduced by Guskey (2000), influencing the quality of the professional development, i.e. context, process, and content. These sources and factors are successfully translated into a generic model for a professional development programme to prepare and assist teachers in implementing NLT modules (Figure 3.1).

The usability of the generic module was shown by the operationalization into a specific professional development programme to prepare and assist teachers with the implementation of the specific NLT module called 'The hydrogen car'. The translation of the generic elements of the professional development model into a professional development programme for a specific NLT module proved possible for 'The hydrogen car'. We also translated the generic elements of the professional development programme model into a professional development programme for a module, called 'Brains and learning'.

From Table 3.1 it can be deduced that characteristics A (Teachers have different Master's degrees for at least one subject), J (Teachers should develop their knowledge), and M (Teachers should cooperate with colleagues) appear in all three factors. These characteristics therefore deserve special attention, because they are important to design for multidisicplinarity and practicality. Teachers 
having different Master's degrees (Characteristic A) should establish the prior knowledge of their students in order to adjust teaching. Prior knowledge is conceptualized as the learner's content knowledge related to the domain studied, present before a particular instruction. Research suggests that prior knowledge is one of the most important prerequisites for learning (Gurlitt \& Renkl, 2010). Prior knowledge also provides a framework through which new information may be organized and assimilated. Students learn and remember new information best when it is linked to relevant prior knowledge. Teachers who link classroom activities and instruction to prior knowledge build on their students' familiarity with a topic and enable students to connect the curriculum content to their own culture and experience. In our programme we address this by discussing students' prior knowledge in the preparation seminar with teachers.

In the professional development programme, teachers develop different kinds of knowledge (Characteristic J): Pedagogical content knowledge, referring to the actions and strategies of teaching, organization of classroom experiences, providing for diverse learner needs, evaluation and implementation of learner's prior notions, and transformation of ideas into understandable pieces; and practical knowledge, the knowledge needed to perform the specific NLT module, including student learning, methodology and time frame. We address these elements during the professional development programme. In particular, in the 'before teaching' phase, pedagogical content knowledge will be developed, while the practical knowledge will be developed during enactment, i.e. teaching the module.

Teachers should cooperate with colleagues (Characteristic M) from the same school and from different schools. As described before, NLT has several specific features. At school level, the multidisciplinary team of teachers has the freedom to select the modules for each examination domain, and decides on the order in which the modules will be taught. Also the team of teachers determines which and how many teachers will teach a specific module. The teachers can decide that one teacher will teach the module or that two or three teachers will teach one module. In the first case, teachers should cooperate with teachers to obtain content information about another integrated subject of the module, and the teacher can ask their colleague to provide a guest lecture. In the second case, teachers of different disciplines not only work together in a team but also develop and perform lessons together. In this professional development 
programme, teachers from different schools who teach the same module work together. Teachers deal with the same kinds of problems and can therefore support each other. Regular cooperation between teachers can lead to a network.

Support during teaching of the module is especially important when teachers have to implement new approaches in their classes (Dede et al., 2009). In our programme we used e-mail as a simple tool to support and exchange information between teachers. While it is a simple tool enabling all teachers to participate, practice often shows a poor participation rate (Berger et al., 2008). To address this problem the coordinator of the professional development programme takes the weekly initiative of sending every participant an e-mail. In the introduction and in the sections describing the generic character of the model, designing for multidisciplinarity and practicality were emphasized. In the two specific modules - the 'hydrogen car' and 'brains and learning' - these characteristics are exemplified. In a follow up study, teacher learning from these professional development programmes will be looked for. 


\section{CHAPTER 4}

\section{Evaluating teachers' satisfaction about a professional development programme for implementation of a multidisciplinary science subject ${ }^{4}$}

This study aims to evaluate a professional development programme that prepares and assists teachers with the implementation of a multidisciplinary science module, basing the evaluation on participants' reactions, the first level of Guskey's five-level model for evaluation (2002). Positive evaluations at the higher levels in Guskey's model are thought to depend upon those at the first level, that is, teachers' positive appreciation for the professional development programme. Different instruments (questionnaires, e-mail correspondence, and interviews) were used at various stages in the four-part professional development programme. The data were categorized by the stage in the programme to which they pertained: individual preparation; preparation seminar; online support; or reflection meeting. The data from all participating teachers were combined in tables, with some parts paraphrased in a few sentences.

In general, the teachers were satisfied with the professional development programme. This paper identifies several elements that ensure teacher satisfaction in the multidisciplinary professional development programme, indicates which are the difficult elements of this programme, and suggests how these difficulties can be handled.

4 This chapter is based on the article submitted as: Visser, T. C., Coenders, F. G. M., Terlouw, C., \& Pieters, J. M. (2012). Evaluating teachers' satisfaction about a professional development programme for implementation of a multidisciplinary science subject. 


\subsection{INTRODUCTION}

The Ministry of Education, Culture, and Science in the Netherlands encourages multidisciplinary education. For their future careers, students must be able to work in multidisciplinary teams to solve interdisciplinary issues. Schools are therefore increasingly integrating multidisciplinary education into their programmes. In August of 2007, the Minister of Education, Culture, and Science introduced an optional science subject called Nature, Life and Technology (NLT) at the upper level of secondary education. NLT is a multidisciplinary subject, integrating elements from physics, chemistry, biology, mathematics, and physical geography.

Teachers involved in the implementation of a curriculum innovation such as NLT, a new multidisciplinary subject, require new knowledge, skills and routines in order to teach the new subject adequately (Bergen \& Van Veen, 2004; Van den Akker, 1999). Over the years, research on effective professional development for teachers has shown that teachers can be prepared for a new curriculum through active involvement in the design and implementation of the curriculum innovation (Garet et al., 2001; Keys \& Bryan, 2001; LoucksHorsley et al., 2003; Penuel et al., 2007). Professional development becomes relevant and effective when long-term, collaborative, school-based approaches are used that focus on the learning of all students, that are linked to teachers' daily school practice, teachers' prior knowledge, and the curricula that teachers must follow, and that also adjust to their diversity of behaviors and beliefs (Desimone, 2009; Garet et al., 2001; Hunzicker, 2011; Lieberman \& Pointer Mace, 2010; Penuel et al., 2007). In an earlier study, we used the research on professional development discussed above to design a generic model for a professional development programme for preparing teachers to teach a multidisciplinary science subject (Visser, Coenders, Terlouw, \& Pieters, 2012a). The aim of the current paper is to evaluate this previously designed and implemented professional development programme. In the conceptual framework section, we will explain in more detail the following: NLT as a multidisciplinary science subject; the concept of the professional development programme and how it has been instantiated in the particular professional development programme under evaluation; and the concept of evaluation of professional development. 


\subsection{CONCEPTUAL FRAMEWORK}

\subsubsection{Nature, Life, and Technology}

NLT is related to traditional science subjects but differs because of its multidisciplinary and modular structure. A NLT module consists of a situated practice (for example, nuclear fusion, sound design, or medicine) in which specific concepts traditionally belonging to physics, chemistry, biology, mathematics, and physical geography are explored. The NLT examination programme consists of six different domains; for each domain at least one of the three to eight existing modules must be taught. The modular and multidisciplinary character of NLT means that the content of the NLT modules amounts to more than just the sum of the contents of the traditional science subjects involved. Science teachers usually have a degree in one of the traditional science subjects. Therefore, teaching the NLT modules is challenging, because the modules not only deal with a teacher's own discipline, but also involve high-level content from other science disciplines. In order to encourage schools to offer high-quality education in this new subject, the National Steering Committee formulated a number of criteria that schools should meet to become an officially registered implementation school (Steering Committee NLT, 2007). The multidisciplinary nature of NLT requires that at least three teachers with different Master's degrees (physics, chemistry, biology, mathematics, or physical geography) collaborate in a multidisciplinary teaching team. Such a multidisciplinary team has the freedom to select the modules for each examination domain, and can decide on the order in which the modules will be taught in their school. The school administration, in close consultation with the teaching team, determines which and how many teachers will be teaching a specific module. For instance, at one particular school, the module called 'Medicines' is taught by a team of two teachers, one a biology teacher and one a chemistry teacher. At another school, they decided to let one biology teacher rather than a team of teachers teach the module called 'Cardiovascular system' (a different module than 'Medicines' but in the same examination domain) to the same class level. Implementation varies from school to school as different choices are made.

Implementation of a new subject with a complex and multidisciplinary nature such as NLT can therefore be regarded a curriculum innovation, in particular with regard to NLT's structure, content, and delivery. 


\subsubsection{Professional development programme}

Guskey (2000) defined professional development as "those processes and activities designed to enhance the professional knowledge, skills and attitudes of educators so that they might, in turn, improve students' learning" (p. 16). According to this author, three important factors influencing the quality of professional development are context, process, and content.

In an earlier study we designed a generic model for a professional development programme to prepare teachers and assist them during the implementation of new multidisciplinary science curriculum on a multidisciplinary science subject (Visser et al., 2012a). For this model, we combined the three factors Guskey described with three aspects important for the design of such a programme: multidisciplinary science features including school practices; the curriculum design phases; and professional development characteristics (Visser et al., 2010). These aspects and factors were translated into a generic model for a professional development programme for a multidisciplinary science subject, shown in Figure 4.1. The model designed can be used for all the NLT modules.

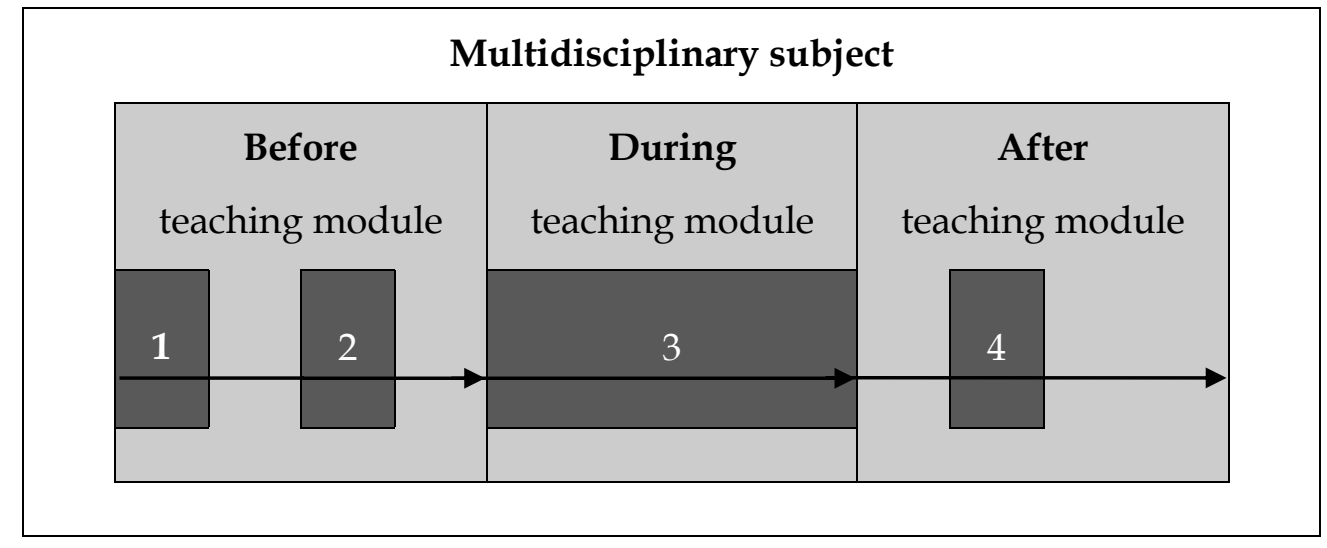

1 individual preparation

2 preparation seminar

3 online support

4 reflection meeting

Figure 4.1 Generic model for a professional development programme (Visser et al., 2012a)

This professional development programme assists and supports teachers before, during, and after implementation of the new curriculum in a multidisciplinary science module. As mentioned before, three factors are 
relevant in this respect: context, process, and content. The context of the designed professional development programme in this case is the implementation of NLT within specific school programmes. The process consists of three phases. The first phase is scheduled before the actual implementation of a NLT module. The second phase takes place during implementation of the NLT module. The third phase occurs after the NLT module has been taught. The characteristics used to design the professional development programme are also the foundation for the content, that is, the stages of which the professional development programme is composed (Visser et al., 2012a). The content of the professional development programme is specified as the four stages identified by the numbers 1 to 4 in Figure 4.1. Each of these stages addresses particular types of issues. For instance, the issue of 'the possibility of changing parts of the subject matter', is tackled in the preparation seminar in the before teaching phase, as it is important at that point for teachers to exchange ideas about possible changes to be made.

Over the years, much research has been done about the content of professional development programmes. For each stage (numbers 1 to 4 in Figure 4.1), we explain below first, what the literature has to say about this element of professional development programmes, followed by how this was addressed in our designed professional development programme for a multidisciplinary science subject.

The participants in the professional development programme are: a coordinator to chair the professional development programme, an expert of the content of the module, a representative from the regional NLT information centre who knows about the possibilities for organizing field trips, the teachers who will teach the same module from different schools, and the school lab assistants.

The before-teaching phase consists of an individual preparation part and a collaborative preparation part.

Individual preparation (Figure 4.1, number 1).

Teachers who are implementing a curriculum innovation will go through a process of change. The Concerns Based Adoption Model (CBAM) by Hall and Loucks (1978) is considered a valuable model to describe what individual teachers go through during the process of innovation. In the initial phase of a professional development programme, teachers must therefore become aware 
of all the concerns in the process of innovation. Also a professional development programme is more successful when it connects everyday school practice and teachers' prior knowledge, and adjusts to the diversity of behaviors and beliefs of the participants (Cotton, 2006; Luft, 2001).

In the designed model for a professional development programme, the individual preparation starts a few weeks before teaching. The coordinator asks the teachers (via e-mail) to look over the upcoming module and consider three questions: (a) What knowledge and skills do I want my students to acquire in this module? (b) What kind of assessment methods and instruments do I intend to use? (c) What questions do I have for the preparation seminar? As it can take a long time for equipment for practical activities to be delivered, teachers are advised to find out what science equipment their school already has and what needs to be purchased or borrowed.

\section{Preparation seminar (Figure 4.1, number 2).}

Professional development is most relevant when it focuses on teachers' existing needs; teachers' personal needs therefore are the starting point for the preparation seminar (Dunne, 2002; Erickson et al., 2005; Lieberman \& Pointer Mace, 2008). Incorporating teachers' own input in their interactions with colleagues (Day, 1999; Garet et al., 1999) creates a strong sense of ownership (Ogborn, 2002; Van den Akker, 1998; Vermunt, 2006; Wikeley, 2005) and encourages active learning. Collaborative involvement with teachers of different schools in an interactive process can create a network, where teachers support and inspire each other and professionalize themselves (Clement \& Vandenberghe, 2000; Jones, Asensio, \& Goodyear, 2000).

In the designed model for a professional development programme the preparation seminar is held with all stakeholders, two to three weeks before teaching. An overview of the outline of the preparation seminar is depicted in Table 4.1.

After arrival at the seminar, teachers' questions from their individual preparation activity are collected, categorized and included in the seminar programme (Table 4.1, II). The questions can be related to content, planning, or equipment. Thereafter, teachers get an overview of the structure and operationalization of the entire module (Table 4.1, III), followed by a more indepth approach to some substantive aspects of the module, such trying out 
experiments, designing a module outline for use in their own class, and developing additional (learning) materials (Table 4.1, IV). The breadth and depth of these substantive aspects depend on the topic and content of the module. Through discussion and exchange of experiences, ideas, and good practices, participants tackle issues related to these substantive aspects. Reflection on the programme and making appointments for the next phase conclude the seminar (Table 4.1, V). The seminar is a first step to the creation of a collaborative network among teachers from different schools who will be teaching the same module.

Table 4.1 Collaborative seminar programme including underlying goal and teacher activities

\section{Outline of the}

\section{Collaborative Seminar}

Programme

Goal

What teachers do

I. Opening

II. Soliciting teachers' questions to be included in the programme

To create strong sense of ownership with the programme.

III. Discussion of the overall module

IV. Substantive aspects of the module

- Experiments

- Module outline

- Design materials

V. Appointments
To familiarize with alternative ideas, and to form a clear picture of the overall module.
Teachers mention personal questions.

Discuss and exchange experiences, ideas, and good practices.
To handle practicalities, and discuss solutions for practical problems.

To prepare module and lesson outline.

To develop additional learning materials.

To organize support during teaching and organize field trips and guest lectures.
Try-out experiments from the module.

Outline the module for own class use.

Discuss additional learning materials, assessments methods and instruments.

Reflect on the professional development programme and make appointments.

VI. Closure 
Online support (Figure 4.1, number 3).

Teachers need support during the teaching phase, especially when they need to implement new approaches in their classes (Dede et al., 2009). Due to time constraints, organizing face-to-face meetings during the teaching phase is complicated; however, an online component can provide such support (Berger et al., 2008; Owston et al., 2006). To support teachers during this teaching phase, e-mail exchange can be selected as a tool enabling all teachers to participate in the online exchange (Berger et al., 2008). Owsten (2006) suggests that short weekly postings of teachers' reflections might stimulate others to participate in the exchange.

In the designed model for a professional development programme, the coordinator organizes collaborative online support for all teachers, which continues for the entire teaching period. E-mail exchange is chosen as enabling all teachers to participate in the online exchange. During the teaching phase of the NLT module, on each Friday teachers receive an e-mail from the coordinator requesting them to describe their individual good practices and problematic experiences with the module for that week. They can also post personal requests for assistance or guidance on aspects of the module in this email, called the 'Friday e-mail'. All responses are summarized by the coordinator and returned to all participating teachers a few days later. The coordinator ensures that all teachers' questions are addressed.

Reflection meeting (Figure 4.1, number 4).

Teachers' reflection about their own practice is important for their professional development and facilitates cooperation among colleagues (Margalef Garcia \& Pareja Roblin, 2008). Joint reflection is an important learning activity (Meirink, 2007), as strengths and weaknesses of the teaching-learning process emerge and are described for future use.

In the designed model for a professional development programme teachers meet for collaborative reflection when the NLT module is finished and when teachers have had enough time to assess student learning outcomes. During the reflection meeting, issues related to the NLT module are discussed, such as strengths and weaknesses, learning goals, the module outline, teaching methods, and assessment methods. Through such a collaborative process, teachers can build up confidence for the next module to be taught. 


\subsubsection{Evaluation}

Professional development evaluation is an essential component of programme improvement and renewal and long-term success (Rovai, 2003).

Guskey (2002) developed a five-level model for evaluating professional development. The levels in this model are hierarchically arranged from simple to complex, with each higher level building on the ones before it. The more basic level of positive appreciation for the professional development programme is therefore necessary for positive results at the higher evaluation levels such as 'teacher learning' and, finally, 'student learning outcomes'. Given this dependency of higher levels on those coming before, in this article, the focus is on Guskey's first level, participants' reactions. Things to consider at this level according to Guskey are 'basic human needs' such as the quality of food and comfort of the room, and whether participants 'liked' the experience, whether the materials and presentation 'make sense' and whether presenters seem 'knowledgeable and helpful'. Because the first level is the foundation of the other evaluation levels, the professional development programme must be serviceable for all participants. Participants' evaluative reactions are described in this study as a measure of 'satisfaction'.

According to Kamphorst (2012) $)^{5}$, the concept 'satisfaction' can be studied from three perspectives: (a) psychological well-being (factors associated with past experiences, personality traits, and expectations), (b) occupational satisfaction (future aspirations and professional expectations), and (c) consumer satisfaction (experience of certain environment in which people as consumers' functioning, the latter also identified by Oliver (2006).

Satisfaction in this study is about consumers' satisfaction and is defined as the following aspects: awareness of concerns, addressing these concerns, contributing ideas, usefulness, and creating self-confidence. The evaluation is positive when teachers are not dissatisfied.

If the professional development programme fails to satisfy participants' needs, a determination should be made as to whether this is due to the design or the delivery of the professional development programme.

5 Hanze University of Applied Sciences, The Netherlands, in a personal communication. 


\subsection{RESEARCH QUESTION}

This study aims to use Guskey's first level to evaluate the professional development programme that prepares and assists teachers with implementation of the new curriculum for the multidisciplinary science subject of NLT. The general research question is 'How do participating teachers evaluate the professional development programme in terms of satisfaction?' There are four specific sub-questions: (a) How do participating teachers evaluate the individual preparation? (b) How do participating teachers evaluate the preparation seminar? (c) How do participating teachers evaluate the online support? (d) How do participating teachers evaluate the reflection meeting?

\subsection{METHOD}

\subsubsection{Context}

The professional development programme was carried out twice, for two different NLT modules. Because at least one module from each NLT examination domain has to be taught at each school (Steering Committee NLT, 2007), we chose modules from two different NLT examination domains. The first is more physics oriented, while in the second module the focus is more on biology. Both modules are new and written for upper secondary school level. The first professional development programme, for the module 'The hydrogen car', ran from August 2009 till November 2009. The second professional development programme, accompanying the module 'The brain and learning', began in October 2009 and ran up to January 2010.

\subsubsection{Participants}

A written invitation to participate in this professional development programme was sent to thirteen teachers at thirteen different officially registered NLT implementation schools in the eastern part of the Netherlands. Five schools did not respond to the invitation and three schools were excluded from the professional development programme. These three schools were not yet teaching NLT at the upper secondary school level because of a later start of implementation. One school was ready to participate in the professional 
development programme but withdrew because the teacher changed jobs. A group of six teachers from four different secondary schools participated in the first professional development programme on the module 'The hydrogen car'. Three participants were chemistry teachers (William, Ben, and Daniel), two were physics teachers (Adam and Jack), and one was a mathematics teacher (Oliver). All were male and all had more than nine years of teaching experience. They had all taught at least one NLT module before; however, the module 'The hydrogen car' was new for all teachers. In two schools this module was taught by teams of two teachers. The two teaching teams both consisted of one chemistry teacher and one physics teacher.

Five different teachers from the same four schools with the same four classes of students participated in the second professional development programme in order to prepare for the second module on 'The brain and learning'. Three participants were biology teachers (Emma, Sophie, and Luke), one was a chemistry teacher (Max), and one was a physics teacher (Owen). Three were male and two were female, and all had more than nine years teaching experience. They had all taught at least one NLT module before; however, the module 'The brain and learning' was new for all teachers. At one school the module was taught by a team of two teachers, one chemistry and one biology teacher.

\subsubsection{Data instruments and analysis}

To answer the research questions, different instruments were used at various stages in the professional development programme. Right after the preparation seminar (Figure 4.1, number 2), each teacher filled in a questionnaire (A). During teaching, all the (Friday) e-mail correspondence as part of the online support (Figure 1, number 3) was collected (B). Before the reflection meeting (Figure 4.1, number 4), another questionnaire was sent (C). Shortly after the reflection meeting, an interview was held with each of the teachers (D). All the interviews were recorded and transcribed. Table 4.2 shows which instruments were used in which part of the professional development programme.

The data were organized by the four stages of the professional development programme to which they pertained: individual preparation, preparation seminar, online support, or reflection meeting. The data from all teachers across both professional development programme episodes were combined in word tables, and some parts of these tables were paraphrased in a few sentences. 
Table 4.2 Overview of the instruments used in the four stages of the professional development programme

\begin{tabular}{|c|c|c|c|c|}
\hline & \multicolumn{4}{|c|}{ Instruments } \\
\hline & $\begin{array}{c}\text { A } \\
\text { questionnaire }\end{array}$ & $\begin{array}{c}B \\
\text { e-mails from } \\
\text { online support }\end{array}$ & $\begin{array}{c}\text { C } \\
\text { questionnaire }\end{array}$ & $\begin{array}{c}D \\
\text { interview }\end{array}$ \\
\hline $\begin{array}{l}\text { 1. Individual } \\
\text { preparation }\end{array}$ & & & & $x$ \\
\hline 2. Preparation seminar & $x$ & & $x$ & $x$ \\
\hline 3. Online support & & $x$ & $x$ & \\
\hline 4. Reflection meeting & & & $x$ & $x$ \\
\hline
\end{tabular}

\section{Individual preparation (1)}

Two questions evaluating the individual preparation stage were posed in the interview (Instrument D). First, 'Is an e-mail from the coordinator useful for starting earlier with the preparation of a module?' Secondly, 'Is it useful to identify the science equipment needed for the module?'

Teacher questions from the individual preparation were collected at the beginning of the preparation seminar and then incorporated into the seminar programme, to create a strong sense of ownership with the programme. By collecting these questions, we observed whether teachers did the individual preparation activity.

\section{Preparation seminar (2)}

To evaluate the preparation seminar, teachers were given some open questions to solicit reactions about 'What was missing in the preparation seminar?' (Instruments A and D), and a five-part question 'How did the preparation seminar contribute to ideas: (a) for preparing the experiments, (b) for the planning and organization of the module, (c) for different assessment methods, (d) for field trips or guest lecturers, and (e) for motivating students?' (Instrument A).

These questions about the contribution of the preparation seminar were also asked as questions on a Likert scale from 1-5 with ' 5 ' as excellent (Instrument C). Instrument $C$ included as well the following two extra questions: 'Has the preparation seminar contributed to ideas: (f) about the chapter order in your planning and $(\mathrm{g})$ how to deal with the prior knowledge of students?' 
The 'chapter order' refers to the order in which a module can be taught. Normally one would teach first chapter 1 followed by 2, 3, 4 etc. but in this subject alternatives are available and also logical: for instance teach the practical chapter concurrent with the theoretical chapter, or bring the chapter with the students' own research more to the front.

Some more open questions were posed immediately after the preparation seminar (Instrument A); 'How useful was attending the preparation seminar?', 'How has your understanding of teaching changed after the preparation seminar?', and 'How has your self-confidence changed after the preparation seminar?'

\section{Online support (3)}

The coordinator of the professional development programme organized regular online support among all teachers by asking the teachers every Friday to describe their individual good practices and problematic experiences with the module for that week in an e-mail; they could also post requests for assistance or guidance on aspects of the module.

After teaching the module, the teachers were asked how useful the Friday email exchange was and whether they would prefer a different medium of exchange (Instrument C).

\section{Reflection meeting (4)}

In the final interview, three open questions about the reflection meeting were posed to the teachers: 'How do you assess the collaborative reflection meeting?', 'What are useful elements from discussing the module during the evaluation meeting?', and 'What are useful elements from discussing contributing issues?' (Instrument D).

During the professional development programme teachers collaborated in different ways with colleagues from different schools. The teachers were asked after teaching and in the final interview: 'Do you assess the collaboration with colleagues from different schools positively or negatively?', followed by asking 'What was positive about the collaboration with colleagues from other schools?' (Instruments C and D). 


\subsection{Results}

In the next section, the findings for both professional development programmes will be presented according to the four research sub questions.

\section{Reactions on the individual preparation (1)}

Two questions were posed to evaluate the individual preparation. With regard to the first question, teachers from both modules agreed that it is important to start early with preparation of the module. As the subject and modules are new (teachers must acquire new knowledge, skills, and routines) this importance is well founded, because normally preparation took place just before teaching, as teachers said, 'due to school constraints'. According to all teachers, the e-mail from the coordinator helped to start the preparation earlier. With regard to the second question, all the teachers reported that the individual preparation was also helpful for checking and ordering the science equipment needed for the module.

'What questions do I have for the preparation seminar?' could have been related to content, planning or equipment. The eleven teachers of modules I and II formulated thirteen content questions, twenty planning questions and four questions about equipment. It appeared that Max and Luke, teachers of module II (The brain and learning), did not carry out the individual preparation activity adequately. Max's inadequate preparation was due to his insignificant role in the planned teaching of the class, which was to be lead by his co-teacher Sophie. Luke fell short in preparation because of a later time deadline. The defined time period for the preparation seminar was two to three weeks before teaching the module. For Luke, this was impossible, as he would start teaching the module nine weeks later. Therefore, Luke was at the preparation seminar but did not have any questions he would have liked to have answered in the preparation seminar. Ben's statement exemplifies the way the teachers responded in generating questions: 'I would like to receive an overview of the whole module (planning), the ins and outs about the experiments of the module (content, planning, and equipment) and discuss the content of the assessment method (content)'.

\section{Reactions on the preparation seminar (2)}

Teachers answered some open questions to evaluate the preparation seminar. When asking 'What was missing from the preparation seminar?', ten of eleven teachers did not think anything was missing. Only Emma said, 'I missed 
concrete information like telephone numbers for field trips and guest lecturers'. In the final interview the teachers were asked the same question again. This time seven of the eleven teachers did not think anything was missing. Three teachers of module I missed 'trying out the complete experiments of the module', and Max said, 'I'd have liked some more information on different teaching methods like movies, etc.'.

The teachers responded to open questions about the contribution of the preparation seminar to different categories of ideas, and their responses are described below, with some teacher statements included to illustrate the general tenor of the answers. A teacher could provide multiple answers. The number of teachers who responded similarly is shown in parentheses.

a. All eleven teachers from modules I and II responded that the preparation seminar contributed to ideas for preparing the experiments. Particular responses included: 'where to purchase necessary equipment' (4), 'all the materials for the experiments were shown' (3), and 'talked about supplementary experiments and research' (1). William said, 'I received practical tips and good support for the lab assistant'. Two others responded in a similar manner.

b. Nine out of eleven teachers from modules I and II indicated that the preparation seminar contributed to ideas for the planning and organization of the module. Among the responses were: 'gained ideas to teach the module, lesson plan' (9), 'ideas for assessment methods' (3), 'suggestions for teaching the sequence of the chapters, parts students study individually and in a group' (3) and 'materials that can be used' (1). Ben said, 'We discussed different possibilities for teaching the module; now I can quickly design a lesson plan at home'.

c. All six teachers from module I indicated that the preparation seminar contributed to ideas for different assessment methods. Particular responses given were: 'using portfolios' (3), 'theoretical test' (2), 'presentations' (2), and 'assess groups of students' (2). Adam responded: 'I gained lots of ideas, for instance, a different way to do a theoretical test'.

d. Four out of five teachers from module II indicated that the preparation seminar contributed to ideas for field trips or guest lecturers. Their responses included: 'gained ideas' (4), and 'explicit contacts and appointments must be made' (2). Luke said: 'I have to read a bit more of the module, but I probably won't organize a field trip or a guest lecture'. 
e. All five teachers from module II indicated that the preparation seminar contributed to ideas for motivating students. Responses that were made: 'motivating films' (3), 'change chapter sequence' (2), 'themes for students' own research projects' (1), 'a catchy introduction to the module' (1), and 'experiments and field trips' (1). Max said: 'From now on, the starting point of a module is motivating students'.

All six teachers from module I and three out of five teachers from module II (Luke, Sophie and Max) responded to similar questions presented in a Likertscale format, as described above. The Likert scale was from 1 to 5 (5 = contributed a lot). Table 4.3 shows the number of participants rating each question, and includes the mean scores.

Table 4.3 Number of participants rating each question on a 1-5 Likert scale about the contribution of the preparation seminar to ideas (Instrument C)

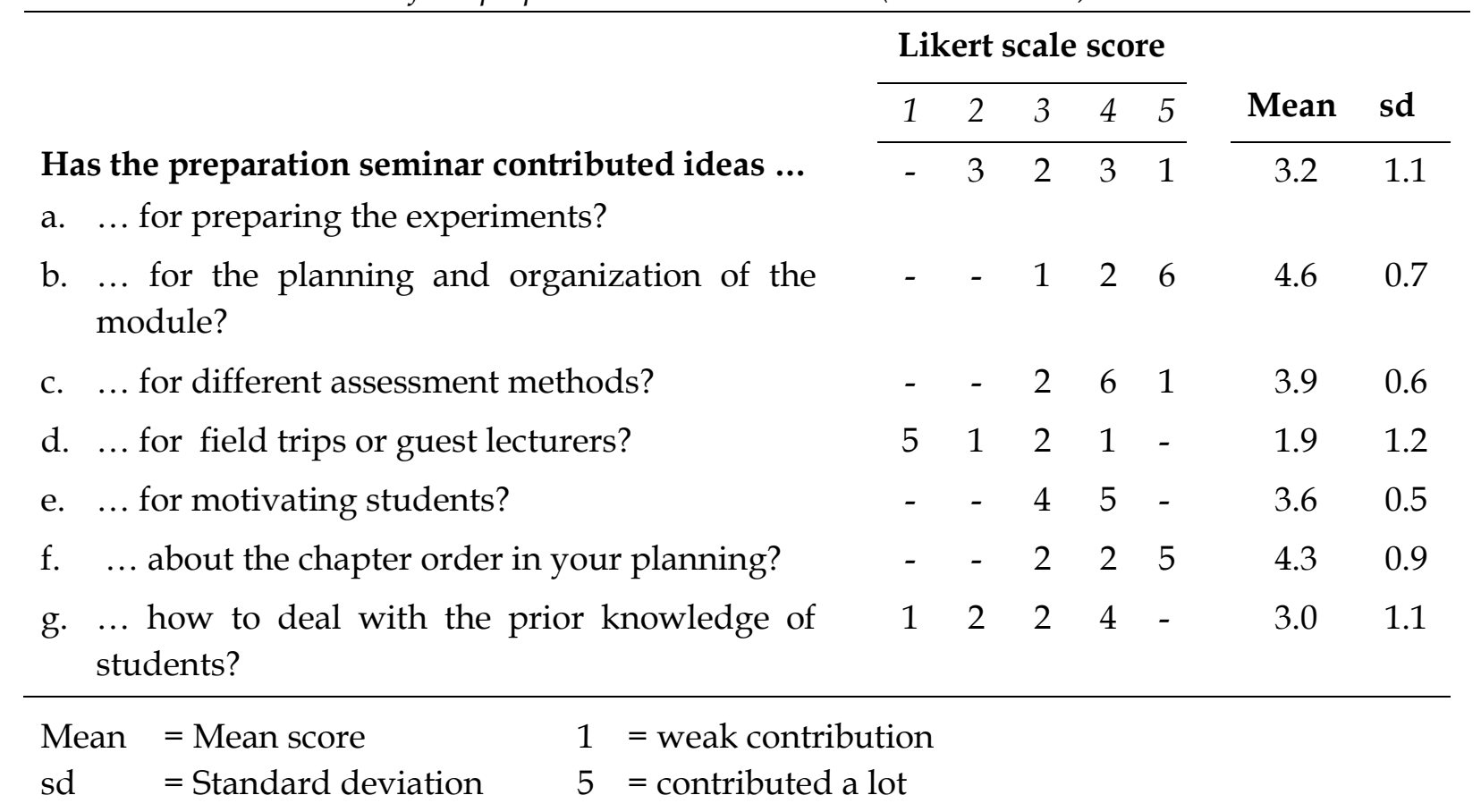

The reliability (internal consistency) of the teachers' answers was calculated, resulting in a Cronbach's alpha of 0.93. Taking into account the norm that Cronbach's alpha should be larger than 0.80 we consider this questionnaire to be reliable (Heus de, van der Leeden, \& Ganzendam, 1995). 
Additional open questions were posed immediately after the preparation seminar. One was, 'How useful was attending the preparation seminar?'. All eleven teachers perceived the preparation seminar to be useful. Their responses included that it was 'a well prepared day' (by 3 teachers), it had 'an open work atmosphere' (6), 'in a nice room' (1), with 'good food' (5). The seminar was 'motivating' (4), 'effective' (4) and gave a 'good overview of the module' (2). Sophie said: 'The seminar was effective, I now have a good overview of the entire module including the assessment methods and the organization'.

Teachers were also asked, 'How has your understanding of teaching changed after the preparation seminar?' and 'How has your self-confidence changed after the preparation seminar?' After the preparation seminar, all the teachers said they had a better understanding of teaching the module than before. Ten out of eleven teachers had more confidence in teaching the module after the preparation seminar, because of 'more background knowledge' (4), 'a better overview of the module' (4) and 'gained lots of ideas for teaching the module' (5). One teacher, Ben, said: 'I did not gain more confidence; I will manage it'.

\section{Reactions on the online support (3)}

An overview of the e-mail traffic during the teaching weeks is depicted in Table 4.4. The numbers of lessons per week and the amount of teaching weeks per NLT module differ per school. The school administration, in close consultation with the teaching team, makes different choices; therefore, implementation varies from school to school.

Luke sent only two e-mails, as a result of the later period of teaching the module in his school, which left an overlap of two weeks with the other schools. Due to a lack of time, Emma withdrew from the professional development programme after the preparation seminar. In total, there were four requests during teaching. William had two requests. First, he would like to organize a field trip to the university, but the contact person he met at the preparation seminar did not respond. He asked the coordinator to help him to contact this person. Second, he asked all participating teachers of module I for help about marking the students' exercises: 'What is a good assessment method or instrument for students' exercises?' Jack requested whether someone could send him the answers of the exercises, because he had lost them. Sophie requested a copy of a movie mentioned in the module, that introduced a particular theoretical component, for her school. 
Table 4.4 Overview of teaching information and number of responses to the coordinator on the Friday e-mail

\begin{tabular}{|c|c|c|c|c|c|c|}
\hline & School (teacher) & $\begin{array}{c}\text { Lessons } \\
\text { per week }\end{array}$ & $\begin{array}{c}\text { Teaching } \\
\text { weeks }\end{array}$ & $\begin{array}{c}\text { Responses } \\
\text { in Friday } \\
\text { e-mail }\end{array}$ & $\begin{array}{c}\text { Percentage } \\
\text { of } \\
\text { response }\end{array}$ & $\begin{array}{c}\text { Total } \\
\text { requests }\end{array}$ \\
\hline \multirow{4}{*}{$\begin{array}{l}\frac{1}{0} \\
\frac{0}{3} \\
\frac{0}{2}\end{array}$} & A (Ben and Adam) & 3 (50 min) & 8 & 5 & $63 \%$ & 0 \\
\hline & B (Oliver) & $2(50 \mathrm{~min})$ & 11 & 6 & $55 \%$ & 0 \\
\hline & C (Daniel and Jack) & 3 (50 min) & 8 & 7 & $88 \%$ & 1 \\
\hline & D (William) & $3(60 \mathrm{~min})$ & 6 & 6 & $100 \%$ & 2 \\
\hline \multirow{4}{*}{ 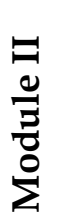 } & A (Sophie and Max) & 3 (50 min) & 8 & 7 & $88 \%$ & 1 \\
\hline & B (Luke) & $2(50 \mathrm{~min})$ & 11 & 2 & $18 \%$ & 0 \\
\hline & C (Emma) & 3 (50 min) & 8 & 0 & $0 \%$ & 0 \\
\hline & D (Owen) & $3(60 \mathrm{~min})$ & 6 & 6 & $100 \%$ & 0 \\
\hline
\end{tabular}

The teachers were asked how useful the Friday e-mail exchange was and whether they would prefer a different medium of exchange. Five out of eleven teachers found it useful. They said: 'useful tips' (by 5 teachers), 'notification of similar problems that I experience' (3), 'exchange and tips of exercises for tests' (2). Daniel found it not so useful, he said: 'I got very little from the Friday email exchange. The Friday e-mail request came sometimes at a busy time'. Seven out of eleven teachers did not prefer a different medium of exchange. Three teachers preferred a collaborative meeting during the teaching phase, and one teacher (Max) did not answer this question. Sophie said: 'I aspect a higher output, including material exchange with a collaborative meeting instead of Friday e-mail exchange'.

\section{Reactions on the reflection meeting (4)}

Four of the six teachers of module I were present at the reflection meeting. Adam and Oliver were absent due to obligations elsewhere. The reflection meeting after module II was cancelled because of a variety of circumstances. Emma withdrew from the professional development programme after the preparation seminar. Owen could not participate in the reflection meeting because of illness during the period when the reflection meeting was being organized. Besides that, because of the differences in teaching weeks between schools, there was not a good point at which to organize the reflection meeting. 
Max and Sophie had finished teaching, while Luke was half way through teaching the module, because of his later start as mentioned before.

Table 4.5 shows the three questions and short answers about the reflection meeting.

Table 4.5 Questions and answers concerning satisfaction regarding the reflection meeting from four teachers participating in the professional development programme of module I

\begin{tabular}{|c|c|}
\hline & $\begin{array}{l}\text { Module I (The hydrogen car) } \\
4 \text { teachers participating }\end{array}$ \\
\hline $\begin{array}{l}\text { How do you assess the } \\
\text { collaborative reflection } \\
\text { meeting? }\end{array}$ & $\begin{array}{l}\text { - useful (3) } \\
\text { - pleasant end to the professional development } \\
\text { programme(2) } \\
\text { - exchange of information about how other schools } \\
\text { implemented the module (1) } \\
\text { - ideas for improvement for next year (1) }\end{array}$ \\
\hline $\begin{array}{l}\text { What are useful } \\
\text { elements from } \\
\text { discussing the module } \\
\text { during the evaluation } \\
\text { meeting? }\end{array}$ & $\begin{array}{l}\text { - ideas for improvement for next year (3) } \\
\text { - } \text { other teachers confirmed my own thoughts (2) }\end{array}$ \\
\hline $\begin{array}{l}\text { What are useful } \\
\text { elements from the } \\
\text { discussion of the } \\
\text { points contributed? }\end{array}$ & $\begin{array}{l}\text { - each school has similar problems (2) } \\
\text { - ideas for dealing with small numbers of students in the } \\
\text { class (1) } \\
\text { - ideas for scheduling NLT (1) } \\
\text { - ideas for informing grade three students about taking NLT } \\
\text { (1) }\end{array}$ \\
\hline
\end{tabular}

The collaboration with colleagues from different schools was assessed positively by all eleven participating teachers. When asked what was positive about the collaboration with colleagues from other schools, they said: 'the exchange of ideas and good practices' (by 6 teachers), 'learning from each other' (3), 'dealing with similar issues' (3), and it was 'inspiring' (1). A teacher could give multiple different answers. William said: 'the exchange of ideas with colleagues is pleasant and inspiring'. 


\subsection{CONCLUSIONS AND DISCUSSION}

The focus of this paper is on Guskey's (2002) first evaluation level, participants' reactions. A positive appreciation for the professional development programme is thought to be necessary for positive results at the higher levels of Guskey's five-level model for evaluation. The general research question in this study was as follows: 'How do participating teachers evaluate the professional development programme in terms of satisfaction?'. Overall, the participating teachers positively appreciated this professional development programme designed to assist and support teachers before, during and after implementation of a multidisciplinary science module. The teachers were generally satisfied with the professional development programme. Several elements of the programme ensured teacher satisfaction. During the individual preparation the teachers became acquainted with the module, became aware of key aspects of the module, and formulated questions about elements they considered problematic. The preparation seminar addressed these concerns, contributed to their acquired new ideas, was useful for motivation and implementation in class, and created self-confidence. The online support addressed concerns that emerged during teaching, and the final reflection meeting provided ideas for improvement for next year.

Literature shows that professional development is more effective when it is longterm (Desimone, 2009; Garet et al., 2001; Hunzicker, 2011; Lieberman \& Pointer Mace, 2010; Penuel et al., 2007). However, this study shows that organizing a longterm professional development programme for NLT teachers is a challenging endeavor, because of the following three specific characteristics of NLT:

1. NLT is taught by one or more teachers from different science disciplines. Practically, this entails that when a module has a strong physics component; a physics teacher will be the responsible teacher or will be a member of the teaching team. When the next module is biology-oriented, a biology teacher will be in charge. A professional development programme to prepare and assist teachers in the first example will mainly have physics teachers participating, whereas for the second module it will be mainly biology teachers who enter the programme. At the individual teacher level, this inhibits a long-term continuous professional development programme. In this study, teachers from four secondary schools attended the two professional development programmes. At these four schools, the 
administration (in close consultation with the teaching team) decided to let other teachers teach the second module. Therefore, the teachers in charge of module I were all different from the teachers of module II. On top of this, the number of teachers responsible for a module varied: the first module was taught by six teachers, two single teachers and two pairs, whereas the second module had five teachers, three single teachers and one pair.

2. The multidisciplinary teaching team also has the freedom to select the modules for each examination domain, and can decide the order in which the modules will be taught in their school. In practice, this implies that the same class level in different schools is taught different modules or the same modules in a different order. At the individual teacher level, this obstructs the continuity of a long-term professional development programme. However, even if schools choose to teach the same modules and let them be taught by the same teachers, the characteristic described in the next paragraph remains an obstacle for the organization of the professional development programme.

3. The school administration has some freedom to determine the lesson timetable. In practice this means that schools differ in the number of lessons per week, and therefore in the number of teaching weeks per module. This causes asynchronous teaching periods across schools, interfering with the organization of the individual preparation before teaching and the effectiveness of the collaboration in the online support during teaching. In this study, little overlap (20\%) existed between the teaching weeks of module II at the four schools. When the teaching periods for the module overlapped by about $75 \%$, as was the case for module I, teachers at schools prepared individually, and had similar experiences so that online support could facilitate collaborative exchange. Possible solutions for emerging problems were discussed. This encourages active learning and can ultimately lead to the formation of a support network (Clement \& Vandenberghe, 2000; Garet et al., 1999). We therefore conclude that when organizing a professional development programme, attention should be paid to the defined period between the individual preparation, the preparation seminar, and the start of teaching the module. It is important that the time between these phases is not too long, so that the professional development programme will be connected to teachers' daily school practice 
and the curricula that teachers must follow. In this way the professional development becomes more relevant and effective (Desimone, 2009; Dunne, 2002; Garet et al., 2001; Hunzicker, 2011; Lieberman \& Pointer Mace, 2010; Penuel et al., 2007).

In this study, we chose e-mail as a simple tool to enable all teachers to participate in the online support during teaching. When teachers implement new approaches in their classes, support during teaching is important but complicated (Dede et al., 2009). Because of teachers' heavy daily work load, they lack time for online interactions; this often results in a poor participation rate (Berger et al., 2008; Owston et al., 2006). In order to improve the participation rate, the coordinator of the professional development programme in this study took the weekly initiative of sending every participant an e-mail on Friday (Visser et al., 2012a). Due to the coordinator's initiative, the number of responses from the teachers for these so called Friday e-mail was relative high, five to seven mails in the six to eleven weeks of teaching (55\% - 100\% responses on the e-mails). The Friday e-mail seemed to be a promising medium of exchange, but the content of the correspondence was disappointing. Teachers mainly posted information about the subject matter they taught, what students did during the lessons the past week, and what they were planning to do the following week. Three out of eleven teachers made four requests. Only one of these requests was relevant for all participants: 'What is a good assessment method or instrument for students' exercises?'. The coordinator could help with the other three requests: 'Help with contacting a person from the university, receiving the answers of the exercises, and receiving a copy of a movie'. Five out of eleven teachers assessed the Friday-email as useful. The teachers shared their experiences of similar problems, exchanged additional materials, and learned useful tips for teaching the module. Three out of eleven teachers preferred a different medium of exchange during teaching, for example, a faceto-face meeting. The weekly Friday e-mail exchange is time consuming. The mail arrives at a busy moment, and teachers need discipline to respond every week. Therefore, in the organization of a professional development programme, it is advisable to reduce the frequency of responses to once a fortnight instead of once a week, to maintain continuity between the meetings, with the possibility of sending a personal request when needed. When participating teachers prefer a collaborative face-to-face meeting during the teaching period, and time constraints allow it, this can additionally be arranged. 


\subsection{IMPLICATIONS}

Teaching NLT is complex as it requires one or more teachers from different science disciplines to co-teach the modules. Another feature demonstrating its unique character is that the teaching team has to select the modules, the order in which these will be taught, and the timetable to be used. This complex environment makes it a challenge to develop a professional development programme that satisfies all participating teachers. This paper evaluates the important first level, because this level is the foundation for the other higher evaluation levels. Teachers learn most when they appreciate the professional development programme. Subsequent research will explore Guskey's level two to five respectively: what participants learned from the professional development programme, if organizational factors hinder the success of the professional development programme, whether participants used new knowledge and skills in class, and how it affected students' learning outcomes. The result of this evaluation can provide a better understanding of the theoretical perspectives for an effective professional development programme for teachers, designed to support the implementation of a multidisciplinary science module. 


\title{
CHAPTER 5 \\ The learning effects of a multidisciplinary professional development programme ${ }^{6}$
}

\begin{abstract}
Professional development becomes relevant and effective when teachers are actively involved, collaborate, and when it is linked to teachers' daily school practice (Hunzicker, 2011). Preparation of teachers for a curriculum implementation such as the new subject Nature, Life, and Technology, can be done by a professional development programme where teachers are actively involved (Visser et al., 2012a). This study evaluates the designed and implemented professional development programme with respect to its effectiveness in terms of degree of teacher learning and development. Effects are evaluated for five learning areas: Instructional strategies, differences in students' prior knowledge, adjustments to the module, assessment methods and instruments, and field trips and guest lectures. Eleven teachers from four different schools participated in two professional development programmes, six teachers in the first professional development programme and five teachers in the programme for the subsequent module. Questionnaires and interviews were used to assess the effects in the different learning areas. The findings show that the professional development programme is a useful venture for teachers' professional growth in different learning areas.
\end{abstract}

6 This chapter is based on the article submitted as: Visser, T. C., Coenders, F. G. M., Pieters, J. M., \&. Terlouw, C. (2012). The learning effects of a multidisciplinary professional development programme. 


\subsection{INTRODUCTION}

The Minister of Education, Culture and Science in the Netherlands has introduced a new, integrated science subject called Nature, Life, and Technology (NLT) in secondary education. NLT is a multidisciplinary subject with a modular structure, which integrates elements from physics, chemistry, biology, mathematics, and physical geography.

Teaching NLT is complex, as it requires one or more teachers from different science disciplines to co-teach the modules. Another unique feature of teaching NLT is that the teaching team must select the modules, determine the order in which these will be taught, and create a timetable. Professional development can be a way to prepare teachers for implementing such a curriculum innovation (Loucks-Horsley et al., 2003; Penuel et al., 2007). The complex environment of NLT makes it a challenge to develop a professional development programme that will meet the needs of all participating teachers.

In an earlier study, we designed a generic model for preparing teachers to teach a multidisciplinary science module (Visser et al., 2012a), based on the findings of studies on professional development (Desimone, 2009; Hunzicker, 2011; Lieberman \& Pointer Mace, 2010). The evaluation study in chapter 4 showed that teachers were satisfied with the programme, the design of which was discussed in chapter 3 (Visser et al., 2012a). We consider participant satisfaction to be the first step towards evaluating learning effects and in-class use by teachers of what was learned from this professional development programme.

The aim of this chapter is to evaluate the designed and implemented multidisciplinary professional development programme with respect to its effectiveness in terms of degree of teacher learning, in-class use of what teachers learned, and impact on student achievement. The conceptual framework for this study will include: The multidisciplinary science subject of NLT; the professional development programme, including the learning areas and activities that it addressed; and the concept of evaluation of professional development. 


\subsection{CONCEPTUAL FRAMEWORK}

\subsubsection{Nature, Life, and Technology (NLT)}

In August 2007, a new subject called NLT was introduced in the upper level of secondary education in the Netherlands. The general objective of NLT is to make the natural sciences and technology more attractive to students and to show the relationships among the different science subjects. NLT has a modular structure, integrating elements from physics, chemistry, biology, mathematics, and physical geography. Each module consists of a situated practice (for example, forensic technology, robotics, or holography) in which specific concepts traditionally belonging to those five subjects are explored. The NLT examination programme consists of nine different domains; at least one module from each domain must be taught. Within each domain the teacher can choose from several modules. NLT is not a compulsory subject: schools have the freedom to offer it or not and students to take it or not.

At the school level, the implementation of NLT has several specific features (Steering Committee NLT, 2007). First, the multidisciplinarity of NLT requires physics, chemistry, biology, mathematics, and physical geography teachers to cooperate in a multidisciplinary team. Second, teachers involved in teaching NLT have a Master's degree in one of the five disciplinary subjects concerned, but have not been specifically trained for this new multidisciplinary subject. Third, the multidisciplinary team of teachers at each school has the freedom to select the modules for each examination domain and to decide the order in which the modules will be taught. Finally, the school administration, in close consultation with the teacher team, determines which and how many teachers will be teaching a specific module. Because teacher teams can make different choices, NLT implementation varies from school to school.

At the class level, NLT also has a number of specific characteristics. Instructional strategies for NLT are more diverse than those used in the monodisciplines. Students mostly work in small groups and do a lot of practicals and research projects. Not all students will have experience with all of the subjects integrated in NLT, because it is not compulsory for students to take all of the science subjects NLT includes. For example some students do not take biology or physics. Teachers of NLT have the freedom to make changes to the subject content, for example as a result of new developments in science, lack of time, 
overloaded modules, or items that appear in the news. The assessment methods and instruments for NLT are also more diverse than those used in the monodisciplines. For example, summative assessment can be based on a portfolio consisting of a wide variety of materials such as practical reports, a collection of homework, and student self-reflections. A presentation or a paper can be used for assessing the students' own research or design projects. Finally, one of the objectives of NLT is to inform students about and to bring them in contact with a broad range of higher education studies and possible careers, through field trips and guest lectures.

Because of these specific NLT features and characteristics, implementing a new complex and multidisciplinary subject such as NLT is considered to be a curriculum innovation for the teachers involved. This definitely requires a professional development programme for teachers implementing a NLT module.

\subsubsection{Professional development programme}

In a previous study (chapter 3) we introduced a generic model for a professional development programme to prepare teachers for and to assist them during the implementation of NLT (Visser et al., 2012a) (See Figure 5.1). The model can be used for all the NLT modules.

The following professionals participated in the professional development programme: a coordinator to chair the programme, a content expert for the module, a representative from the regional NLT information centre familiar with field trip opportunities, teachers from different schools who were going to be teaching a specific module, and school lab assistants. 


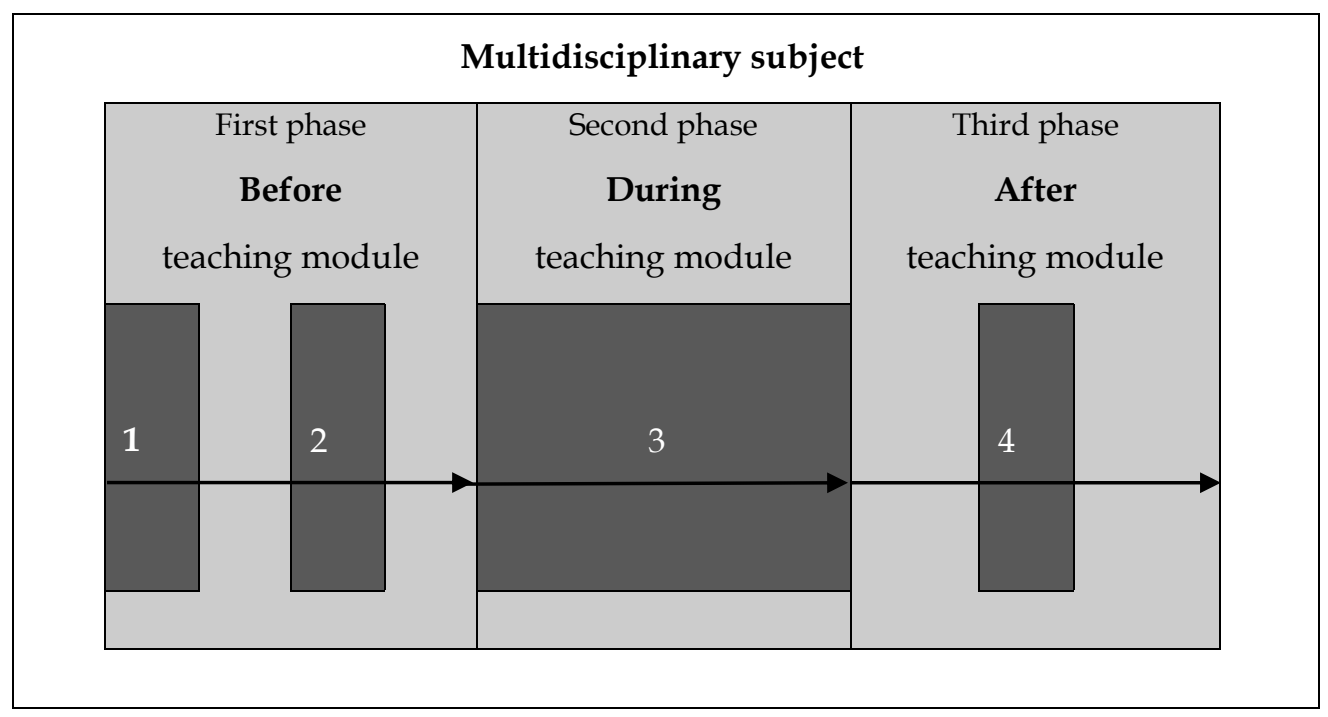

Learning episodes:

1 individual preparation

2 preparation seminar

3 online support

4 reflection meeting

Figure 5.1 Generic model for a professional development programme

The professional development programme consisted of three phases. The first phase was scheduled before teaching the module. The second phase took place during teaching. The third phase occurred after the module had been taught. In each phase one or more learning episodes took place. A learning episode is a defined period of time during which teachers are engaged in one or more activities that have been planned to support teacher learning. The learning episodes are shown in Figure 5.1 and identified by the numbers 1 to 4 .

Teacher learning is an important prerequisite for successful implementation of educational innovations. These innovations have often failed because the need for teacher learning was not identified (Lieberman \& Pointer Mace, 2008). Throughout the NLT professional development programme, introduced earlier in this chapter, the focus was on the following seven learning areas related to the specific NLT features and characteristics described and justified in the Committee's report (Steering Committee NLT, 2007; Visser et al., 2012a): 
I. Instructional strategies. These are more diverse than those used in the monodisciplines. Teachers must decide which kinds of instructional strategies and instruments will be useful for teaching the module.

II. Differences in students' prior knowledge. As noted earlier, students are not obliged to take all of the subjects included in NLT. There are always individual differences in students' prior knowledge, but for NLT these differences can be large, as students might be lacking experience with a complete subject area. Depending on the number of students lacking background in a specific subject, different options exist for addressing this.

III. Adjustments to the module. Teachers have the freedom to make changes to the modules. For example, when the module is too long for the lesson-time available, teachers may reduce the number of periods to be spent on it or modify the subject content.

IV. Assessment methods and instruments. As a subject, NLT is assessed through a school examination for which the school is responsible. There is no national exam. Different assessment methods and instruments are necessary to do justice to the deeper and broader character of NLT. The often implicit learning outcomes from a personal enquiry or design project are hard to assess through a written test, but can be assessed by means of a student presentation or through a paper, for example.

V. Field trips and guest lectures. Students are informed about and exposed to a broad range of higher education studies and possible careers during field trips and guest lectures. Contacts with companies, higher education, and universities are necessary in order to organize these.

VI. Collaboration with colleagues. Teachers collaborate in teams with colleagues from their own school. Besides the NLT team, they participate in their own mono-disciplinary team, such as the biology team. They share materials, experiences, information, and ideas. A teacher can teach a module with a co-teacher, in which case they also prepare the module together and distribute tasks. There is also collaboration with the lab-assistant(s) about practical issues such as preparation of the experiments. Teachers who collaborate in teams with colleagues from other schools support each other by sharing materials, experiences, and ideas.

VII. Content knowledge. The teachers involved in teaching NLT have a Master's degree in one of the five disciplinary subjects it includes. However, the content of the NLT modules goes beyond these science subjects, which 
means that teachers must find ways to familiarize themselves with this content knowledge.

For each learning episode (numbers 1 to 4 in Figure 5.1), the activities described below were addressed in our professional development programme. The before teaching phase consisted of learning episodes 1 and 2.

Learning episode 1 was the individual preparation part. The coordinator asked the teachers (via e-mail) to read the selected module, bearing in mind three questions: (a) What knowledge and skills do I want my students to acquire in this module? (b) What kind of assessment methods and instruments do I intend to use? (c) What questions do I need to have answered at the preparation seminar? The teachers were also advised to find out what science equipment their school already had and what needed to be purchased or borrowed.

Learning episode 2 was the collaborative preparation seminar, held with all stakeholders two to three weeks before teaching of the module. Immediately after opening the seminar, the questions teachers had generated in their individual preparation were collected, categorized and included in the seminar programme. Through discussion and exchange of experiences, ideas, and good practices, teachers were expected to get an overview of the structure and operationalization of the entire module. Next, depending on the topic and content of the module, substantive aspects were addressed: experiments, module outline, and additional learning material. Experiments were tried out, and a module outline was collaboratively designed through exchanging ideas, experiences, and good practices. Additional learning material, assessment methods and instruments were discussed. Reflection on the programme and making appointments for the next phase concluded the seminar.

Learning episode 3 pertained to collaborative online support organized by the coordinator for participating teachers, over the entire teaching period. E-mail exchange was chosen, enabling all teachers to participate in the online exchange. On each Friday, teachers received an e-mail from the coordinator requesting them to describe their individual good practices and problematic experiences with the module for that week. Teachers could also post personal requests for assistance or guidance on aspects of the module in this e-mail, 
called the 'Friday e-mail'. All responses were summarized by the coordinator and each summary was returned to all participating teachers a few days later.

Learning episode 4 was the final phase, in which teachers met for a collaborative reflection meeting after teaching the NLT module and when teachers had the assessed student learning outcomes. During the reflection meeting, issues related to the NLT module were discussed, such as: strengths and weaknesses, learning goals, module outline, teaching methods, and assessment methods.

\subsubsection{Evaluating effectiveness of the professional development programme}

Evaluation of the effectiveness of teacher professional development programmes is an essential component element of programme improvement and renewal, long-term success (Rovai, 2003) and eventually an essential factor in student learning (Fishman et al., 2003; Jeanpierre et al., 2005; Luft, 2001; Stolk et al., 2011). In our study we presume that the effectiveness of a professional development programme is also related to the success of the implementation of the curriculum innovation. Teachers who are actively involved in the implementation of a curriculum innovation by (re)designing and adapting curriculum materials will implicitly learn and eventually develop professionally. Evaluation of a professional development programme that aims to engage teachers in the implementation needs to focus on the immediate learning of teachers and on the near and far transfer of their competencies as well. However, many evaluations of professional development of teachers only assess the participants' satisfaction and/or their opinions of their professional development experiences (Lowden, 2005). In order to assess the teachers' acquired competencies from professional development, evaluations must be based on an effort to better understand the influence of professional development on teachers and to eventually document its impact on student learning. In order to create an outcome that is longer lasting and more effectively matching the required competences, the learning process itself must be triggered and reinforced by an activity-based approach (Garet et al., 2001; Loucks-Horsley et al., 2003; Penuel et al., 2007). Not only successful curriculum implementation but effective teacher learning as well are more likely to occur when a professional development programme is consistent with school practices and has an inductive and problem-based orientation (Hunzicker, 2011; Lumpe, 2007; Richter, Kunter, Klusmann, Lüdtke, \& Baumert, 2011). The professional development programme designed for our NLT teachers has these 
characteristics, and the learning process is of an implicit nature (Eraut, 2004). The outcomes of this kind of teacher learning transcend domain knowledge and skills, and testing these outcomes requires methods that are compatible with the type of learning and outcomes, including application in professional practice, that are to be achieved. Guskey (2002) developed a five-level model for evaluating professional development that fits with the objectives, process, and outcomes of our professional development programme. Levels 1, 2, 4, and 5 in this model are hierarchically arranged, with each higher level building on the ones before. The levels are respectively:

1. Participants' reaction, which focuses on teachers' satisfaction regarding the usability of the programme;

2. Participants' learning, which focuses on the knowledge and skills the teachers have acquired;

3. Organizational support, which focuses on organizational factors that can hinder or facilitate the success of improvement efforts;

4. Participants' use of new knowledge and skills, which focuses on whether or not new knowledge and skills teachers have acquired are applied in their professional practice;

5. Student learning outcomes, which address student learning.

The evaluation of Level 1 (participants' reaction) for the NLT professional development programme was undertaken in a previous study (Visser, Coenders, Terlouw, \& Pieters, 2012b). That study revealed that in general the participating teachers appreciated the professional development programme and fulfilled primary motives.

In the current chapter, the remaining four levels of Guskey's model are used to evaluate the professional development programme. Levels 2 and 4 directly relate to outcomes of the professional development programme for the individual teacher. For level 2, two research questions have been formulated: one to assess the influence on teacher learning of the before teaching phase, and one to assess the overall impact of the programme. Evaluation on level 4, with a research question, pertained to the application of learning in the classroom. Level 3 is not hierarchical, but is considered as a condition for success of the professional development programme rather than as a result. Our focus is primarily on the learning outcomes of the professional development 
programme for teachers, but we will deal with levels 3 and 5 as well, for reasons of completeness.

\subsection{RESEARCH QUESTIONS}

The general research question is 'How effective is the multidisciplinary professional development programme?' The five sub-questions are: (a) How did the 'before teaching phase' contribute to the pedagogical and curricular intentions of participating teachers' (level 2)? (b) What new learning outcomes from the seven learning areas did teachers apply in their classes (level 4)? (c) What did teachers in general learn from the entire professional development programme (level 2)? (d) Did organizational factors hinder the success of the professional development programme (level 3)? (e) What are the student learning outcomes from the modules addressed in the professional development programme (level 5)?

\subsection{METHODS}

\subsubsection{Participants}

Eleven teachers from four different secondary schools voluntarily participated in the professional development programme: four chemistry teachers, three biology teachers, three physics teachers, and one mathematics teacher. All teachers had more than nine years of teaching experience in their own discipline and all had previously taught at least one NLT module.

\subsubsection{Procedure}

During the entire study, eleven teachers from four different schools participated in the professional development programme, spread over two different NLT modules. The designed professional development programme that was carried out for two different NLT modules was considered an embedded case study (Yin, 2003). 
Six teachers (three in chemistry, two in physics, one in mathematics) participated in the professional development programme for the first module (module I) called 'The hydrogen car', from August till November 2009. Five different teachers (three in biology, one in chemistry, one in physics) participated in the professional development programme for the consecutive module (module II) called 'The brain and learning', from October 2009 until January 2010. The two selected modules for the professional development programme ('The hydrogen car' and 'The brain and learning') were new for all teachers. Table 5.1 shows an overview of the participating teachers, their monodiscipline, the modules they taught, the number of lessons per week, and student characteristics. All students chose chemistry and mathematics, but some students did not choose biology, physics, or physical geography, which were not compulsory. Because module I is physics-oriented and module II is biology-oriented, prior knowledge in physics would be more necessary for module I and biology prior knowledge more necessary for module II.

Table 5.1 Characteristics of module instruction per school

\section{Teachers}

\begin{tabular}{|c|c|c|c|c|c|c|c|c|c|c|c|}
\hline & 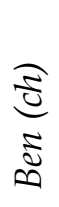 & $\begin{array}{l}\frac{2}{2} \\
\frac{1}{1} \\
\frac{1}{0} \\
\frac{1}{1}\end{array}$ & 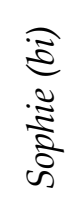 & $\begin{array}{l}\frac{\mathfrak{d}}{\tilde{c}} \\
\sum_{z}^{2}\end{array}$ & 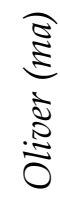 & 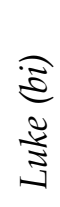 & 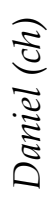 & $\begin{array}{l}\frac{a}{2} \\
\frac{\tilde{J}}{E} \\
E\end{array}$ & 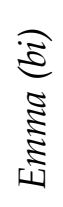 & 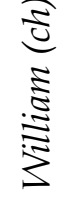 & $\begin{array}{l}\frac{1}{2} \\
\frac{2}{0} \\
0 \\
0\end{array}$ \\
\hline School & $\mathrm{A}$ & $\mathrm{A}$ & A & A & B & B & $\mathrm{C}$ & C & $\mathrm{C}$ & $\mathrm{D}$ & $\mathrm{D}$ \\
\hline Module & I & $\mathrm{I}$ & II & II & $\mathrm{I}$ & II & I & I & II & I & II \\
\hline Lessons per week & \multicolumn{4}{|c|}{3} & \multicolumn{2}{|c|}{2} & \multicolumn{3}{|c|}{3} & & 3 \\
\hline Number of weeks & \multicolumn{4}{|c|}{8} & \multicolumn{2}{|c|}{11} & \multicolumn{3}{|c|}{8} & & 6 \\
\hline Number of students & \multicolumn{4}{|c|}{17} & \multicolumn{2}{|c|}{6} & \multicolumn{3}{|c|}{12} & & 17 \\
\hline $\begin{array}{l}\text { Number of students } \\
\text { without physics }\end{array}$ & \multicolumn{4}{|c|}{1} & \multicolumn{3}{|c|}{0} & \multicolumn{2}{|l|}{2} & & 2 \\
\hline $\begin{array}{l}\text { Number of students } \\
\text { without biology }\end{array}$ & \multicolumn{4}{|c|}{7} & \multicolumn{2}{|c|}{4} & & \multicolumn{2}{|l|}{0} & & 2 \\
\hline
\end{tabular}

$\mathrm{I}=$ The hydrogen car

$\mathrm{II}=$ The brain and learning

$$
\begin{aligned}
\mathrm{ch} & =\text { chemistry teacher } \\
\mathrm{ph} & =\text { physics teacher } \\
\mathrm{bi} & =\text { biology teacher } \\
\mathrm{ma} & =\text { mathematics teacher }
\end{aligned}
$$


In school A, both modules were taught by teams of two teachers. Module I was taught by Ben (chemistry teacher) and Adam (physics teacher) and module II was taught by Sophie (biology teacher) and Max (chemistry teacher). They taught their modules in eight weeks, with three lessons per week. The NLT class consisted of 17 students; one student was not taking physics and seven were not taking biology.

In school B, Oliver (mathematics teacher) taught module I and Luke taught module II. They each taught their module in eleven weeks, with two lessons per week. The NLT class consisted of six students all taking physics, but four of whom were not taking biology.

In school C, module I was taught by the team of Daniel (chemistry teacher) and Jack (physics teacher). Emma (biology teacher) taught module II. They taught their modules in eight weeks, with three lessons per week. The NLT class consisted of 12 students; two students did not take physics.

In school D, William (chemistry teacher) taught module I and Owen (physics teacher) taught module II. They each had six weeks, with three lessons per week. The NLT class consisted of 17 students, two students were not taking physics and two were not taking biology.

Emma (school C) withdrew from the professional development programme after the preparation seminar (learning episode 2) because of personal circumstances. Owen (school D) could not participate in the reflection meeting (learning episode 4) because of a long illness. Therefore, Emma and Owen were not included in the results reported here.

\subsubsection{Data sources}

To collect data to answer the research questions, data sources A-F were used at various stages in the professional development programme (see Table 5.2). 
Table 5.2 Overview of the data sources used to answer the five research questions

\begin{tabular}{|c|c|c|c|c|c|c|}
\hline \multirow[t]{2}{*}{ Research questions } & \multicolumn{6}{|c|}{ Data sources } \\
\hline & $\begin{array}{c}\text { A } \\
\text { e-mails } \\
\text { from } \\
\text { online } \\
\text { support }\end{array}$ & $\begin{array}{c}\text { B } \\
\text { questionnaires }\end{array}$ & $\begin{array}{c}\text { C } \\
\text { teacher } \\
\text { interviews }\end{array}$ & $\begin{array}{c}\mathrm{D} \\
\text { student } \\
\text { interviews }\end{array}$ & $\begin{array}{c}\mathrm{E} \\
\text { outlines } \\
\text { of } \\
\text { modules }\end{array}$ & $\begin{array}{c}\mathrm{F} \\
\text { assessment } \\
\text { results }\end{array}$ \\
\hline $\begin{array}{l}\text { 1. How did the } \\
\text { before teaching } \\
\text { phase contribute } \\
\text { to intentions? }\end{array}$ & & $x$ & & & & \\
\hline $\begin{array}{l}\text { 2. What did teachers } \\
\text { apply in their } \\
\text { classes? }\end{array}$ & $x$ & $x$ & $x$ & $x$ & $x$ & \\
\hline $\begin{array}{l}\text { 3. What did teachers } \\
\text { learn overall? }\end{array}$ & & $x$ & $x$ & & & \\
\hline $\begin{array}{l}\text { 4. Did organizational } \\
\text { factors hinder the } \\
\text { success of the } \\
\text { programme? }\end{array}$ & & & $x$ & & & \\
\hline $\begin{array}{l}\text { 5. What are student } \\
\text { learning } \\
\text { outcomes? }\end{array}$ & & & & $x$ & & $x$ \\
\hline
\end{tabular}

During teaching all of the (Friday) e-mail correspondence that was exchanged as part of the online support (Figure 5.1, number 3) was collected (Data source A). Before the reflection meeting (Figure 5.1, number 4) a questionnaire was sent (Data source B). Shortly after the reflection meeting interviews were held with the individual teachers (Data source C) and with three students from each class (Data source D). All of the interviews were recorded and transcribed. We got the outline of the module from the teachers (Data source E) and their assessment results (Data source F). This data source F consists of paper and pencil tests, portfolios, and students' own research reports.

Research question 1 is answered with responses to data sources $B$, as shown in Table 5.2 and 5.3. The first question on the questionnaire (Data source B) had multiple parts and was 'how did the preparation seminar contribute to [various learning areas]' and 'how did you experience the collaboration with other schools'. Teachers responded to the questions on a Likert scale ranging from 1 to 5 ( $5=$ contributed a lot). Questions 2 and 3 from Table 5.3 were open questions and were posed both on the questionnaire and during the interview. 
Table 5.3 Operationalization of the questions used to answer Research Questions 1 and 3, contribution to ideas and teacher learning

\begin{tabular}{|c|c|c|c|}
\hline & Data sources & & \\
\hline & $\begin{array}{l}\text { Questionnaire } \\
\text { (Source B) }\end{array}$ & $\begin{array}{l}\text { Questionnaire } \\
\text { (Source B) }\end{array}$ & $\begin{array}{l}\text { \& Interview } \\
\text { (Source C) }\end{array}$ \\
\hline & $\begin{array}{l}\text { Questions on a Likert } \\
\text { scale 1-5 }\end{array}$ & Open questions & \\
\hline & $\begin{array}{l}\text { Contribution from the } \\
\text { seminar }\end{array}$ & $\begin{array}{l}\text { Learning as reported by } \\
\text { the teacher }\end{array}$ & $\begin{array}{l}\text { Learning as } \\
\text { interpreted by the } \\
\text { researcher }\end{array}$ \\
\hline Questions $\rightarrow$ & $\begin{array}{l}\text { 1. How did the } \\
\text { preparation seminar } \\
\text { contribute to ... }\end{array}$ & $\begin{array}{l}\text { 2. What did you learn } \\
\text { from the professional } \\
\text { development } \\
\text { programme about ... }\end{array}$ & $\begin{array}{l}\text { 3. What would you } \\
\text { do differently next } \\
\text { year when you teach } \\
\text { the module again } \\
\text { regarding ... }\end{array}$ \\
\hline Learning area $\downarrow$ & & & \\
\hline $\begin{array}{l}\text { I. Instructional } \\
\text { strategies }\end{array}$ & $\begin{array}{l}\text {...preparing the } \\
\text { experiments? } \\
\text {...giving feedback to } \\
\text { students? } \\
\text {...motivating } \\
\text { students? }\end{array}$ & $\begin{array}{l}\text {...instructional } \\
\text { strategies? }\end{array}$ & $\begin{array}{l}\text {...instructional } \\
\text { strategies? }\end{array}$ \\
\hline $\begin{array}{l}\text { II. Differences } \\
\text { in prior } \\
\text { knowledge }\end{array}$ & $\begin{array}{l}\text {...dealing with } \\
\text { differences in } \\
\text { students' prior } \\
\text { knowledge? }\end{array}$ & $\begin{array}{l}\text {...differences in prior } \\
\text { knowledge? }\end{array}$ & $\begin{array}{l}\text {...differences in } \\
\text { prior knowledge? }\end{array}$ \\
\hline $\begin{array}{l}\text { III. Adjustments } \\
\text { to the } \\
\text { module }\end{array}$ & $\begin{array}{l}\text {...my planning of the } \\
\text { chapter sequence of } \\
\text { the module? } \\
\text {...planning and } \\
\text { organization of the } \\
\text { module? }\end{array}$ & $\begin{array}{l}\text {...adjustments to the } \\
\text { module? }\end{array}$ & $\begin{array}{l}\text {...adjustments to the } \\
\text { module? }\end{array}$ \\
\hline $\begin{array}{l}\text { IV. Assessment } \\
\text { methods and } \\
\text { instruments }\end{array}$ & $\begin{array}{l}\text {...the use of different } \\
\text { types of assessment? }\end{array}$ & $\begin{array}{l}\text {...assessment methods } \\
\text { and instruments? }\end{array}$ & $\begin{array}{l}\text {...assessment } \\
\text { methods and } \\
\text { instruments? }\end{array}$ \\
\hline $\begin{array}{l}\text { V. Field trips } \\
\text { and guest } \\
\text { lectures }\end{array}$ & $\begin{array}{l}\text {..the organization of } \\
\text { a field trip or guest } \\
\text { lecture? }\end{array}$ & $\begin{array}{l}\text {...field trips and guest } \\
\text { lectures? }\end{array}$ & $\begin{array}{l}\text {...field trips and } \\
\text { guest lectures? }\end{array}$ \\
\hline $\begin{array}{l}\text { VI. Collaboration } \\
\text { with } \\
\text { colleagues }\end{array}$ & $\begin{array}{l}\text { 1. How did you } \\
\text { experience the } \\
\text { collaboration with } \\
\text { other schools? }\end{array}$ & $\begin{array}{l}\text {...collaboration with } \\
\text { colleagues? }\end{array}$ & $\begin{array}{l}\text {...collaboration with } \\
\text { colleagues? }\end{array}$ \\
\hline $\begin{array}{l}\text { VII.Content } \\
\text { knowledge }\end{array}$ & & $\begin{array}{l}\text {...the content } \\
\text { knowledge }\end{array}$ & $\begin{array}{l}\text {...the content } \\
\text { knowledge? }\end{array}$ \\
\hline
\end{tabular}


Research question 2 is answered with teachers' responses on data sources B and C, while students' interviews (Data source D) were used to triangulate these data (Table 5.4). The 'Friday e-mail' (Data source A) and the module outline (Data source E) were also used to triangulate the data from data sources B and C.

Table 5.4 Operationalization of the questions used to answer Research Question 2, Class use

\begin{tabular}{|c|c|c|c|}
\hline \multirow[b]{2}{*}{$\begin{array}{l}\text { Learning } \\
\text { area }\end{array}$} & \multicolumn{3}{|c|}{ Data sources } \\
\hline & $\begin{array}{l}\text { Questionnaire } \\
\text { (Source B) }\end{array}$ & $\begin{array}{l}\text { Teachers' interview } \\
\text { (Source C) }\end{array}$ & $\begin{array}{l}\text { Students' interview } \\
\text { (Source D) }\end{array}$ \\
\hline $\begin{array}{l}\text { I. } \\
\text { Instructional } \\
\text { strategies }\end{array}$ & $\begin{array}{l}\text { Did you let students do } \\
\text { all the experiments? } \\
\text { Did you give feedback } \\
\text { to students during } \\
\text { the module? } \\
\text { Did you do something } \\
\text { extra to motivate } \\
\text { students for the } \\
\text { module? }\end{array}$ & $\begin{array}{l}\text { Did you let students do all } \\
\text { the experiments? } \\
\text { How was the lesson output } \\
\text { usually? }\end{array}$ & $\begin{array}{l}\text { Did you do all the } \\
\text { experiments? } \\
\text { How was the lesson } \\
\text { output usually? }\end{array}$ \\
\hline $\begin{array}{l}\text { II. } \\
\text { Differences } \\
\text { in prior } \\
\text { knowledge }\end{array}$ & $\begin{array}{l}\text { Did you cope with } \\
\text { students who were } \\
\text { not taking a subject } \\
\text { in their school } \\
\text { programme that was } \\
\text { important for their } \\
\text { prior knowledge of } \\
\text { the module? }\end{array}$ & $\begin{array}{l}\text { How did you cope with } \\
\text { students who were not } \\
\text { taking a subject in their } \\
\text { school programme that } \\
\text { was important for their } \\
\text { prior knowledge of the } \\
\text { module? }\end{array}$ & $\begin{array}{l}\text { How did the teacher } \\
\text { cope with students } \\
\text { who were not taking } \\
\text { a subject in their } \\
\text { school programme } \\
\text { that was important } \\
\text { for their prior } \\
\text { knowledge of the } \\
\text { module? }\end{array}$ \\
\hline $\begin{array}{l}\text { III. } \\
\text { Adjustments } \\
\text { to the } \\
\text { module }\end{array}$ & $\begin{array}{l}\text { Did you mix the } \\
\text { chapter sequence of } \\
\text { the module in your } \\
\text { planning? } \\
\text { Did the students } \\
\text { receive an outline of } \\
\text { the module? } \\
\text { Did you make } \\
\text { adjustments to the } \\
\text { module? }\end{array}$ & $\begin{array}{l}\text { What was your planning of } \\
\text { the chapter sequence of } \\
\text { the module? } \\
\text { What outline of the module } \\
\text { did the students receive? } \\
\text { Which adjustments to the } \\
\text { module did you make? }\end{array}$ & $\begin{array}{l}\text { How was the planning } \\
\text { of the chapter } \\
\text { sequence of the } \\
\text { module? } \\
\text { Did you receive an } \\
\text { outline of the } \\
\text { module? } \\
\text { Did you do something } \\
\text { that was not written } \\
\text { in the module? }\end{array}$ \\
\hline $\begin{array}{l}\text { IV. } \\
\text { Assessment } \\
\text { methods and } \\
\text { instruments }\end{array}$ & $\begin{array}{l}\text { Did you use different } \\
\text { kinds of assessment } \\
\text { methods and } \\
\text { instruments? }\end{array}$ & $\begin{array}{l}\text { Which forms of assessment } \\
\text { methods and instruments } \\
\text { did you use? }\end{array}$ & $\begin{array}{l}\text { Which assessment } \\
\text { methods did you do } \\
\text { for this module? }\end{array}$ \\
\hline $\begin{array}{l}\text { V. Field trips } \\
\text { and guest } \\
\text { lectures }\end{array}$ & $\begin{array}{l}\text { Did you organize a } \\
\text { field trip or guest } \\
\text { lecture connected to } \\
\text { the content of the } \\
\text { module? }\end{array}$ & $\begin{array}{l}\text { What field trip or guest } \\
\text { lecture connected to the } \\
\text { content of the module did } \\
\text { you organize? }\end{array}$ & $\begin{array}{l}\text { What field trip or } \\
\text { guest lecture did } \\
\text { your teacher } \\
\text { organize? }\end{array}$ \\
\hline
\end{tabular}


Table 5.4 Operationalization of the questions used to answer Research Question 2, Class use (Continued)

\begin{tabular}{|c|c|c|c|}
\hline \multirow[b]{2}{*}{$\begin{array}{l}\text { Learning } \\
\text { area }\end{array}$} & \multicolumn{3}{|c|}{ Data sources } \\
\hline & $\begin{array}{l}\text { Questionnaire } \\
\text { (Source B) }\end{array}$ & $\begin{array}{l}\text { Teachers' interview } \\
\text { (Source C) }\end{array}$ & $\begin{array}{l}\text { Students' interview } \\
(\text { Source D) }\end{array}$ \\
\hline $\begin{array}{l}\text { VI. } \\
\text { Collaboration } \\
\text { with } \\
\text { colleagues }\end{array}$ & $\begin{array}{l}\text { Did you have contact } \\
\text { with the National } \\
\text { Steering Committee } \\
\text { for help? } \\
\text { Did you have contact } \\
\text { with teachers outside } \\
\text { the school other than } \\
\text { the Friday e-mail? } \\
\text { Would you readily } \\
\text { contact one of the } \\
\text { participating teachers } \\
\text { while teaching a } \\
\text { further module? }\end{array}$ & $\begin{array}{l}\text { How was the collaboration } \\
\text { between the teachers? }\end{array}$ & $\begin{array}{l}\text { How was it to get the } \\
\text { module taught by } \\
\text { two teachers? }\end{array}$ \\
\hline $\begin{array}{l}\text { VII. Content } \\
\text { Knowledge }\end{array}$ & & & $\begin{array}{l}\text { Could your teacher(s) } \\
\text { help you well with } \\
\text { the content of the } \\
\text { module? }\end{array}$ \\
\hline
\end{tabular}

\subsubsection{Data analysis}

The general approach was as follows. The researcher organized the data from each teacher according to the five research questions. For research questions 2 and 3 the data were subsequently organized according to the seven learning areas to which they pertained, i.e.: instructional strategies, differences in students' prior knowledge, adjustments to the module, assessment methods and instruments, field trips and guest lectures, collaboration with colleagues, and content knowledge. For each participant, we created a separate Word table for each research question, containing all of the teachers' qualitative data. In the next section we explain how we analyzed the data to answer the five research questions.

Research question 1. How did the before teaching phase contribute to the pedagogical and curricular intentions of participating teachers'?

The responses to the question 'contribution from the seminar' (Table 5.3) were given for each learning area on a Likert scale from 1-5. Means and standard deviations were calculated. 
Research question 2. What new learning outcomes from the seven learning areas did teachers apply in their classes?

In the second column of Table 5.4 the questions used to find out about class use are shown, and in the third column are the questions about how the students perceived this.

Data sources A (the Friday e-mail), D (student interviews), and E (module outline) were used to triangulate the data from data sources B and C. The 'Friday e-mail' provided extra insight into the collaboration of the teacher teams, the use of the experiments and the assignments, and the correspondence with other schools and the National Steering Committee. Data source E (module outline) provided information about the chapter sequence, adjustments made to the module, and assessment methods and instrument used by the teachers.

Research question 3. What did teachers in general learn from the entire professional development programme?

Two kinds of responses were collected: learning as reported by the teachers themselves and learning as observed by the researcher (Table 5.3). When teachers reported in the questionnaire or interview that they had learned something, this was taken as an instance of 'learning as reported by the teacher'. When teachers did not respond to this question, this was taken as an instance of no 'learning as reported by the teacher'. When teachers indicated in the questionnaire or interview the intention to do something differently next year we interpreted this as a kind of learning. We consider it as learning that resulted from the experience of teaching the module and from the post-teaching reflection, which enabled the teachers to learn from their experiences by making them articulate insights and conclusions. This was taken as an instance of 'learning as interpreted by the researcher'. We also compared these two types of responses about learning (reported by teacher and observed by researcher) to see if they corresponded or differed.

Research question 4. Did organizational factors hinder the success of the professional development programme?

This research question was answered through the interview question: 'Are there any organizational factors that hindered you during the teaching of the module?' 
Research question 5. What are the student learning outcomes from the modules addressed in the professional development programme?

The mean scores of student learning outcomes on all assessment instruments were calculated and combined in a table.

\subsubsection{Determination of reliability}

Inter-rater reliability was determined for the data before further analysis. The procedure was identical to that applied by Coenders (2010). Two researchers not previously involved in this research were asked to act as assessors and to check a representative sample from the Word tables with the qualitative data against the questionnaires and interview transcripts.

The assessors were given the characteristic phrases in the table plus the corresponding questionnaires and the interview transcripts for three teachers. They were asked first to compare the characteristic phrases in the table with the questionnaires and the transcripts, and to indicate whether they would support or reject the characteristic phrases in the table. Second, they were asked to determine whether characteristic phrases were missing in the table. This resulted in $92 \%$ agreement on the characteristic phrases already in the table, calculated according the procedure by Coenders (2010). Disagreements were discussed until consensus was reached. The second assessor added four missing phrases, which were added to the Word tables after discussion.

To establish inter-rater reliability, both assessors were given two identical tables, the questionnaire and the interview transcript. This resulted in $94 \%$ full agreement.

\subsection{Results}

The designed professional development programme was carried out for two different NLT modules and is seen as an embedded case study situation (Yin, 2003). In this section, the findings for the teachers for both professional development programmes will be presented, by research question. 
Research question 1. How did the before teaching phase contribute to the pedagogical and curricular intentions of participating teachers'?

Table 5.5 shows an overview of 'How the preparation seminar contributed to ideas in the different learning areas' according to the participating teachers for module I 'The hydrogen car' and module II 'The brain and learning' (Table 5.2, Data source B). A response of 1 corresponded to no contribution, 5 to contributing a lot. The mean score (M) and the standard deviation (sd) for each learning area are displayed at the right.

The reliability (internal consistency) of the teachers' answers was calculated, resulting in a Cronbach's alpha of 0.95. Taking into account the norm that Cronbach's alpha should be larger than 0.80 we consider this questionnaire to be reliable (Heus de et al., 1995). However, the size of the sample and the length of the questionnaire demand caution about the realibility of the instrument.

It can be seen in Table 5.5 that all values are above a mean of 3.0 (Questionnaire, data source B; 5-point Likert scale) and therefore represent positive evaluations, except for 'giving feedback to students' and 'organizing field trips and guest lectures'. 


\section{Teachers}

\begin{tabular}{|c|c|c|c|c|c|c|c|c|c|c|c|c|}
\hline & & & & & & & & & & & & \\
\hline Learning area & Questions & 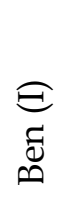 & $\begin{array}{l}\ominus \\
\tilde{\Xi} \\
\frac{\pi}{2} \\
\frac{\pi}{4}\end{array}$ & 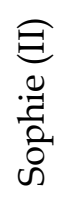 & $\underset{\substack{\Xi \\
\sum}}{\bigoplus}$ & 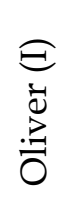 & 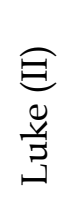 & 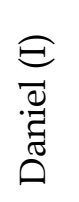 & 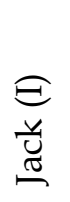 & 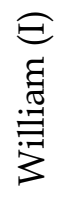 & M & $\mathrm{sd}$ \\
\hline & How did the preparation seminar contribute to ... & & & & & & & & & & & \\
\hline I. Instructional & ...preparing the experiments? & 2 & 2 & 2 & 3 & 3 & 5 & 4 & 4 & 4 & 3.2 & 1.1 \\
\hline strategies & ...giving feedback to students? & 3 & 3 & 1 & 3 & 4 & 2 & 2 & 2 & 1 & 2.3 & 1.0 \\
\hline & ...motivating students? & 3 & 3 & 3 & 4 & 4 & 3 & 4 & 4 & 4 & 3.6 & 0.5 \\
\hline $\begin{array}{l}\text { II. Differences in } \\
\text { prior knowledge }\end{array}$ & $\begin{array}{l}\text {...dealing with differences in students' } \\
\text { prior knowledge? }\end{array}$ & 4 & 4 & 2 & 4 & 1 & 4 & 3 & 2 & 3 & 3.0 & 1.1 \\
\hline $\begin{array}{l}\text { III. Adjustments } \\
\text { to the module }\end{array}$ & $\begin{array}{l}\text {...my planning of the chapter sequence of } \\
\text { the module? }\end{array}$ & 5 & 5 & 4 & 4 & 5 & 3 & 5 & 3 & 5 & 4.3 & 0.9 \\
\hline & $\begin{array}{l}\text {...planning and organization of the } \\
\text { module? }\end{array}$ & 5 & 5 & 4 & 5 & 5 & 3 & 5 & 4 & 5 & 4.6 & 0.7 \\
\hline $\begin{array}{l}\text { IV. Assessment } \\
\text { methods and } \\
\text { instruments }\end{array}$ & ...the use of different types of assessment? & 4 & 4 & 3 & 3 & 4 & 4 & 4 & 4 & 5 & 3.9 & 0.6 \\
\hline $\begin{array}{l}\text { V. Field trips and } \\
\text { guest lectures }\end{array}$ & $\begin{array}{l}\text {...the organization of a field trip or guest } \\
\text { lecture? }\end{array}$ & 1 & 1 & 2 & 4 & 1 & 3 & 1 & 1 & 3 & 1.9 & 1.2 \\
\hline $\begin{array}{l}\text { VI. Collaboration } \\
\text { with colleagues }\end{array}$ & $\begin{array}{l}\text { How did you experience the collaboration with } \\
\text { other schools? }\end{array}$ & 5 & 5 & 3 & 5 & 4 & 3 & 5 & 5 & 5 & 4.4 & 0.9 \\
\hline
\end{tabular}

$1=$ weak contribution

$5=$ contributed a lot
(I) $\quad=$ module 'The hydrogen car'
(II) $\quad=$ module 'The brain and learning' 
Research question 2. 'What new learning outcomes from the seven learning areas did teachers apply in their classes?'

Table 5.6 presents an overview of what teachers reported using in their class (Table 5.2; Data source B, questionnaire). When the teacher answered 'Yes' to the questions on Data source B that are given in Table 5.4, we indicated this in Table 5.6 with 'Yes'. When a teacher answered 'No', we indicated this with a minus (-) sign.

The findings reported in Table 5.6 generally indicate what teachers used in their classes. What the teachers did in their classes is reported in more detail for each of the seven learning areas below. For that purpose the responses from the teachers to the follow-up question (Data source B, Table 5.2) 'If you answer the question with 'Yes', please explain in more detail how' and the responses from Data source C, the teacher's interview (Table 5.2), have been paraphrased for each teacher. To illustrate 'What new learning in these learning areas teachers used in their classes and how they used it', exemplary interview quotes are selected.

The responses from the student interviews (Data source D, Table 5.2) supported the teacher responses on all the elements asked about. Selected student statements are shown. 
Table 5.6 Overview of what teachers used in their classes

\section{Teachers}

\begin{tabular}{|c|c|c|c|c|c|c|c|c|c|c|}
\hline Learning area & Questions & $\begin{array}{l}\underset{\tilde{D}}{E} \\
\text { E }\end{array}$ & 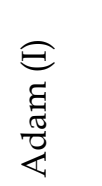 & 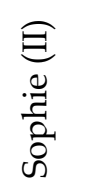 & 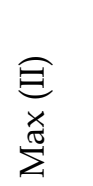 & 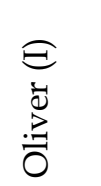 & 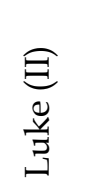 & 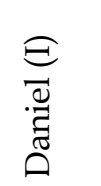 & 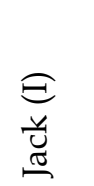 & $\underset{\Xi}{\bigoplus}$ \\
\hline I. Instructional & Did you do all the experiments? & Yes & Yes & Yes & Yes & Yes & Yes & Yes & Yes & Yes \\
\hline & $\begin{array}{l}\text { Did you give feedback to students } \\
\text { during the module? }\end{array}$ & Yes & Yes & Yes & Yes & Yes & - & Yes & Yes & Yes \\
\hline & $\begin{array}{l}\text { Did you do something extra to } \\
\text { motivate students for the module? }\end{array}$ & - & - & Yes & - & - & - & - & Yes & - \\
\hline $\begin{array}{l}\text { II. Differences in } \\
\text { prior knowledge }\end{array}$ & $\begin{array}{l}\text { Did you cope with students who } \\
\text { were not taking a subject in their } \\
\text { school programme that was } \\
\text { important for their prior } \\
\text { knowledge in the module? }\end{array}$ & - & - & Yes & Yes & - & - & Yes & Yes & Yes \\
\hline $\begin{array}{l}\text { III. Adjustments to } \\
\text { the module }\end{array}$ & $\begin{array}{l}\text { Did you change the chapter } \\
\text { sequence of the module in your } \\
\text { planning? }\end{array}$ & Yes & Yes & Yes & Yes & - & - & Yes & Yes & Yes \\
\hline & $\begin{array}{l}\text { Did the students receive an outline } \\
\text { of the module? }\end{array}$ & Yes & Yes & Yes & Yes & Yes & Yes & Yes & Yes & Yes \\
\hline & $\begin{array}{l}\text { Did you make adjustments to the } \\
\text { module? }\end{array}$ & Yes & Yes & Yes & Yes & Yes & Yes & Yes & Yes & Yes \\
\hline
\end{tabular}




\section{Teachers}

\begin{tabular}{|c|c|c|c|c|c|c|c|c|c|c|}
\hline Learning area & Questions & 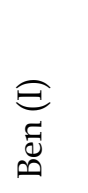 & 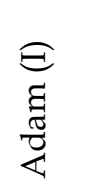 & 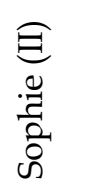 & $\underset{\substack{\circlearrowright \\
\stackrel{\Xi}{\Xi}}}{\stackrel{\Xi}{E}}$ & 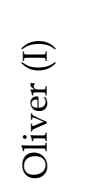 & 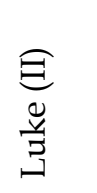 & 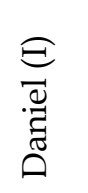 & 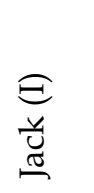 & $\begin{array}{l}\underset{\Xi}{\Xi} \\
\stackrel{\Xi}{\Xi} \\
\underset{3}{3}\end{array}$ \\
\hline $\begin{array}{l}\text { IV. Assessment } \\
\text { methods and } \\
\text { instruments }\end{array}$ & $\begin{array}{l}\text { Did you use different kinds of } \\
\text { assessment methods and } \\
\text { instruments? }\end{array}$ & Yes & Yes & Yes & Yes & Yes & Yes & Yes & Yes & Yes \\
\hline $\begin{array}{l}\text { V. } \\
\text { Field trips and } \\
\text { guest lectures }\end{array}$ & $\begin{array}{l}\text { Did you organize a field trip or guest } \\
\text { lecture connected to the content of } \\
\text { the module? }\end{array}$ & - & - & Yes & Yes & - & Yes & - & - & Yes \\
\hline \multirow[t]{2}{*}{$\begin{array}{l}\text { VI. Collaboration } \\
\text { with colleagues }\end{array}$} & $\begin{array}{l}\text { Did you have contact with the } \\
\text { National Steering Committee for } \\
\text { help? }\end{array}$ & - & - & - & - & - & - & - & - & Yes \\
\hline & $\begin{array}{l}\text { Would you readily contact one of the } \\
\text { participating teachers while } \\
\text { teaching a further module? }\end{array}$ & Yes & Yes & - & Yes & - & - & - & Yes & Yes \\
\hline
\end{tabular}

(I) = the module 'The hydrogen car'

(II ) = the module 'The brain and learning'
Yes $=$ The answer to the question is 'Yes'

- $\quad=$ The answer to the question is ' $\mathrm{No}^{\prime}$ 


\section{Instructional strategies: What did teachers apply in their classes?}

All nine teachers used all of the experiments from the modules. The online support e-mails (Data source A, Table 5.2) and the student interviews (Data source D, Table 5.2) also confirm this.

Eight of the nine teachers provided feedback to their students during the module. However, Luke said: 'I had no time to give feedback, next time I must do this'.

Two of the nine teachers did something extra to motivate the students for the module. Jack: 'We taught the module with two teachers. We made clear to the students that the module was new for us as well and we offered the students space and time to investigate things by themselves.' Sophie said: 'We changed the chapter sequence to motivate students. We started with a more practical part instead of a theoretical part.'

How was the instruction organized to carry out this instructional strategy? A student in the NLT class taught by Sophie and Max said: 'We mostly worked independently in small groups on the exercises from the module and on our own research project. Sometimes the theoretical explanation was given to the whole class at the start of the lesson.' The other teachers had more structural variation between theoretical explanation and working independently in small groups. A student of Daniel and Jack said: 'We had a lot of variation in the lessons: theoretical explanations, independent small group work, or doing experiments. In the classroom there were always computers available to work on. If you had questions, then you could ask them'.

\section{Differences in prior knowledge: What did teachers apply in their classes?}

Four of the nine teachers did not make a distinction between students in coping with the differences in students' prior knowledge. Oliver's students all had taken physics and therefore he did not have to deal with large differences in prior knowledge when teaching the module 'The hydrogen car'. The Ben-Adam team and Luke gave the normal theoretical explanation in class and emphasized to their students that they should ask questions when they experienced problems in understanding. One of Luke's students said: 'The teacher made no distinction between the students, something I appreciated'. This student appreciated that all students (with or without biology) were treated the same way and no exceptions were made. Five of the nine teachers did something extra beyond providing the theoretical explanation in order to deal with the differences in students' prior knowledge. During student group 
composition the Sophie-Max team and William had the students make mixed groups of students. For module II 'The brain and learning', taught by Sophie and Max, prior knowledge of biology is important. Every group had to include at least one student who was taking biology. For module I 'The hydrogen car' physics is important prior knowledge. As one of William's students said: 'Each student group had a student with physics as a member of their group'. The Sophie-Max and Daniel-Jack teams also took this difference into account with their choice of assessment methods and instruments. A student in Daniel and Jack's class said: 'The students who were not doing physics could answer different exercises.'

\section{Adjustments to the module: What did teachers apply in their classes?}

Two of the nine teachers did not change the teaching sequence of the module they taught, Oliver and Luke taught the chapters in the order they were given. The other teachers used alternative sequences. The teachers of module I taught the practical chapter concurrently with the theoretical chapter. The Sophie-Max team taught module II, and started with the students' own research project, chapter 6. The outline of the module (Data source E) confirms this. A student of Sophie and Max said: 'It was nice to get some easy stuff at first and then the more difficult stuff at the end. Changed chapter sequence happens more often in NLT'. All students received an outline of the module, as was confirmed from the student interviews.

All nine teachers made adjustments to the module. All omitted subject matter because of a limited number of available lessons. Besides this, Luke cancelled the planned student presentations at the last moment because, as a student of Luke said: 'The presentations were cancelled to save time because a neuroscientist came for a guest lecture'. William inserted an extra assignment for his students: they had to write a transport plan for 2020. The adjustments to the module were confirmed by the online support e-mails (Data source A), the outline of the module (Data source E), and student interviews (Data source D).

\section{Assessment methods and instruments: What did teachers apply in their classes?}

All teachers used more than one assessment method and instrument. All teachers administered a paper and pencil test that made up between $25-75 \%$ of the final mark. All students had to hand in a portfolio including practical reports that made up between $20-30 \%$ of the final mark. All students except 
Luke's had to do their own research project that made up between $25-40 \%$ of the final mark. On top of these three assessment instruments, Oliver's students had to hand in one extra portfolio containing responses for all of the exercises. Sophie and Max's students had to do an extra paper and pencil test. The assessment methods and instruments used by the Daniel-Jack team and William were as follows: 'paper and pencil test $(50 \%)$, portfolio $(25 \%)$, and student research project $(25 \%)^{\prime}$. The student interviews (Data source D) confirm the assessment methods and instruments used by all the teachers.

\section{$V$. Field trips and guest lectures: What did teachers apply in their classes?}

Five of the nine teachers did not organize a field trip or guest lecture. Adam said: 'We didn't find any good options. For me, a guest lecture is not suitable; the students have to see the professional area through a field trip'. Four of the nine teachers tried to organize a field trip or guest lecture. Sophie tried to organize a field trip to the hospital but this failed. Max organized a guest lecture from a psychologist but the psychologist cancelled at the last moment. A neuroscientist gave a guest lecture for Luke's students. William planned two field trips. One was cancelled because of school circumstances and one because William started organizing it too late. But a car mechanic, a former student of the school, gave a guest lecture for William's class about the latest technologies in cars. A student of William confirmed this and added: 'We quite often get a guest lecture in NLT.'

\section{Collaboration with colleagues: What did teachers apply in their classes?}

William contacted the National Steering Committee to help him with the organization of two field trips at the university. Ben and Adam contacted a teacher at another school. They asked teachers from a school close by to borrow some of their fuel cells. The other seven teachers had no contact with teachers from another school. The online support e-mails (Data source A) also confirm this. Five of the nine teachers said that they will readily contact one of the participating teachers when they need help during teaching a further module. Sophie, Oliver, and Luke responded that they do not know the other participants very well, but that after this programme it is easier to contact them. Daniel said: ' $\mathrm{I}$ 'd rather try to arrange it internally'. 
The collaboration between school colleagues in practice (Data source C):

Ben and Adam both worked on preparing the module. Ben took care of the chemistry section and was available for all three lessons per week. Adam took care of the physics part, and he was available for two of the three lessons per week. Both teachers rated the collaboration as pleasant and going well. A student said: 'The collaboration between the teachers was very good. Especially because the same one of the two teachers was present every lesson'.

At Sophie and Max's school, Max was only available for one of the three lessons per week. Sophie was in charge of the preparation and the teaching. There was a basic collaboration between Sophie and Max, and in fact they distributed the tasks. A student said: 'The collaboration was fine. There were not always two teachers, because Max had other lessons. Sophie was in charge. It was nice to have the module taught by two teachers.'

Jack and Daniel distributed the teaching according to the disciplines. Daniel took care of the chemistry part and Jack the physics section. Both teachers found the collaboration pleasant and going well. A student said: 'It was useful to have two teacher experts at different mono-disciplines for one NLT module. Questions could be answered very well now, but it was difficult to determine whom you should ask'.

VII. Content Knowledge: What did teachers apply in their classes?

All of the students reported that their teacher or teachers could answer their questions about the module well (Data source D). A student of Luke said: 'I thought he had a good understanding of the module. He did very well. I really had a lot of questions, and Luke was able to answer these.'

Research question 3. 'What did teachers in general learn from the entire professional development programme?'

Table 5.7 shows an overview of teacher learning. In the next section teacher learning for each of the seven learning areas will be described, including exemplary quotes (Data source C, Table 5.2). 


\section{Teachers}

Learning area

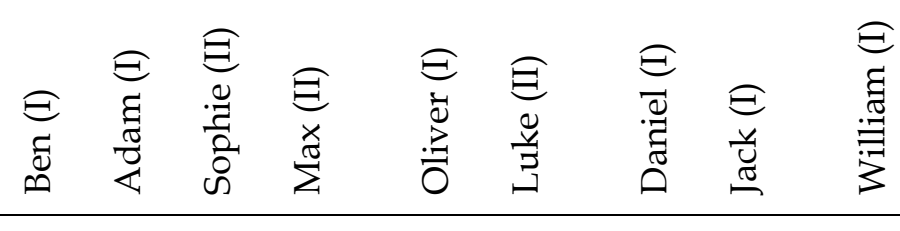

I. Instructional strategies

$\begin{array}{lllllllllll}+^{\bullet} & +^{\bullet} & +^{+} & +^{+} & +^{+} & +^{+} & - & +^{+} & +^{\bullet}\end{array}$

II. Differences in prior

knowledge

III. Adjustments to the module

IV. Assessment methods and instruments

V. Field trips and guest lectures

VI. Collaboration with colleagues

VII. Content knowledge

$+=$ Learning reported by the teacher

- = No learning reported by the teacher

$+=$ Learning interpreted by the researcher

- = Learning interpreted by the researcher matched learning reported by the teacher
(I) = the module 'The hydrogen car'

(II) $=$ the module 'The brain and learning'

\section{Instructional strategies: What did teachers learn?}

The teachers learned from the entire professional development programme, considering both what teachers reported having learned and future plans about the preparation of experiments, the student learning process, and motivating students. Seven teachers (Ben, Adam, Max, Oliver, Luke, Jack, and William) responded that they had learned about the experiments. William said 'I learned that next time, the lab assistant or I must try out the entire experiment before using it in class'. Ben and Adam made a similar comment. Other responses about the experiments were: 'I learned how to organize the experiments over two lessons (Oliver)', and 'try out the total experiment by myself (Jack)'. Max and Luke wanted to change some parts of the experiment to make it more effective. 
Four teachers (Sophie, Luke, Jack, and William) responded that they had learned about the student learning process. Sophie and William mentioned that they want to give students earlier and more feedback and consistently check the learning process and progress of the students. Jack said: 'next time, maybe let students work in groups arranged by the teacher'.

Max learned something about motivating students, saying 'I learned to stimulate students by paying attention to interesting things they may not immediately understand'.

\section{Differences in prior knowledge: What did teachers learn?}

Not all the students take physics or biology along with NLT, and therefore they may have substantially different prior knowledge. Seven teachers learned about ideas for handling these differences. Ben, Oliver, Jack, and William responded that they know to check what subjects that students take at the start of a module. Depending on the number of students that are not doing a subject, they will decide on the best way to cope with these differences. For instance, when many students are not taking physics, the teacher will act differently than when it is only one student. There was only one student who did not take physics in Ben and Adam's class. Ben said: 'Give more attention and explanation for the physics sections', and Adam said: 'Emphasize to students that they should ask questions when they have problems with understanding'. Other options when the groups of students not taking a subject are larger: 'Group composition and use the right vocabulary (Sophie)' for instance, arrange groups of students by putting a student who does not take biology in a group of students that all take biology. 'When the group of students not taking a subject is larger, I will use different assignments for students without physics (Oliver)'. Daniel mentioned making an extra information booklet with the necessary prior knowledge for the module.

\section{Adjustments to the module: What did teachers learn?}

Ben and Max learned to use a non-linear sequence for the chapters of the module. Ben, Sophie and William learned about the planning and organization of the module. Ben, for example, said: 'It is a good idea to teach the practical chapter concurrently with the theoretical chapters, bring variation in teaching by letting the students start with their own research project'. Max said: 'I learned to make adjustments to the module to motivate students'. Sophie 
changed the chapter sequence, which led to problems as students lacked specific information that was dealt with in the chapter she had skipped. Sophie said: 'It is not always useful to make adjustments to the module, look critically whether it makes sense to change the chapter sequence'. Because of a lack of time and an overloaded module. Ben and William said they considered removing the chapter with the difficult formulas.

\section{Assessment methods and instruments: What did teachers learn?}

Seven teachers learned how to use different types of assessment. Oliver said: 'I learned that it is not necessary to assess a module with a paper and pencil test. A portfolio or a presentation is also a good assessment method'.

Six teachers had thoughts about the use of the students' research project. Ben, Adam, Daniel, Jack, and William realized that the students' own research project needs a more precise description. Oliver mentioned that the next time students must write a paper about their own research project, he will consult the Dutch language teacher about the requirements for evaluating a paper. Ben, Adam, and Sophie learned about the use of a portfolio. Ben and Adam said that it is a good idea to let students use their portfolio during the paper and pencil test, instead of assessing the portfolio separately. Sophie said: 'When students are allowed to use their portfolio during their paper and pencil test, comprehension questions must be asked'.

\section{Field trips and guest lectures: What did teachers learn?}

Six teachers learned about aspects relating to the organization of a field trip or guest lecture. Ben said: 'Field trips and guest lectures are a useful extension of the module. William's idea to invite a former student from our school to give a guest lecture is a good idea'. Adam and Daniel stated that a field trip would have been nice, and according to Sophie, Max, and William field trips and guest lectures should be arranged in an earlier stage during preparation and more often.

\section{Collaboration with colleagues: What did teachers learn?}

Six teachers had thoughts about collaboration with colleagues. Max, Oliver, and William responded that the lab assistant was great, helped with a lot of the work, and should always be present at the preparation seminar. William said: 'The lab assistant should be involved early on with the preparation and implementation of the experiments'. For Daniel and Jack team teaching was new and they experienced what it entails. Both mentioned that it was 
instructive to collaborate so closely with a colleague, and thought that team teaching saves time, because you prepare only the pieces for your own discipline and correction work can be shared. Jack said: 'It was pleasant to discuss how things are done in chemistry classes, my co-teacher Daniel's subject'. Daniel said: 'From Jack I learned, among other things, classroom management and student misconceptions in physics education'. Sophie mentioned that the collaboration was fine but basic; they distributed the tasks.

\section{Content Knowledge: What did teachers learn?}

Except for Daniel, all teachers reported having retrieved and acquired content knowledge. Daniel used to work with fuel cells when employed by The Energy Research Centre Netherlands (ECN) and therefore did not acquire new content knowledge. Ben, Adam, Oliver, and Jack learned about production of hydrogen and its storage possibilities, advantages and disadvantages of using hydrogen fuel cells, and experiments with the fuel cells. A few years ago, William had coached a group of students with their hydrogen car research project and therefore was rather knowledgeable about this topic. William acquired new knowledge mainly about the experiments with the fuel cells.

Sophie, Max, and Luke acquired content of the module 'The brain and learning'. The topics they learned about were: multiple intelligences, different learning styles, and types of mind and memories. Sophie also said: 'I learned how students learn (different learning styles) and how I can take this into account as a teacher'.

Gathering ideas, using them in class, and participation in the reflection meeting can provide teachers with new ideas and can suggest changes to be incorporated into their teaching repertoire. Combining research question 1, gaining of ideas (Table 5.5), question 2, class enactment (Table 5.6), and question 3, teacher learning (Table 5.7), Table 5.8 was constructed to illustrate the connections observed for these participants between gaining new ideas, class use, and teacher learning for five learning areas. The learning areas 'Collaboration with colleagues' and 'Content knowledge' are excluded, because the data from research question 1,2, and 3 are not complete and pertain to different levels. From the information in Table 5.5, an ' $x$ ' is used here when the teacher acquired ideas (a mean score of ' 3 ' or above on a 5 point Likert scale) in a given learning area. Otherwise a period (.) is used. From the information in Table 5.6, when a teacher answered mainly 'Yes' in a learning area, the teacher used the learning area and the cell is marked here in grey. From the informa- 
tion in Table 5.7, a plus sign (+) is used here when a teacher learned something as reported by the teacher personally as well as teacher learning interpreted by the researcher. Otherwise a minus sign (-) is used. These variables are combined in Table 5.8, which also identifies the eight different possible combinations that can occur and records their frequency of occurrence.

Table 5.8 Patterns that occur when combining contribution of ideas from Table 5.5, use in teacher's class from Table 5.6, and teacher learning from Table 5.7

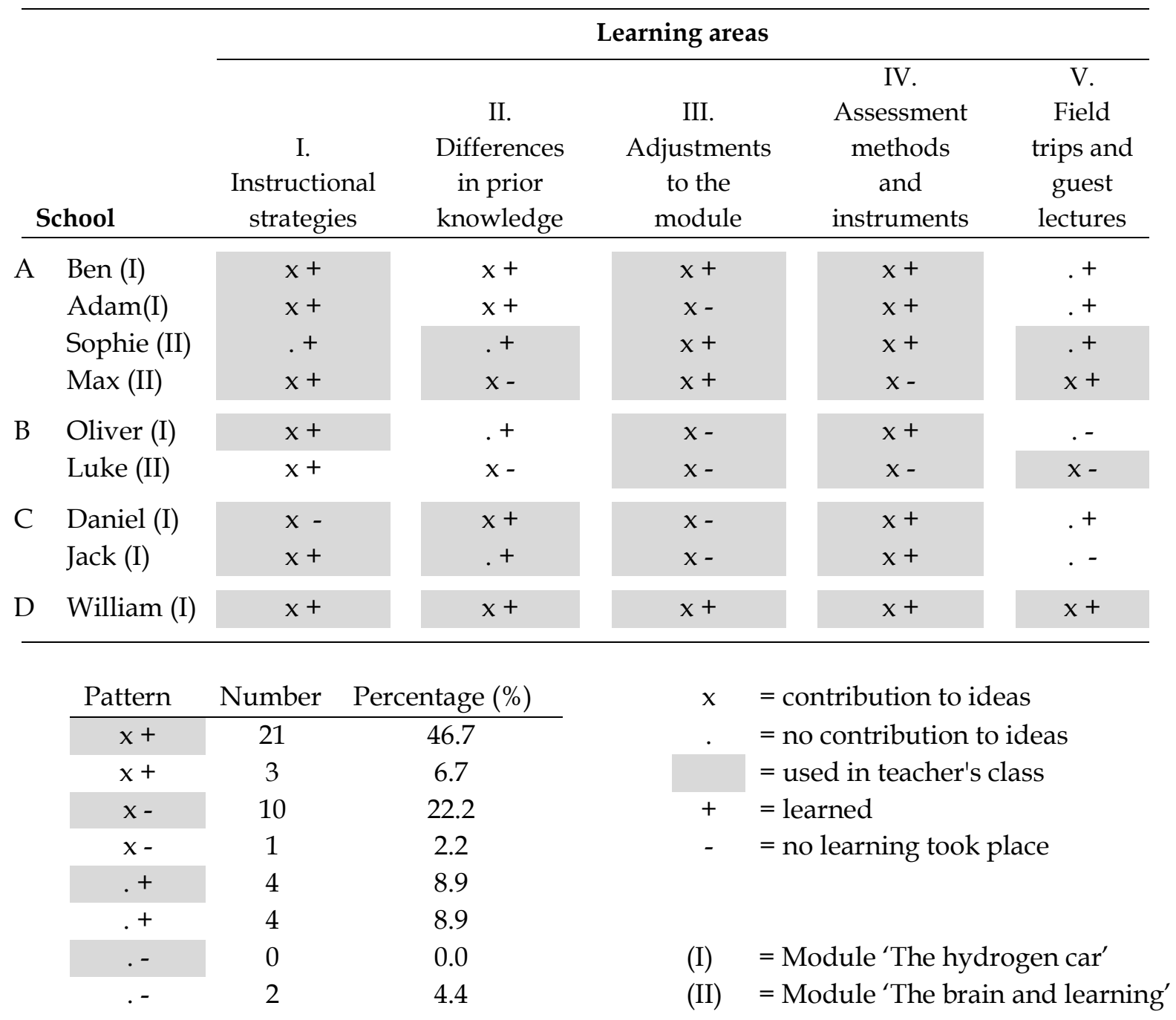

In Table 5.8, we can see that seven of the possible eight patterns occur in this study. The four highest rated patterns provide together nearly $90 \%$ of the total percentage. The pattern that occurs the most $(46.7 \%)$ is $x+$. This means that the teacher acquired ideas in that learning area, used that learning area in class, and learned from what was experienced with regard to that learning area. 
Research question 4. Did organizational factors hinder the success of the professional development programme?

All of the teachers answered that there were no obstacles during the preparation and during teaching of the module in school. All teachers had access to a classroom with practical facilities and lab equipment. All teachers had support from a lab assistant when necessary. Computers were also available for the students.

Luke answered: 'We didn't have any obstacles during the teaching of the module. We used a laboratory, and I had a lab assistant at my disposal at any time I liked.'

Research question 5. What are students' learning outcomes for the module addressed in the professional development programme?

Different kinds of learning outcomes were addressed with the different assessment methods. The paper and pencil test was used to assess cognitive learning. The portfolio and student research were used to assess affective and psychomotor learning outcomes. In these assessment methods the students also had to reflect on their own learning. Table 5.9 shows the means and standard deviations for students' scores on all of the assessment methods (paper and pencil test, portfolio, and student research project), by module and school.

Table 5.9 Assessment results from the students per school

\begin{tabular}{|c|c|c|c|c|c|c|c|c|c|c|c|c|}
\hline $\begin{array}{l}\overline{8} \\
\overline{8} \\
\bar{y} \\
\text { n. }\end{array}$ & $\begin{array}{l}\frac{0}{J} \\
\frac{0}{2} \\
\Sigma\end{array}$ & Teacher names & 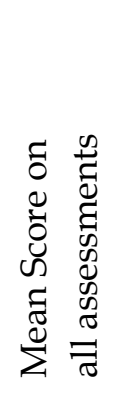 & రृ & 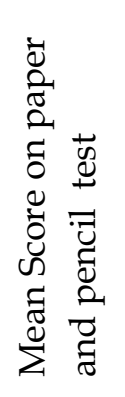 & ర్ల & 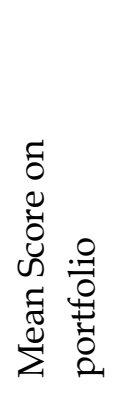 & ర్ & 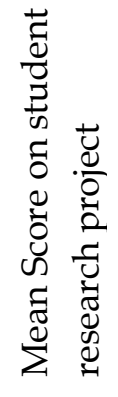 & D & 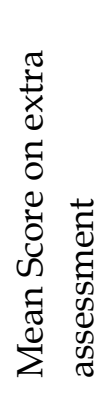 & ర్ \\
\hline A & I & Ben \& Adam & 6,6 & 0,6 & 6,3 & 1,2 & 7,2 & 0,5 & 6,3 & 0,9 & & \\
\hline A & II & Sophie \& Max & 6,8 & 0,8 & 6,7 & 0,9 & 6,8 & 1,3 & 6,6 & 1,3 & 7,6 & 1,0 \\
\hline B & I & Oliver & 7,0 & 0,4 & 7,9 & 0,9 & 6,9 & 0,4 & 6,5 & 1,2 & 6,5 & 0,4 \\
\hline B & II & Luke & 6,6 & 1,5 & 6,4 & 1,8 & 7,3 & 0,9 & & & & \\
\hline $\mathrm{C}$ & I & Daniel \& Jack & 7,2 & 0,5 & 6,9 & 1,0 & 7,5 & 0,3 & 7,5 & 0,6 & & \\
\hline $\mathrm{D}$ & I & William & 6,3 & 1,4 & 7,3 & 1,1 & 7,3 & 0,7 & 6,8 & 0,5 & & \\
\hline
\end{tabular}




\subsection{CONCLUSION}

In an earlier study, we designed a professional development programme with four different learning episodes to prepare teachers for and assist them during the implementation of new multidisciplinary science modules by addressing seven different learning areas (Visser et al., 2012a). This study aimed to identify the effects of a multidisciplinary professional development programme. We distinguished five sub-questions.

Research question 1 addressed how the before teaching phase contributed to ideas about the seven different learning areas. Learning episodes 1 and 2, the individual preparation and the collaborative preparation seminar in the before teaching phase, were incorporated in the programme to give teachers the possibility of becoming acquainted with the module, becoming aware of key aspects of the module, and addressing problematic elements, and to contribute to new ideas. From these findings we can conclude that the before teaching phase consisting of the individual preparation and the preparation seminar did contribute to ideas about different learning areas for teachers. The learning area 'Adjustments to the module' had the highest scores, followed by 'Assessment methods and instruments'. Overall, teachers said that the before teaching phase contributed a lot in these areas. Three teachers gained ideas in each of the learning areas, even for learning area $V$, 'Field trips and guest lectures'.

Research question 2 pertained to the new learning in these learning areas that teachers used in their classes. In learning episode 3, online support during teaching, teachers enacted the module as planned, did experiments, and gave feedback to their students. The findings showed that all participating teachers did all of the experiments (learning area I), made adjustments to the module and designed an outline of the module (learning area III), and used different assessment methods and instrument during the module (learning area IV). All teachers but one provided feedback to their students during the module (learning area I), and all teachers but two changed the chapter sequence of the module (learning area III).

Research question 3 aimed to identify the overall learning outcomes from the entire professional development programme (learning episodes 1, 2, 3, and 4). At the end of the entire professional development programme a reflection 
meeting, learning episode 4, was held to solicit ideas for improvements for the next year. The findings showed that teachers did learn about the different learning areas, and the idiosyncratic nature of their learning is also noticeable. All teachers but one learned for more than half of the learning areas. Learning about 'Instructional strategies', and 'Content knowledge' was evident for all teachers but one. All teachers but two showed learning about 'Differences in prior knowledge', and 'Assessment methods and instruments'.

Research question 4 pertained to the organizational factors that influence the success of the professional development programme. All of the teachers responded that there were no obstacles during the preparation and teaching of the module in school. Organizational factors did not hinder the teachers during the professional development programme.

In research question 5, students' learning results were addressed. The teachers acquired knowledge and skills during the entire professional development programme that were necessary to assist students to learn at a high level. The assessment results for the students at all of the schools show a score above 6.3 on a scale of 1 to 10 . For the complex content knowledge from these modules this can be considered as convincing learning results.

In conclusion, our findings show that this professional development programme is a useful venture for teachers' professional growth in different learning areas. Findings from this study provide empirical evidence of the impact of this multidisciplinary professional development programme.

\subsection{DIscussion}

The professional development programme was designed and implemented to prepare teachers with and assist them during the implementation of a multidisciplinary module. When teachers are not familiar with an innovation, they need to become equipped to carry it through, for example through a professional development programme (Borko et al., 2010; Penuel et al., 2007) in which ideas are gained about preparing experiments, dealing with differences in prior knowledge, making adjustments to the module, and using different types of assesment. During teaching, teachers enact the (gained) ideas together with the (new) 
multidisciplinary science module in class. Gathering ideas, using them in class, and participation in the reflection meeting provided teachers with new ideas and suggested changes to be incorporated into teachers' teaching repertoire.

Teachers gained ideas during the before teaching phase about one or more of the seven identified learning areas, used the new knowledge about the learning area in their classes, and did indicate that they learned about that particular learning area during the entire professional development programme. This pattern of explicit learning is what we could expect and what is also reported in literature (Bolhuis \& Simons, 1999): Teachers gain ideas (orientation to enactment), use them in their class (enactment), and learn from doing so (explicit reflection on enactment). The other pattern that often occurred with our participants was that teachers gained ideas about a learning area, used the new knowledge about the learning area in their classes, but did not explicitly indicate that they learned about this learning area during the entire professional development programme. This might be unexpected and internally inconsistent. Although teachers gained ideas and used them in their class, they did not report any overall learning gain. Presumably, their overt interpretation is that they did not explicitly learn from the programme for this learning area, although there is evidence that they used the material in a certain way and are satisfied with the material and the way they used it. This is a clear indication of an implicit learning outcome, which we discussed in the introduction to this chapter as an outcome that we might observe. As experienced teachers, they could have figured out what they would like to do differently or the same in the following year. This implicit learning outcome could be concluded from the answer to the question 'What would you do differently regarding the different learning areas when you teach the module again next year'. However, teacher learning could also occur when no ideas were contributed during the before teaching phase, and when these ideas were either used or not used in the classroom. Evidently, teacher learning also took place during teaching or in the reflection meeting in the after teaching phase. This kind of learning is also referred to as implicit learning, learning that takes place at the workplace, which in this study happened during the classroom enactment and the preparation before and reflection after the classroom sessions.

Another point worth mentioning in discussing the outcomes of this study is the widely acknowledged power of learning through collaboration between professionals (Borko, 2004; Meirink, Imants, Meijer, \& Verloop, 2010). In collaboration, new knowledge can be created or existing knowledge can be 
extended by exchanging ideas or experiences, developing and discussing new materials, getting feedback from colleagues, and giving moral support. Secondary education has a tradition of having teachers working in teams in the context of domain-specific departments. For NLT, the department consists of at least three teachers from the different disciplines (Steering Committee NLT, 2007). Besides these teacher team collaborations, some schools, in close consultation with the teacher team, determine how many teachers will be teaching a specific module. In our study of this professional development programme, teachers collaborated with teachers from different schools and there were three teaching teams. This research supports the conclusion that individual teachers learn as much as teachers in a teacher team in the professional development programme. The learning effect observed across both of these situations can be explained by the active involvement of teachers in the design and implementation of lessons or modules (Voogt, Fisser, Pareja Roblin, Tondeur, \& van Braak, 2012).

What is the impact of the entire professional development programme? The goal of the professional development programme was to prepare teachers for and assist them during the implementation of a multidisciplinary module. The teachers gained ideas about different learning areas. During teaching, teachers enacted these new ideas together with teaching the multidisciplinary science module in their classrooms. The ideas, class uses, and reflection meetings caused teacher learning and can produce lasting changes for the teacher when implementing new modules, insofar as they can incorporate what they have learned into their teaching repertoire.

Overall, teachers learned for more than half of the learning areas, and their students had good learning results. The professional development programme was suited to the school context, insofar as the teachers experienced no organizational factors that hindered them during the preparation and teaching of the module.

An important issue worth mentioning is that one teacher teaching module II learned less, gaining only with respect to instructional strategies. He differed from the other teachers in that he carried out the module later in the school year than the other teachers did. He started teaching the module nine weeks later and therefore did not carry out the individual preparation activity adequately (Visser, Coenders, Terlouw, \& Pieters, 2012c). This suggests that attention 
should be paid to the defined time period between learning episodes 1, 2 and 3 . The purpose of the first learning episode was to let teachers recall their prior knowledge (Gurlitt \& Renkl, 2010), to let them become aware of concerns associated with the module, and to create ownership with the programme from the start of the module (Ogborn, 2002; Wikeley, 2005).

This study showed that the professional development programme is more successful when it is linked to immediate school practice, to teachers' prior knowledge (Cotton, 2006; Luft, 2001), and to reflection organized around their own practice (Margalef Garcia \& Pareja Roblin, 2008; Meirink, 2007).

This study showed that a professional development programme having four learning episodes involving individual preparation, a preparation seminar, online support, and a reflection meeting, did result in teacher learning. The before teaching phase was important, as this provided teachers with new ideas related to their prior knowledge and existing practices. This programme then led to practical advice on how to use these ideas in class and to expected student learning gains. This practical advice reduced the need for lesson preparation and was important for achieving desired class enactment. The during teaching phase was important, as teachers need support during the teaching phase (Dede et al., 2009), especially when implementing new ideas in their classes. To support teachers during this teaching phase, e-mail exchange was organized as collaborative online support during the entire teaching period. The teachers shared their experiences of similar problems, exchanged additional materials, and learned useful tips during the e-mail exchange for teaching the module (Visser et al., 2012c). However, the e-mail exchange was time-consuming and it would be better to reduce the frequency of responses to once a fortnight instead of once a week, to maintain continuity between the before teaching and after teaching meetings, with the possibility of sending a personal request when needed. The after teaching phase was important for reflection. Teachers' reflection about their own practice was important for their professional development and to improve their own teaching (Margalef Garcia \& Pareja Roblin, 2008). In terms of its learning results, the reflection meeting provided insight and conclusions from the experiences of teaching the module. Joint reflection was an important learning activity (Meirink, 2007), as strengths and weaknesses of the teachinglearning process emerged and were discussed by all teachers. Through such a collaborative process, new ideas are described for future use and teachers build up confidence for the next module to be taught. 


\title{
CHAPTER 6 \\ Conclusions, discussion, and recommendations
}

\begin{abstract}
This chapter outlines the results of a professional development programme as a strategy for curriculum implementation in multidisciplinary science education. In section 6.1 the aim and research questions will be summarized and elaborated. In section 6.2 the main findings of the previous chapters are summarized and reported according to the three sub-studies. Section 6.3 presents reflection on the general research approach and its outcomes, followed by presentation of design principles. The chapter ends with section 6.4, recommendations for future research.
\end{abstract}

\subsection{AIM AND RESEARCH QUESTIONS}

School teachers must deal with curriculum innovations during their teaching careers. Multidisciplinary education such as teaching the new subject NLT is challenging, because of the specific NLT features and characteristics described in chapter 1 , section 1.2.2. A few of these features and characteristics are:

- NLT requires teachers from the different disciplines of physics, chemistry, biology, mathematics, and physical geography to cooperate in a multidisciplinary team in order to implement new curriculum materials.

- The teachers involved in teaching NLT have a Master's degree in one of the aforementioned mono-disciplinary subjects, but are not specifically trained for this new multidisciplinary subject.

- Students are not obliged to take all of the subjects integrated in NLT. This means that some students do not take biology, physics or geography, which eventually results in different levels of initial student knowledge for these three subjects. 
The implementation of NLT can therefore be seen as a complex curriculum innovation involving multiple stakeholders, in particular, teachers. It is widely acknowledged that teachers play an important role during curriculum innovations, as they have to enact the new curriculum in their classes. The success of the implementation of a new curriculum depends, among other factors, on the active involvement of teachers in the curriculum design process, on teacher professional development opportunities, and on their feeling of ownership of this curriculum (Borko, Jacobs, \& Koellner, 2010; Hargreaves, 1994; Penuel, Fishman, Yamaguchi, \& Gallagher, 2007; Wikeley, 2005). Various professional development activities can be developed and carried out to prepare teachers for an educational reform. Preparing teachers for a new curriculum can be considered as a mutually adaptive learning process in which the goals and methods of the professional development activity are modified to suit the needs and interests of participating teachers and in which the teachers align their knowledge, skills, and beliefs with the new curricular demands.

The goal of this research was threefold. In the first study, characteristics for developing a professional development programme in order to improve the implementation of a multidisciplinary module were determined. The second study dealt with the design of such a programme, followed by carrying out the programme for two different multidisciplinary science modules. Finally, in study three, this programme was evaluated, first, with respect to teacher satisfaction with the programme, and second, in terms of its effectiveness. Here we looked at the degree of teacher learning, in-class use of what teachers had learned, and impact on student achievement. The overall findings of this research will form the basis for design principles for professional development and for recommendations for future research.

This study was guided by the following overall research question:

'What is the effectiveness of a professional development programme as a strategy for improving the implementation of a multidisciplinary science curriculum?' 
To answer this overall research question, the following four sub-research questions were formulated:

1. Which characteristics are essential for a professional development programme to promote the implementation of a multidisciplinary science module?

2. What does a generic model for a professional development programme to prepare and assist teachers for a multidisciplinary science module look like, and how can this be translated into a programme suitable for a specific NLT module?

3. How do participating teachers evaluate the professional development programme in terms of satisfaction?

4. How effective is the multidisciplinary professional development programme in achieving teacher learning and in successfully enacting in class?

Each of these four sub-research questions was answered in succession, in chapters 2 to 5 .

\subsection{SUMMARIZING THE MAIN FINDINGS OF THE PREVIOUS CHAPTERS}

In this section we summarize the main findings of this study, from the three sub-studies. The three sub-studies were, respectively:

Study 1 is described in chapter 2, and concerned essential characteristics for a professional development programme promoting the implementation of a multidisciplinary science module;

Study 2 is described in chapter 3 , and concerned design and application of a generic model for a professional development programme for a multidisciplinary science subject;

Study 3 is described in chapter 4 , and concerned evaluating a professional development programme for implementation of a multidisciplinary science module in terms of teachers' satisfaction, and in chapter 5, which addresses the learning effects of a multidisciplinary professional development programme. 


\subsubsection{Results of the first study: Essential characteristics for a professional development programme for promoting the implementation of a multidisciplinary science module.}

This study focused on the identification of characteristics for a professional development programme. These characteristics were identified empirically and theoretically, and school practices were also taken into account. The general research question in this first study was as follows: 'Which characteristics are essential for a professional development programme to promote the implementation of a multidisciplinary science module?'

We discussed the empirical basis for a professional development programme directed towards the implementation of new multidisciplinary modules in secondary science education in the Netherlands. We used a three-step approach. The first step concerned evidence from the classroom settings of the schools. Teachers were interviewed about the procedure followed and the decisions made in implementing a module in their school, and the adaptations made to tailor the module to their particular classroom settings. As a second step, specific curriculum features of NLT as a subject were taken into account. The data from the teachers' interviews were analyzed and categorized into three groups. On the one hand, the analysis was based on the professionality categories of Hoyle and John (1995): restricted professionality, extended professionality, and the 'neither restricted nor extended professionality' group. On the other hand, it was based on relevant national curriculum documents. The third step consisted of evidence generated by curriculum implementation literature pertaining to effective characteristics of implementing an innovation. Each of these three steps approached the problem of identifying the essential characteristics for a professional development programme from a different angle. In order to develop the characteristics of the professional development programme, we began with teachers and their practices, connected these characteristics to the features of NLT, and linked them up with what has been described as successful curriculum implementation in the research literature. The combination of these three steps can be regarded as an effective and efficient method of triangulation, resulting in a number of systematically obtained characteristics for a professional development programme. 
Using the above three steps, five characteristics were identified as essential for incorporation into a professional development programme to promote the implementation of a NLT module:

1. Teachers should develop their knowledge. Teachers should be given ample opportunities to acquire new knowledge and skills, for example, science content, instructional strategies, and assessment methods. Experts, colleagues, and specific literature can provide this knowledge;

2. Teachers should cooperate with colleagues. Teachers should first be given opportunities to exchange and discuss experiences and ideas with colleagues. Discussion topics can be teaching methods and content, but also practical issues such as how to use a specific activity in class. Having teachers develop additional materials or assessment instruments can intensify cooperation;

3. Teachers should network. The result of the professional development programme should be a well-organized network in which teachers from different schools participate in collaborative activities;

4. The module should be made relevant and attractive for students. Teachers should design stimulating curricular elements to increase students' interest and motivation; and

5. Teachers should be well prepared and organized for their lessons. Teaching and learning difficulties should be discussion issues during the professional development programme, and opportunities to exchange good practices should be provided.

\subsubsection{Results of the second study: Design and application of a generic model for a professional development programme for a multidisciplinary science subject.}

Effectively implementing a new multidisciplinary subject such as NLT is a complex endeavor, because teachers do not have specific prior training for this new subject, and they are not familiar with cooperating with colleagues from other science disciplines. In order to prepare teachers adequately for NLT it is essential to set up a professional development programme, as reported in this second study. Study 2 also describes the application of this programme to a specific NLT module. The general research question was: 'How does a generic model look like for a professional development programme to prepare and assist teachers for a multidisciplinary NLT module?' 
Three sources that are important for the design of such a programme have been elaborated: (a) multidisciplinary science features including school practices (specific NLT features and characteristics), (b) curriculum design phases (applying the general curriculum design phases (Marsh \& Willis, 2003; Verhagen, Kuiper, \& Plomp, 1999) to NLT at school, and (c) professional development characteristics (derived from Study 1). We combined these three sources with three factors influencing the quality of the professional development: context, process, and content (Guskey, 2000). These sources and factors were converted into a generic model for a professional development programme to prepare and assist teachers. This model is outlined in Figure 6.1.

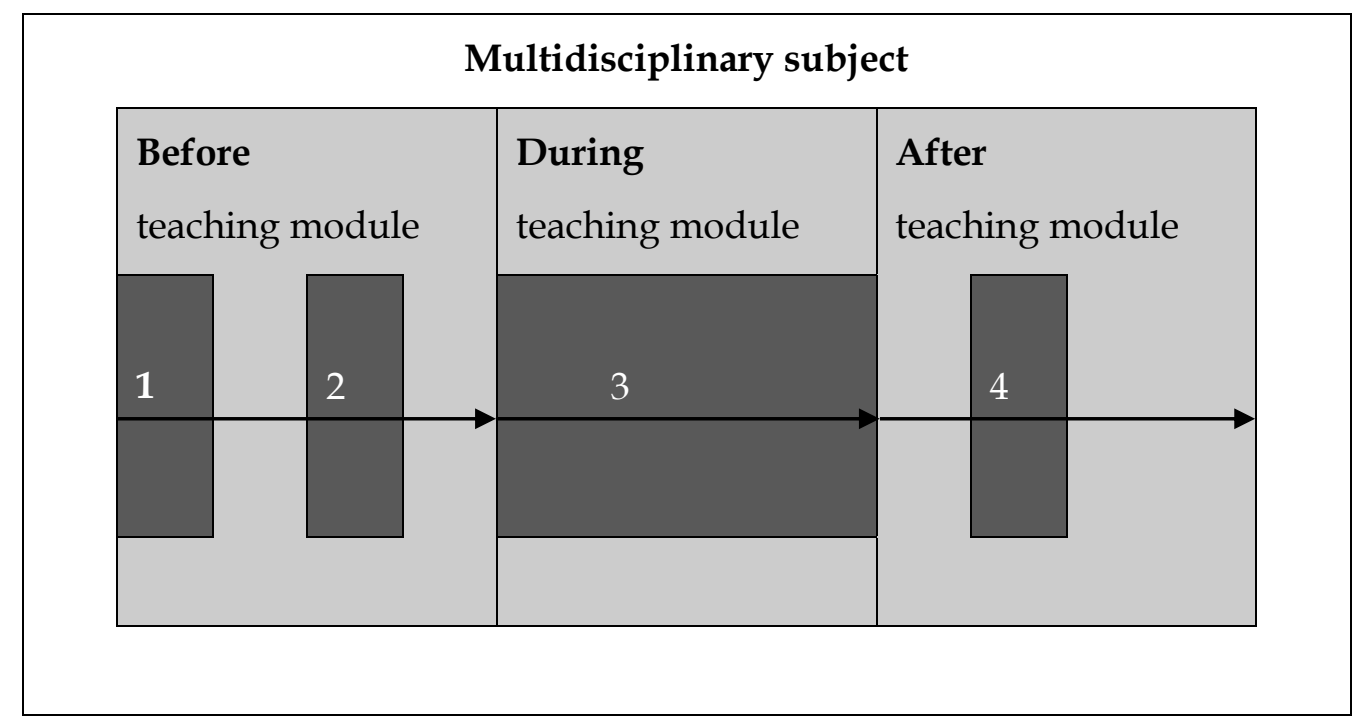

$\mathbf{1}$ individual preparation

2 preparation seminar

3 online support

4 reflection meeting

Figure 6.1 Generic model for a professional development programme

The programme is chaired by a coordinator and consists of three phases, situated before, during, and after teaching the module. The structure of the professional development programme is specified as the four stages identified by the numbers 1 to 4 in Figure 6.1. These stages will be explained below:

Stage 1: Individual preparation, in which teachers receive an e-mail from the coordinator asking them to look over the module and consider issues such as: (a) What knowledge and skills do I want my students to acquire in this module? 
(b) What kind of assessment methods and instruments do I intend to use in this module? (c) What questions do I have for the preparation seminar? Because it can take a long time for equipment for practical activities to be delivered, teachers are advised to find out what materials their school already has and what needs to be purchased or borrowed.

Stage 2: Preparation seminar, which uses the teachers' personal questions from the individual preparation as its starting point, in order to focus on class implementation and existing needs.

Stage 3: Online support given to teachers who need support during the teaching phase, especially when they have to implement new approaches in their classes. Stage 4: Reflection meeting in which strengths and weaknesses, assessment methods, learning goals, teaching methods, and module outline are discussed.

The designed professional development programme was intended to assist and support teachers before, during, and after implementation of a multidisciplinary science module. The usability of the designed generic module was shown by the operationalization into specific professional development programmes to prepare and assist teachers with the implementation of specific NLT modules. The translation of the generic elements of the professional development model into a professional development programme for a specific NLT module proved possible for both 'The hydrogen car' and 'The brains and learning' modules.

Three experts evaluated the model. The professional development model and an explanation of the model were sent to these three experts on NLT. They were asked to score the professional development programme model on different aspects from the programme. Those different aspects and the procedure of the expert appraisal are described in detail in chapter 3, section 3.5. All three experts judged the appraised aspects of the model as sufficient or good. Only 'teachers' possibility of supplementing content knowledge deficiencies' was judged to be insufficient. Teachers have a Master's degree for only one science subject and are therefore non-specialists in the other science subjects. We acknowledge the notion that teachers might have deficiencies in specific content knowledge. As it is impossible for teachers to acquire the knowledge of the other science disciplines at the required level in a short time span, instead, the multidisciplinary NLT team at school can help with this. As NLT teacher teams must consist of at least three teachers specializing in different science 
disciplines (Steering committee NLT, 2007). In the professional development programme we focus on class use of modules in relation to pedagogical content knowledge, planning, and equipment.

\subsubsection{Results of the third study: Evaluating a professional development programme for the implementation of a multidisciplinary science module and its learning effects}

The focus of this third study is on the evaluation of the designed and implemented multidisciplinary professional development programme. Guskey (2000) developed a five-level model for evaluating professional development. Levels 1, 2, 4, and 5 in this model are hierarchically arranged, with each higher level building on those before it. Guskey's levels (2002) are, respectively:

1. Participants' reaction, to assess teachers' satisfaction regarding the usability of the programme;

2. Participants' learning, which focuses on the knowledge and skills the teachers have acquired;

3. Organizational support, in which organizational factors that can hinder or facilitate the success of improvement efforts are described;

4. Participants' use of new knowledge and skills, which focuses on whether or not new knowledge and skills teachers have acquired are applied in their professional practice; and

5. Student learning outcomes, which addresses student learning.

The evaluation of Level 1 (participants' reaction) for the NLT professional development programme is reported in chapter 4. The general research question was: 'How do participating teachers evaluate the professional development programme in terms of satisfaction?' Overall, the participating teachers positively appreciated this professional development programme designed to assist and support teachers before, during and after implementation of a multidisciplinary science module. Several elements of the programme stages ensured teacher satisfaction. During the individual preparation the teachers acquainted themselves with the module, became aware of key aspects of the module, and formulated questions about elements they considered problematic. The preparation seminar addressed these concerns, contributed to getting new ideas, was useful for motivation and implementation in class, and created self-confidence. The online support 
addressed concerns that emerged during teaching, and the final reflection meeting provided ideas for improvement for the next year.

In chapter 5, the remaining four levels of Guskey's model were used to evaluate the professional development programme. The general research question was as follows: 'How effective is the multidisciplinary professional development programme?' Levels 2 and 4 directly relate to outcomes of the professional development programme for the individual teacher. Level 3 is considered as a condition for success of the professional development programme rather than as a result. Because our interest was on the results of the professional development programme, we report on level 3 those factors possibly hindering the programme at the end, after student learning.

For Level 2, teacher learning, two research questions were formulated: one to assess the influence on teacher learning of the before teaching phase, and one to assess the overall impact of the programme. The focus throughout the designed professional development programme was on the following seven teacher learning areas related to the specific features and characteristics of NLT (Visser, Coenders, Terlouw, \& Pieters, 2012): I) Instructional strategies, II) Differences in students' prior knowledge, III) Adjustments to the module, IV) Assessment methods and instruments, V) Field trips and guest lectures, VI) Collaboration with colleagues, and VII) Content knowledge. Overall, we can conclude from the data that this professional development programme contributed to teachers' professional growth in these different learning areas.

With regard to the before teaching phase, we concluded from the data that this phase contributed to teacher learning with regard to getting new ideas about different learning areas. The learning area 'Adjustments to the module' had the highest scores, followed by 'Assessment methods and instruments'. Three teachers gained ideas in each of the learning areas, even for the learning area 'Field trips and guest lectures'.

With regard to the data on overall impact of the programme, we concluded that the teachers did learn in these different learning areas. All teachers but one learned in more than half of the learning areas. Learning about 'Instructional strategies', and 'Content knowledge' was evident for all teachers but one. All teachers but two learned in the areas of 'Differences in prior knowledge', and 'Assessment methods and instruments'. 
Level 4 pertained to teachers' use in their class of the knowledge acquired in those learning areas. From the data we concluded that the teachers enacted the module as planned. All participating teachers did all the experiments (learning area I), made adjustments to the module and designed an outline of the module (learning area III), and used different assessment methods and instruments during the module (learning area IV). All teachers but one provided feedback to their students during the module (learning area I), and all teachers but two changed the chapter sequence of the module (learning area III).

We concluded from the data regarding Level 3 that there were no organizational factors hindering the teachers during the professional development programme.

In Level 5, the students' learning results were addressed. The assessment results for all the students at all of the schools showed a mean score of 6.3 , as a bottom of the score rage on a scale of 1 to 10 .

\subsection{REFLECTIONS ON THE GENERAL RESEARCH APPROACH AND ITS OUTCOMES}

This dissertation was guided by design-based research. It is an approach to designing and developing an intervention (e.g. professional development programme), especially to address complex problems in educational practice with many variables for which no clear guidelines for solutions are available yet (Nieveen, 2009). Reeves (2006) described design-based research as an interactive research process with four connected phases: Analysis, development of solutions, iterative cycles of testing and refining solutions, and reflection and production of design principles. In this section we reflect on the entire project and on dissemination of information to the broader educational community. The culmination of this dissertation will be final design principles comprising heuristics that can inform future design of a professional development programme for multidisciplinary science education. 


\subsubsection{Reflection on the analysis of the problem}

In the analysis of the problem phase, the problem is explored intensively. Preparing teachers to implement the new multidisciplinary subject NLT is the focus of this dissertation. Implementing NLT can be seen as a curriculum implementation. As already described, the subject NLT differs from other science subjects in that it is a new subject for which no curriculum or learning goals had yet been designed (Steering committee NLT, 2007). The success of an implementation depends, among other factors, on the quality of the teachers, as they must enact the new curriculum in their classes (Fullan, 2007; Geijsel, Sleegers, Van Den Berg, \& Kelchtermans, 2001). This can be achieved by means of a professional development programme in which teachers are actively involved (Garet, Porter, Desimone, Birman, \& Yoon, 2001; Loucks-Horsley, Love, Stiles, Mundry, \& Hewson, 2003; Penuel et al., 2007). A successful implementation is more likely when a professional development programme is school-based and focuses on teachers' daily school practice (Borko, 2004; Hill \& Cohen, 2005; Waslander, 2007).

In this study, we did not look solely from an academic perspective, but incorporated as well NLT characteristics and school practices. First, the perspectives of eight NLT teachers from different schools who deal with students on a day-to-day basis in classroom settings were used. Second, specific curriculum features of the NLT subject were taken into account, and third, evidence generated by curriculum implementation literature was used.

These three sources allowed us to use triangulation to identify characteristics for such a professional development programme. The result of this identification process was a framework having all of the characteristics that could be distinguished from the classroom setting, categorized into three professionality groups (Hoyle \& John, 1995), restricted professionality, neither restricted nor extended professionality, and extended professionality (Table 2.4). From this framework, five essential characteristics for a professional development programme were selected on the basis that these characteristics were experienced as stimulating by the teachers and were also mentioned in literature as stimulating (Beijaard, Meijer, \& Verloop, 2004; Leliveld, Van Tartwijk, Verloop, \& Bolk, 2008; Van den Akker, 1998). These five essential characteristics were respectively: (a) Teachers should develop their knowledge.

(b) Teachers should cooperate with colleagues. (c) Teachers should network. (d) 
The module should be made relevant and attractive for students. (e) Teachers should be well prepared and organized for their lessons.

A critical comment can be made about the data collection and analysis. A semistructured interview with eight teachers was held. Although the number of teachers was relatively small, the data collection and analysis were complex and time-consuming, and delivered a substantial amount of relevant data. Because each school has a lot of freedom in offering NLT, many different answers were given by the teachers in the semi-structured interviews. This range in the data meant that multiple data transformations (reduction and collapsing of the data) were required, so that the five essential characteristics remaining are at a high level of abstraction. On the one hand too much of the individual characteristics of the specific NLT teachers may have been lost; however, on the other hand, the more abstract essential characteristics for a professional development programme can be used for different multidisciplinary subjects. When incorporating these characteristics into the professional development programme, the structure of the professional development programme can be rigid but it is advisable to keep the content of the professional development programme flexible. This way teachers' individual characteristics can be taken into account in the content of the professional development programme.

The way these five essential characteristics were identified and selected can be generalized to a broader area of professional development programmes for other multidisciplinary science subjects. The three sources used, evidence from literature on effective professional development through curriculum design, domain-specific characteristics of multidisciplinarity, and outcomes of a needs analysis, created a firm basis for identification and selection in our study. One could argue that this approach can be effective for other multidisciplinary science disciplines as well, when decisions need to be made on creating a professional development programme. This approach might be particularly appropriate regarding innovations to be implemented in other science disciplines, and when teachers need to cooperate and the content originates from more than one science subject. An example could be the introduction of context-based education in which two or more science disciplines join up in a specific module. Students acquire essential concepts starting from an authentic context and must inquiry or problem-solving in this particular context. Although, on the one hand the concepts originate from more than one discipline, the adaptation and 
construction of concepts by students inductively progress in an interdisciplinary way, resulting in a higher level of integration. On the other hand, from the teachers' perspectives each having a disciplinary background, less integration is achieved by the deductive approach in supporting students with disciplinary concepts. The context-based approach combines these inductive and deductive teaching approaches, eventually succeeding in acquiring and constructing concepts with an interdisciplinary identity (Gilbert, 2006; Gott \& Duggan, 2007). For instance in the context of the question 'Do plants grow better with chili saltpeter', concepts from chemistry and biology are explored by students. Technical design projects in secondary education - e.g. in the Technasium schools (http://www.technasium.nl/default.aspx) - also apply several disciplines in order to solve a problem in an authentic context. In both examples, the inductive, starting with a problem and progressing by exploration, and deductive, supporting with disciplinary concepts, approaches are integrated.

This combined context-based approach might be generalized to other disciplines as well, e.g. to identifying essential professional development characteristics for an even broader area, for instance, social science. An example could be the 'Discobizz' project (SLO, 2007). In this project, students learn what is involved in starting a nightclub. The students consider the best location for their nightclub and calculate the required investment in real estate. These five essential characteristics will also be important for a professional development programme to prepare teachers for this multidisciplinary project. Several disciplines join up in this entrepreneurship project, and therefore teachers from disciplines such as economy, social sciences, management and organization, and geography will have to cooperate. Teachers must also network with several businesses and organizations outside the school, such as an interior design company, a bank, an advertising firm, a catering enterprise, and the municipality. The module must be made relevant and attractive for students, the teachers must be well prepared for class use, and the teachers should develop relevant knowledge about this project.

From the above described model for context-based education, combing an inductive and deductive approach, it is important to prepare teachers for multidisciplinary education. Most teachers only work together with colleagues from the same subject department (Van Wessum, 1997; Witziers, Sleegers, \& Imants, 1999). To create multidisciplinary education, with the aim of supporting 
interdisciplinary acquisition and construction of concepts, all stakeholders must collaborate together. This cooperation is needed to achieve the objective for which all share responsibility and to show the coherence between the different disciplines to students.

\subsubsection{Reflection on the development of potential solutions phase}

In the development of potential solutions phase, the professional development programme is designed. As a first step, relevant theories, design principles, and existing frameworks are explored in depth to design such a general professional development programme. The second step consists of the development and execution of this programme for specific NLT modules.

There are three important sources for the design of such a programme: multidisciplinary science features including school practices, curriculum design phases, and professional development characteristics (Visser, Coenders, Terlouw, $\&$ Pieters, 2010). These sources were combined with three factors influencing the quality of professional development: context, process, and content (Guskey, 2000). The integration of these sources and factors resulted in a generic model for a professional development programme that prepares and assists teachers during the implementation of a multidisciplinary science module. This model is shown in Figure 6.1. The professional development programme consists of three phases, one before, one during, and one after teaching.

\section{Before teaching phase}

The success of the implementation of a new curriculum depends among other factors on the quality of the teachers. Professional development activities in the Netherlands are normally organized during the school week, not during holidays. The willingness of teachers to engage in professional development activities depends on availability of time, resources, and encouragement from management (Beijaard, Meijer, Morine-Dershimer, \& Tillema, 2005; Fullan, 2007; Hewson, 2007). Professional development is most meaningful when teachers share responsibility for the design and implementation of their own professional development, and when it focuses on class implementation and existing needs (Dunne, 2002; Erickson, Brandes, Mitchell, \& Mitchell, 2005; Lieberman \& Pointer Mace, 2008). This creates a strong sense of ownership (Ogborn, 2002; Van den Akker, 1998; Vermunt, 2006; Wikeley, 2005) and 
encourages active learning by using teachers' own input for their interactions with colleagues (Day, 1999; Garet, Birman, Porter, Desimone, \& Herman, 1999).

Our study did emphasize these elements, and activities were organized in which teachers were actively involved and focused on class implementation and existing needs. In the individual stage, teachers received an e-mail from the coordinator of the professional development programme asking them to look over the module and consider issues such as: (a) What knowledge and skills do I want my students to acquire in this module? (b) What kind of assessment methods and instruments do I intend to use in this module? (c) What questions do I have for the preparation seminar? Looking back at this activity, based on the results of this study teachers were pleased with this activity. The questions prompted the teachers to become acquainted with the module and with key aspects of the module.

Based on the outcome of this study it can be argued that the effectiveness of this individual stage can be improved: teachers should also be asked to consider (a) Will there be differences in my students' prior knowledge? (b) What adjustments would I want to make to the module? (c) What field trips and guest lectures would be meaningful and possible to organize during this module?

The starting point of the collaborative preparation seminar was the teachers' questions from the individual preparation stage. These questions were collected and incorporated in the programme. Teachers were satisfied with this collaborative activity, because it provided them with a good overview of the module, their concerns of the module were addressed, and new ideas acquired. Teachers had more confidence in teaching the module and better understanding of teaching the module than before the seminar. The collaboration with other teachers from other schools was also assessed positively. Previous research has also shown that teachers themselves consider interaction with colleagues to be useful in their own development as professionals (Kwakman, 1999; Lohman, 2005; Meirink, 2007).

As simple as it seems, organizing face-to face meetings is difficult because of time constraints. In the Dutch school culture professional development programmes are organized during the school week, and after lessons. Teachers have a crammed lesson schedule, and as all these schedules are different 
organizing a meeting between teachers from different schools is challenging. For such a professional development programme it is also important that the preparation seminar be just in time. Ideally it should be approximately two weeks before teachers start teaching the module at school, because it focuses on class implementation and existing needs. Therefore it is imperative that teachers at different schools plan to teach the same module at more or less the same period in the school year.

The importance of organizing the preparation seminar at the right time is illustrated by the example of one teacher, Luke. He was going to teach the module nine weeks later in the school year than the other teachers. Because he planned to teach the module much later, Luke was not pressured to do the individual preparation activity adequately; there was no existing need because there still was time to do this later. Compared to the other teachers, Luke learned little (chapter 4).

\section{During teaching phase}

Class enactment is an important part of the professional development programme. It reinforces what teachers learned in the before teaching phase (Coenders, 2010). Designing or redesigning learning materials for a new curriculum and subsequently implementing these in class is very educative for teachers (Coenders, 2010; De Putter-Smits, 2012). According to Dede (2009) support during teaching is complicated but especially helpful when teachers have to implement new teaching approaches in their classes. Time constraints make it complicated to organise face-to-face meetings during teaching, but online support can provide such assistance (Berger, Eylon, \& Bagno, 2008; Owston, Sinclair, \& Wideman, 2006). A simple tool enabling all teachers to participate in online support is e-mail exchange (Berger et al., 2008). However, teachers' heavy daily work load often results in a low rate of participation (Berger et al., 2008; Owston et al., 2006).

To support teachers and to exchange information during teaching, e-mail was used. The participation rate was between $55 \%-100 \%$. This relatively high participation rate can be explained by the active role of the coordinator of the professional development programme. The coordinator took the weekly initiative of sending every participant an e-mail on Friday. Although the participation rate was encouraging, the content of the responded e-mails was 
disappointing. It mainly contained information about what was taught, what students had done in the past week's lessons, and what teachers were planning to do the next week. Three out of the eleven teachers made a total of four requests during the teaching phase. The question arises whether it is really important to support teachers during the implementation of new approaches? This research shows that teachers would rather try to solve their problem internally at their own school first than request assistance from their external network. Asking a school colleague is easier and faster. As NLT is taught by a team of teachers, there are always colleagues within the school who can help out. Most questions teachers have need a quick answer, as classes cannot wait. However, $45 \%$ of the teachers said they found the Friday e-mail useful. Therefore, it is not advisable to omit support during teaching totally. A compromise might be to reduce the e-mail frequency, or to start perhaps an online forum during the teaching phase (Chandrasegaran \& Kong, 2006; Wang \& Yang, 2012).

\section{After teaching phase}

Organizing reflection is seen as a powerful strategy to promote professional development among teachers (Stolk, Bulte, de Jong, \& Pilot, 2009). Joint reflection is an important learning activity (Meirink, 2007), as strengths and weaknesses of the teaching-learning process emerge and are described for future use. Teachers' reflections on their own practices are important for their professional development and facilitate cooperation amongst colleagues (Margalef Garcia \& Pareja Roblin, 2008).

In the reflection meeting for the professional development programme, teachers discussed together the strengths of the module, the weaker points of the module, and useful assessment methods and instruments. Plans for improvements to be made for next year were also suggested and made.

Reflection is something a teacher can do personally, but also collectively. Based on the outcomes of this study, it can be argued that the effectiveness of this reflection meeting can be improved: teachers could first do personal/individual reflection followed by collaborative reflection, just as in the before teaching phase.

Organizing the reflection meeting was not easy. First there was the challenge of finding a date when all teachers could be present. Teachers also lost time in travelling to the agreed meeting place. They wondered whether reflection could not be organized differently? It might be possible to organize it 
differently. For instance, a reflection form could be developed, with questions that teachers first answer alone and then can discuss within their multidisciplinary NLT team at their own school at a time that suits them. They could address topics such as: the module, student prior knowledge, students' learning outcomes, etc..

This kind of refection can provide a collaborative learning opportunity within the multidisciplinary NLT team at school and can create an effective learningor work team. The team uses their expertise to effectively perform as a team to successfully complete a given task. In a work team, learning may occur as a byproduct of collaboration. While in learning teams the goal is to learn while at the same time working on a problem or task (Fransen, Weinberger, \& Kirschner, 2012). A NLT teacher does not teach the same module every year; therefore it is important to reflect with all teachers on the school multidisciplinary team. In this way general expertise about NLT as well as specific expertise about modules will increase within the entire multidisciplinary NLT team.

Reflection on the conditions of the professional development programme.

Different conditions such as the timetable, content of the curricula, individual teacher learning, and domains for professional development programmes will be described below. These conditions are relevant and challenging for making the professional development programme described in this study sustainable.

- It is important for this professional development programme that participating schools teach the same module at a similar period in the school year. Schools differ in the number of lessons per week, and therefore in the number of teaching weeks per module, which can cause asynchronous teaching periods across schools. It is therefore advisable to ask schools about their teaching weeks for the module before organizing the professional development programme.

- It is important that the participating schools align their curricula. NLT teachers have the freedom to select the modules for each examination domain, and can decide on the order in which the modules will be taught.

- As a learning condition for the professional development programme, it is important that the teachers work on team teaching. We noticed that when a module has a strong physics component, a physics teacher will be the responsible teacher or will be a member of the teaching team. When the next module is biology-oriented, a biology teacher will be in charge. A 
professional development programme for the first case will mainly have physics teachers participating, whereas for the second module it will be mainly biology teachers who enter the programme. However, NLT teachers at school must form a multidisciplinary learning team. This facilitates longterm continuous professional development for each of the individual teachers. In a learning team, experiences, knowledge and beliefs can be discussed and exchanged between the teachers. This fosters long-term continued professional development.

- The management must create the necessary conditions for teaching and learning, so that no adverse organizational factors hinder the professional development of the individual teachers and teaching team (Harris, Leithwood, Day, Sammons, \& Hopkins, 2007; Van Veldhuizen, 2011).

- The generic model for a professional development programme can be used in multidisciplinary education domains other than science modules, according to the generally used literature for professional development programmes. Further research should confirm whether this really works.

\subsubsection{Reflection on implementing and evaluation}

In the implementation and evaluation phase, the third phase, the professional development programme to prepare and assist teachers during the implementation of a multidisciplinary science module is put into action and evaluated. This provides further opportunities to refine the professional development programme and to formulate design principles.

There are many empirical studies that have been published about teacher professional development and teacher learning (Coenders, 2010; De PutterSmits, 2012; Hewson, 2007; Putnam \& Borko, 2000). Hewson (2007) argued that insight into teacher professional development can provide valuable information about the programme design.

During this phase, the designed professional development programme was put into action for two specific multidisciplinary NLT modules, called 'The hydrogen car' and 'The brain and learning'. The programmes were subsequently implemented. Small adjustments were made in the professional development programmes between the two modules, because the content of the modules was different. Module I contains difficult practical experiments that needed to be tried out and discussed. Module II had a section with difficult 
biology elements. How to deal with this in the lesson series was discussed in detail during the preparation seminar.

The programme was evaluated using Guskey's (2002) five-level model for evaluating professional development. We evaluated the professional development programme on teachers' satisfaction and its effectiveness in terms of degree of teacher learning, in-class use of what teachers learned, and impact on student achievement. Guskey's model further helps teachers change their practice by evaluation and therefore improvement of professional development, and will have an impact on improving the learning environment for students (Guskey, 2002, 2012). Guskey's evaluation model also proved useful for examining our professional development programme. The participating NLT teachers commented that the professional development activities that were provided for them during the professional development programme were relevant to their needs, provided adequate practice and follow-up for the strategies and ideas introduced, and gave opportunities for feedback. The professional development programme did result in teacher learning in the seven learning areas. Overall, teachers learned in more than half of the learning areas. Teacher learning outcomes showed that the professional development programme was more successful when directly linked to immediate school practice and to teachers' prior knowledge. The professional development programme is suitable for the school context, insofar as the teachers experienced no organizational factors that hindered them during the preparation and teaching of the module.

In the data collection, we used two kinds of responses in order to determine learning. On the one hand, teachers said that they learned something in a learning area (learning reported by the teacher themselves). On the other hand, learning was inferred when teachers indicated that they would do something differently next year. Eight patterns of learning could be distinguished from the results of the nine teachers (see chapter 5). The nine teachers demonstrated two main patterns of learning. The first pattern we expected, that also occurred the most $(47 \%)$ was: Teachers reported having gained ideas during the before teaching phase about one or more of the seven identified learning areas, having used the new knowledge about the learning area in their class during the teaching phase, and also reported in the after teaching phase that they had learned about the learning areas addressed by the entire professional 
development programme. The second pattern that often occurred (22\%) was: Teachers said that they had gained ideas during the before teaching phase about one or more of the identified learning areas, having used the new knowledge about the learning areas in their class during teaching phase, but did not reported in the after teaching phase that they had learned about the learning areas addressed by the entire professional development programme. This was unexpected. However, this appears to be in line with recent findings by Meirink (2007), who found that teachers learn through sequences of activities such as exchanging ideas and experiences with colleagues in combination with experimentation in their own practice, and deliberate evaluation of the experimentation.

Although these teachers reported having gained ideas from different activities in the preparation seminar, and used them in their classes, they did not report any overall learning. These teachers did not have the impression that any learning took place. It is possible that teachers were not aware of the changes they had put into practice. This can be related to 'implicit learning' and 'unintentional learning' (Bolhuis \& Simons, 1999; Eraut, 2004). Implicit learning is generally characterized as learning that proceeds both unintentionally and unconsciously. Unintentional learning is the 'things' we take away from our everyday interactions and experiences. Additionally, the structure and content of the professional development programme prompt the teachers to implicit learning. Therefore, the outcomes are more easy to assess by implicit questions, e.g. by asking what they will do next year, than explicitly, e.g. by asking what they have learned. Our conclusion is that this kind of implicit learning is a major learning mechanism provided by the professional development programme.

\section{Reflection on the five essential characteristics of a professional development programme.}

In the initial phase, analysis of the problem, we concluded that a professional development programme for promoting the implementation of a multidisciplinary science module has five essential characteristics. In the following we will reflect on these five essential characteristics, by relating them to the outcomes of the implementation and evaluation phase of the professional development programme. 


\section{Teachers should develop their knowledge.}

Teachers implementing a new curriculum will go through a process of change. The Concerns-Based Adoption Model (CBAM) by Hall and Loucks (1978) is considered to be a valuable model for describing what individual teachers go through in times of change. The authors described four phases: initiation, adaptation, implementation, and incorporation. The arrangement of these phases shows increasing involvement with the new curriculum. The kinds of questions teachers ask themselves evolve depending on their experiences with the change process. In the initiation and adaptation phases, teachers want to become aware of possible concerns in the implementation process.

As described before, three experts were asked to evaluate the designed and implemented professional development programme. Overall, the experts were positive in their judgment of the model. They were, however, critical about the issue of whether the model offers sufficient possibilities for participants to familiarize themselves with new content knowledge. Although teachers have a Master's degree for one science subject, they might not have sufficient specific content knowledge of the other science subjects in which they are non-specialists. We acknowledge the notion that teachers might lack specific content knowledge of another science discipline. For two reasons, we did not pay specific attention to content knowledge in the professional development programme. One reason was that teachers at the schools had already solved this issue by themselves. A module such as 'The brain and learning' is biology oriented, and biology teachers were mainly teaching this module in schools or the teaching team included a biology teacher. The more minor chemistry and psychology knowledge in the module can be discussed in the multidisciplinary team at school. The other reason was that teachers themselves did not find acquiring content knowledge urgent at this stage of the implementation. During the preparation seminar, teachers' questions were collected by the coordinator to incorporate in the seminar programme. The questions that were collected regarded self- and task concerns. For instance: 'I would like to receive an overview of the whole module, and the ins and outs about the experiments in the module'. This is a question in the adoption phase as described in the CBAM model of Hall and Loucks (1978). In their evaluations, teachers also indicated that their priority is on self- and task concerns and not on the content knowledge. 
Based on this study, the first essential characteristic 'teachers should develop their knowledge' can be restricted for this context. When the professional development programme promotes the implementation of a new multidisciplinary module the teachers should develop their knowledge related to the self- and task concerns of the new multidisciplinary module.

2. Teachers should cooperate with colleagues.

It is widely acknowledged that collaboration between professionals can be an important and effective strategy for teacher learning (Borko, 2004; Desimone, 2002; Meirink, Imants, Meijer, \& Verloop, 2010; Penuel et al., 2007; Van Driel, Beijaard, \& Verloop, 2001). Collaboration with colleagues with different subjectmatter backgrounds provides more motivation and introduces teachers to a broader variety of ideas and teaching methods than collaboration with colleagues with similar subject matter background (Leliveld et al., 2008; Meirink, 2007). The impact of collaboration with colleagues depends on the way the individual teacher interacts with the other teachers (Rice, Croninger, \& Roellke, 2002) and on the active involvement of teachers in the design and implementation of lessons or modules (Voogt, Fisser, Pareja Roblin, Tondeur, \& van Braak, 2012).

In our study three kinds of collaboration occurred: collaboration with colleagues from different schools, collaboration with teachers from their own multidisciplinary NLT team, and teaching teams at school (two teachers teaching one module). Grouping in teaching teams occurred three times: two teaching teams during the first module and one teaching team during the second module.

The collaboration in the professional development programme with colleagues from other schools consisted of discussion, exchange of practices, ideas, experiences and materials, and giving practical feedback. All participating teachers assessed the collaboration with colleagues from the other schools as positive. Teachers also supported and stimulated one another.

This research showed that teachers first tried to solve problems arising during teaching with colleagues from their own multidisciplinary NLT team, instead of colleagues from other schools. Asking a school colleague is easier and faster. 
Teachers in the multidisciplinary NLT team can discuss content knowledge, teaching methods, and share external contacts.

From the learning results of chapter 5, we could conclude that there is no learning difference between teachers in a teaching team (two teachers teaching one module) and individual teachers teaching a module in the professional development programme. This learning effect can be explained by the active involvement of teachers in the design and implementation of lessons or modules (Voogt et al., 2012). The advantages of teaching teams are: there are two experts from different mono-disciplines for one NLT module. These two teachers know all the ins and outs of their own mono-discipline. It saves a teacher the time that would be necessary for the acquisition of the content knowledge for the other mono-discipline. In addition, tasks can be distributed, such as creating assessment instruments and correction work. Teachers also learn from observing the other teacher teaching; it creates new ideas and insights about such aspects as, for instance, teaching methods. It also shows students better connections between different subjects.

Based on this study, the second essential characteristic 'teachers should cooperate with colleagues' seems important. From the findings, it appears that some extra attention could be paid to improving the multidisciplinary approach of the NLT school team through collaboration. Regular consultations strengthen the relations among the various teachers. A professional development programme should create a good learning- and work environment, where learning will be exchanged among teachers.

3. Teachers should network.

Participation in a network with stakeholders having different backgrounds, such as we had in our network, is stimulating (Lumpe, 2007; Stolk et al., 2009). The exchange of new knowledge can be positively influenced by five main conditions (Dawson, 1995; Onderwijsraad, 2005; Van Rooijen, Kalders, \& Van den Hout, 2004): (a) a common goal, (b) stakeholders with different backgrounds, (c) personal contact, (d) participants who want to achieve something, and (e) a coordinator. 
The result of the professional development programme was an organized network, with a more or less formalized structure in which teachers from four different schools participated together with an expert on the module, a representative from the regional NLT Information Centre, and the school technicians. The teachers met before and after the module was taught, and discussed and supported each other during the teaching of the module.

As already noted, in this research we found that the teachers first tried to solve their problem internally at their own school rather than requesting assistance from the external network. Asking a colleague from one's own school is much quicker than asking a colleague in the external network. Most questions teachers had needed a quick answer, as classes could not wait.

Based on this study, the third essential characteristic 'teachers should network' is important but is more necessary at a later stage. In the beginning, teachers should ensure that their internal multidisciplinary school team is developed. No specific attention was paid in the professional development programme to the cooperation of the multidisciplinary NLT team. However, this is something that needs attention. The external network is more useful for organizing guest lectures and field trips, and to exchange and obtain additional materials. Therefore contacts with other schools, universities and companies should be maintained through the network for this later purpose. Contacts beyond school enable students to become familiar with a wide range of higher education options and professions. Therefore, a professional development programme of this type must promote the extended professionality of the teacher.

4. The module should be made relevant and attractive for students.

Studies show that school field trips can have lasting impact on students, associated with strong memories of both cognitive and sociocultural contexts (Dierking \& Falk, 2006; Rebar, 2010). From the findings we can see that only two of the nine teachers responded that they did something extra to motivate students for the module (Table 5.6). It is possible that the other teachers did make the module more relevant and attractive for their students, but did not indicate this as 'extra to motivate students'. We noticed such a possible discrepancy in two teaching teams: Sophie and Jack both answered that they did something extra to motivate students, but their co-teachers Max and Daniel 
answered that they did not do something extra to motivate the students. All teachers made adjustments to the module, but whether this was done to motivate students is unclear. Some teachers organized a field trip or guest lecture, an addition that makes the module more relevant and for some students more motivating.

Teachers indicated that they saw the usefulness of field trips and guest lectures, but organizing these turned out to be difficult. Finding a good opportunity related to the content of the module and located not too far from the school proved hard and time-consuming. It is advisable to attend to this element in the professional development programme, because it not only can motivate students, but one of the NLT goals is to enable students to become familiar with a wide range of higher education studies and professions. Locating companies and universities and maintaining relations with these could be an activity for the external network. The school management play an important role in this; lessons with other teachers sometimes must be changed or canceled and field trips must be facilitated.

Based on this study, the fourth essential characteristic 'the module should be made relevant and attractive for students', deserves even more attention in the professional development programme. In particular, the organization of suitable field trips and guest lectures needs support.

5. Teachers should be well prepared and organized for their lessons.

The findings of chapter 3 showed that the teachers were well prepared for their lessons. The collaborative preparation seminar from the professional development programme played an important role. The seminar was motivating, effective, and gave a good overview of the entire module. All teachers said that they had a better understanding of teaching the module after the seminar than they did before. All but one teacher had more confidence in teaching the module after the preparation seminar, because of having more background knowledge and a better overview of the module, and they gained many ideas for teaching the module.

The preparation by the seminar and preparation in general increases professional growth and subsequent quality of the teacher. From research we 
know that the quality of education is largely determined by the quality of the teacher (Akiba, LeTendre, \& Scribner, 2007; Hattie, 2003). The quality is also expressed by the cognitive flexibility of teachers to respond to specific circumstances: the characteristics of their students, the resources they have available, etcetera. Teachers also taking into account their personal teaching style. Because the NLT examination programme leaves teachers and schools a lot of freedom, and because NLT has a modular structure, NLT teachers can define their own emphases and express their growth and quality even more. The flexible curriculum and the freedom to adapt the lessons is a major opportunity for further professional growth of teachers. Mitchell and Mitchell (2005) showed that the opposite, a rigid curriculum and common assessment structures, are inhibitors of professional growth. One may argue that through the multidisciplinary composition of the team results in even more growth.

Based on this study, the fifth essential characteristic 'teachers should be well prepared and organized for their lessons', must be maintained, because teachers who are prepared have a better understanding of teaching the module and teachers who are well prepared have more confidence in their teaching.

\subsubsection{Reflection in order to formulate design principles}

Once the professional development programme has been implemented and evaluated, additional design principles can be formulated from the research output in order to inform future developers about implementation decisions of such a professional development programme. A design principle consists of a strategy based on arguments, leading to an intended effect (Hofstein \& Kesner, 2006; McKenney, Nieveen, \& Van den Akker, 2006). The term 'strategy' refers in our study to a process and/or a sequence in which stages and activities in a designed professional development programme are planned and executed. A 'principle' contains underlying arguments (theory for effective professional development and evidence-based practical experiences) that relate the chosen strategy, containing one or more strategy components, to the intended pedagogical effects. Design principles have a heuristic nature (McKenney et al., 2006; Pintrich, 2003) with limited validity, as they are embedded within a certain educational situation: students, teachers, chosen contexts, etc.. While the format varies, design principles generally offer the kinds of heuristic guidelines described by Van den Akker (1999): 
If you want to design intervention $\mathrm{X}$ [for purpose/function $\mathrm{Y}$ in context $\mathrm{Z}$ ]; then you are best advised to give that intervention the characteristics $C 1, C 2$, ..., Cn [substantive emphasis]; and do that via procedures P1, P2, .., Pn [procedural emphasis]; because of theoretical arguments T1, T2, ... Tn; and empirical arguments E1, E2, ... En. (p.9)

Such design principles can be used as heuristic guidelines for the instructional designer (Gravemeijer \& Cobb, 2006).

We have formulated design principles about the general structure and the different stages (Figure 6.1, numbers 1 till 4) of the professional development programme, with theoretical analysis as underpinning and empirical results as arguments.

Professional development programmes are most relevant and successful when they focus on teachers' school practices and existing needs (Cotton, 2006; Erickson et al., 2005; Lieberman \& Pointer Mace, 2008). It would be helpful to organize such a professional development programme when teachers at different schools plan to teach the same module at more or less the same period in the school year. This facilitates exchange of experiences as teachers encounter similar issues at the same time. In this research, the teachers participating in the first professional development programme for module I all taught the module at more or less the same period. For module II, the different number of lessons per week and the consequent different number of teaching weeks per module caused asynchronous teaching periods across participating schools. Therefore the teachers participating in the second professional development programme were not always dealing with similar issues at the same time, which the teachers found to be unhelpful.

This combination of theory and results yields design principle 1:

If you want to design a specific programme to prepare and assist teachers for a multidisciplinary (science) module and to have teachers learn in the seven learning fields based on a generic model for a professional development programme (Figure 6.1); then you are best advised to focus on immediate school practice and existing needs by aligning the curricula of the participating schools or only let schools participate who do have aligned their curricula, because this will enable a successful and relevant professional development programme. 
Professional development is effective when it is connected to everyday school practice and to teachers' prior knowledge, belief, and skills, and when teachers feel ownership of the professional development activities (Davis, 2003). Therefore, in the individual preparation stage, stage 1, teachers must look over the module and consider specific relevant aspects (Ogborn, 2002; Wikeley, 2005) The results of the individual preparation will facilitate a meaningful preparation seminar. One teacher participating in the professional development programme for module II fell short in preparation because his asynchronous teaching period gave him a later time deadline. For this teacher the programme was not connected to everyday school practice, as he would start teaching the module nine weeks later.

This yields design principle 2:

If you want to design a specific programme to prepare and assist teachers for a multidisciplinary (science) module, and have teachers learn in the seven learning fields based on a generic model for a professional development programme (Figure 6.1); then ask teachers to look over the module and note potential difficult issues; do this during the individual preparation in the before teaching phase, because this will connect the programme to teacher knowledge and beliefs and to school practices, and is a partial step to creating ownership.

Professional development is most relevant when it focuses on classroom implementation and existing needs (Dunne, 2002; Erickson et al., 2005; Lieberman \& Pointer Mace, 2008) by using teachers' own input for their interactions with colleagues. This creates a strong sense of ownership (Ogborn, 2002; Van den Akker, 1998; Vermunt, 2006; Wikeley, 2005) and encourages active learning (Day, 1999; Garet et al., 1999). Therefore, it is advisable in the preparation seminar, stage 2 , to adjust to teachers' own concerns about the module and to the diversity of behaviors and belief of the participating teachers. The findings of this research show that focusing on teachers' existing needs is considered relevant. The incorporation of teachers' own input also encourages active learning.

This results in design principle 3:

If you want to design a specific programme to prepare and assist teachers for a multidisciplinary (science) module and have teachers learn in the seven learning fields based on a generic model for a professional development programme (Figure 6.1); then list and organize teachers' questions and incorporate them in the preparation seminar in the before teaching phase 
around two weeks before teaching the module, because this will address teachers' concerns directly and involve them actively in the programme.

Teachers need support during the teaching phase, especially when they have to implement new approaches in their classes (Dede et al., 2009). Owsten (2006) suggests that short weekly postings of teachers' reflections may stimulate others to participate in the exchange such as ideas and experiences. In the during teaching phase, stage 3 , weekly online support was organized by sending a Friday e-mail to teachers. Teachers could ask questions for issues they came across in class, exchange tips, and materials. They could also give support to each other and had access to resources in this way they created confidence. But the content of the teachers' responses to the Friday e-mail was disappointing. This research shows that teachers first try to solve their problem internally at their own school rather than requesting assistance from the external network. However, $45 \%$ of the participating teachers rated the Friday e-mail as useful.

Because from the content perspective no satisfactory outcomes were reached, we cannot formulate a design principle for this during teaching phase. We suggest reducing the frequency of the support during teaching and making it voluntary, for example by having an online forum available during the teaching phase.

Joint reflection is an important learning activity (Meirink, 2007), as strengths and weaknesses of the teaching-learning process emerge and can be described for future use. Teachers' reflection about their own practice is important for their professional development and facilitates cooperation among colleagues (Margalef Garcia \& Pareja Roblin, 2008). Our research shows that the reflection meeting, stage 4, provides teachers with information from other colleagues about students' experiences, adjustments that could be made to the module in order to improve it, and other ideas for improvements for the next year. It also shows that extra attention should be paid to improving the multidisciplinary NLT school team.

This results in design principle 4 :

If you want to design a specific programme to prepare and assist teachers for a multidisciplinary (science) module and have teachers learn in the seven learning fields based on a generic model for a professional development programme (Figure 6.1); then organize joint reflection, preferably at the school level with the NLT teaching teams, and do this in the after teaching phase, when the module has been used in class and students have been assessed; this 
will solicit a broader variety of ideas for improvements for the next year and facilitates exchange of experiences among all NLT teachers at the school.

The mentioned design principles are formulated in order to improve the practices of professional development programme designers. The presented design principles offer a worthwhile contribution to the field of professional development in multidisciplinary science education, because they can help professional development designers in their own setting (McKenney et al., 2006).

Design-based research proved to be a suitable approach for this research in this multidisciplinary context. The generally-designed model for the professional development programme was successfully applied for two specific NLT modules. From the initial stages to the end, it empowered the participating teachers to take responsibility and ownership for the professional development programme and for their own learning about the implementation of the NLT module. Participating teachers judged the programme and its impact to be positive in practice in relation to their own teaching of the module.

\subsection{RECOMMENDATIONS FOR FURTHER RESEARCH}

We would like to suggest the following directions for further research:

- Further research should focus on the sustainability of the effectiveness of the professional development programme. Are teachers able to apply what they learned to another module? Is the professional growth of the teachers visible when they teach other NLT modules? In other words does transfer of knowledge automatically occur or are further interventions necessary for this? (Bransford, Brown, \& Cocking, 2000)

- Further research should seek to refine our understanding of the opportunities and challenges involved in scaling up the professional development programme. What is the effectiveness of the essential characteristics on a larger scale? To investigate this, it will be necessary for schools to align their curricula, or developers must determine which schools are teaching the same curricula in the same period of time and solicit their participation.

- Also, further research should investigate whether the empirically supported design principles are useful for designing other professional development programmes within multidisciplinary education. According to Plomp (2009), 
the heuristic design principles will prove to be additionally powerful when they have been validated in the successful design of other similar interventions in various contexts. Yin (2003) argues that generalization is not automatic. Design principles must be tested through replications of the findings in a second, third or even more cases in various contexts, to see if the same results occur. Once such replications have been made, the results could be generalizable to a much larger number of similar contexts.

- This study shows that learning and work teams can assist teachers to professionalize. Further research should investigate the characteristics of learning and work teams in collaborative learning practices in multidisciplinary education to establish which variables mediate learning team effectiveness in what way. 


\section{REFERENCES}

Anderson, T., \& Shattuck, J. (2012). Design-based research: A decade of progress in education research? Educational Researcher, 41(1), 16-25. doi: 10.3102/0013189X11428813

Andrews, D., \& Lewis, M. (2002). The experience of a professional community: Teachers developing a new image of themselves and their workplace. Educational Research, 44(3), 237-254.

Avalos, B. (2011). Teacher professional development in Teaching and Teacher Education over ten years. Teaching and Teacher Education, 27(1), 10-20. doi: 10.1016/j.tate.2010.08.007

Ball, D. L., \& Cohen, D. K. (1996). Reform by the book: What is or might be the role of curriculum materials in teacher learning and instructional reform? Educational Researcher, 25(9), 6-14.

Beijaard, D., Meijer, P. C., Morine-Dershimer, G., \& Tillema, H. (2005). Teacher professional development in changing conditions. Dordrecht: Springer.

Beijaard, D., Meijer, P. C., \& Verloop, N. (2004). Reconsidering research on teachers' professional identity. Teaching and Teacher Education, 20(2), 107-128. doi: 10.1016/j.tate.2003.07.001

Bell, B., \& Gilbert, J. (1996). Teacher development: A model from science education. London: Falmer Press.

Bergen, T., \& Van Veen, K. (2004). Het leren van leraren in een context van onderwijsvernieuwingen: Waarom is het zo moeilijk? [Teachers' learning in a context of educational reforms: Why is it so difficult?]. VELON: Tijdschrift voor lerarenopleiders, 25(4), 29-39.

Berger, H., Eylon, B., \& Bagno, E. (2008). Professional development of physics teachers in evidence based blended learning program. Journal Science Education and Technology, 17(4), 399-409. doi: 10.1007/s10956-008-9109-3

Black, P., \& Atkin, J. M. (1996). Changing the subject. Innovations in science, mathematics and technology education. London: Routledge.

Boersma, K., Eijkelhof, H., van Koten, G., Siersma, D., \& van Weert, C. (2006). De relatie tussen context en concept [The relationship between context and concept]. Retrieved 25 May, 2012 from http://www.betanova.nl/downloads/context/relatie_context_concept.pdf/

Bolhuis, S. M., \& Simons, P. R. (1999). Leren en werken [Learning and working]. Deventer: Kuwer.

Borko, H. (2004). Professional development and teacher learning: Mapping the terrain. Educational Researcher, 33(8), 3-15. 
Borko, H., Jacobs, J., \& Koellner, K. (2010). Contemporary approaches to teacher professional development. In P. Peterson, E. Baker, \& B. McGaw (Eds.), International Encyclopedia of Education (Vol. 3, pp. 548-555). Oxford: Elsevier Scientific Publishers.

Borrego, M., \& Newswander, L. K. (2008). Characteristics of succesful cross-disciplinary engineering education collaborations. Journal of Engineering Education, 97(1), 123-134.

Bulte, A., Westbroek, H., Jong, O. de , \& Pilot, A. (2006). A research approach to designing chemistry education using authentic practices as contexts. International Journal of Science Education, 28(9), 1063-1086.

Bransford, J. D., Brown, A. L., \& Cocking, R. R. (2000). How people learn: Brain, mind, experience, and school. Wachington: National Academy Press.

Burton, W., Holman, J., Lazonby, J., Pilling, G., \& Waddington, D. (2000). Salters advanced chemistry (2nd ed.). Oxford, UK: Heineman.

Campbell, C., \& Henning, M. B. (2010). Planning, teaching, and assessing elementary education interdisciplinary curriculum. International Journal of Teaching and Learning in Higher Education, 22(2), 179-186.

Caprara, G. V., Barbaranelli, C., Steca, P., \& Malone, P. S. (2006). Teachers' self-efficacy beliefs as determinants of job satisfaction and students' academic achievement. Journal of School Psychology, 44(6), 473-490.

Chandrasegaran, A., \& Kong, K. M. C. (2006). Stance-taking and stance-support in students' online forum discussion. Linguistics and Education, 17(4), 374-390. doi: 10.1016/j.linged.2007.01.003

Clarke, D., \& Hollingsworth, H. (2002). Elaborating a model of teacher professional growth. Teaching and Teacher Education, 18(8), 947-967.

Clement, M., \& Vandenberghe, R. (2000). Teachers' professional development: A solitary or collegial (ad)venture? Teaching and Teacher Education, 16(1), 81-101. doi: 10.1016/S0742051X(99)00051-7

Coenders, F. G. M. (2010). Teachers' professional growth during the development and class enactment of context-based chemistry student learning material. Doctoral dissertation: University of Twente, The Netherlands.

Coenders, F. G. M., Terlouw, C., \& Dijkstra, S. (2008). Assessing teachers' beliefs to facilitate the transition to a new chemistry curriculum: What do the teachers want? Journal of Science Teacher Education, 19(4), 317-335. doi: 10.1007/s10972-008-9096-5

Conceição, S., Sherry, L., \& Gibson, D. (2004). Using developmental research to design, develop and evaluate an urban education portal. Journal of Interactive Learning Research, 15(3), 271-286.

Cotton, D. R. E. (2006). Implementing curriculum guidance on environmental education: The importance of teachers' beliefs. Journal of Curriculum Studies, 38(1), 67-83. doi: 10.1080/00220270500038644

Davis, K. S. (2003). "Change is hard": What science teachers are telling us about reform and teacher learning of innovative practices. Science Education, 87(1), 3-30.

Dawson, S. (1995). Organisaties analyseren. Schoonhoven: Academic Service.

Day, C. (1999). Developing teachers: The challenges of lifelong learning. London: Falmer Press.

De Putter-Smits, L. (2012). Science teachers designing context-based curriculum materials: Developming context-based teaching competence. Doctoral dissertation: University of Eindhoven, The Netherlands. 
Dede, C., Ketelhut, D. J., Whitehouse, P., Breit, L., \& McCloskey, E. M. (2009). A research agenda for online teacher professional development. Journal of Teacher Education, 60(1), 8-19. doi: $10.1177 / 0022487108327554$

Desimone, L. (2002). How can comprehensive school reform models be successfully implemented? Review of Educational Research, 72(3), 433-480.

Desimone, L. M. (2009). Improving impact studies of teachers' professional development: Toward better conceptualizations and measures. Educational Researcher, 38(3), 181-199. doi: 10.3102/0013189X08331140

Dezure, D. (2003). Curriculum - Higher education. Innovations in the undergraduate curriculum. In J. W. Guthrie (Ed.), Encyclopedia of Education (2nd ed., Vol. 2, pp. 509513). New York: MacMillan.

Dierking, L. D., \& Falk, J. H. (2006). An examination of fieldtrip strategies and their implementation within a natural history museum. Science Education, 90(3), 434-452. doi: $10.1002 /$ sce. 20117

Duffee, L., \& Aikenhead, G. (1992). Curriculum change, student evaluation, and teacher practical knowledge. Science Education, 76(5), 493-506. doi: 10.1002/sce.3730760504

Dunne, K. A. (2002). Teachers as learners: Elements of effective professional development. 67-77. Retrieved from

http://www.pearsonassessments.com/hai/images/NES_Publications/2002_08Dunne 475_1.pdf

Eijkelhof, H., \& Kruger, J. (2009, August). Improving the quality of innovative science teaching materials. Paper presented at the ESERA Conference, Istanbul.

Eraut, M. (2004). Informal learning in the workplace. Studies in Continuing Education, 26(2), 247-273. doi: 10.1080/158037042000225245

Erickson, G., Brandes, G. M., Mitchell, I., \& Mitchell, J. (2005). Collaborative teacher learning: Findings from two professional development projects. Teaching and Teacher Education, 21(7), 787-798. doi: 10.1016/j.tate.2005.05.018

European Commision. (2000). Lisbon strategy for growth. Retrieved from http://ec.europa.eu/archives/growthandjobs_2009/

Fishman, B. J., Marx, R. W., Best, S., \& Tal, R. (2003). Linking teacher and student learning to improve professional development in systemic reform. Teaching and Teacher Education, 19(6), 643-658.

Folmer, E., Ottevanger, W., Bruning, L., \& Kuiper, W. (2011). Curriculumevaluatie bètaonderwijs tweede fase: Ontwikkeling en invoering NLT 2007-2010 [Curriculum evaluation science education second phase: Development and inplementation NLT 2007-2010]. Enschede: SLO (nationaal expertisecentrum leerplanontwikkeling).

Fransen, J., Weinberger, A., \& Kirschner, P. (2012). Team effectiviness and team development in computer-supported collaborative learning. Educational Psychologist.

Fullan, M. (2007). The new meaning of educational change ( $4^{\text {th }}$ ed.). New York: Teachers College Press.

Garet, M. S., Birman, B. F., Porter, A. C., Desimone, L., \& Herman, R. (1999). Designing effective professional development: Lessons from the Eisenhower program. American Institutes for Research, 12(1), 23-40.

Garet, M. S., Porter, A. C., Desimone, L., Birman, B. F., \& Yoon, K. S. (2001). What makes professional development effective? Results from a national sample of teachers. American Educational Research Journal, 38(4), 915-945. 
Geijsel, F. P., Sleegers, P., Van den Berg, R., \& Kelchtermans, G. (2001). Conditions fostering the implementation of large-scale innovation programs in schools: Teachers' perspectives. Educational Administration Quarterly, 37(1), 130-166.

Geijsel, F. P., \& Meijers, F. (2005). Identity learning: The core process of educational change. Educational Studies, 31(4), 419-430.

Gilbert, J. K. (2006). On the nature of "context" in chemical education. International Journal of Science Education, 28(9), 957-976. doi: 10.1080/09500690600702470

Goedhart, M. (2004). Contexten en concepten: Een nadere analyse [Contexts and concepts: A further analysis]. NVOX, 29(4), 186-190.

Gott, R., \& Duggan, S. (2007). A framework for practical work in science and scientific literacy through argumentation. Research in Science \& Technological Education, 25(3), 271-291. doi: 10.1080/02635140701535000

Gravemeijer, K., \& Cobb, P. (2006). Design research from a learning design perspective. In J. J. H. van den Akker, K. Gravemeijer, S. McKenney \& N. Nieveen (Eds.), Educational design research (pp. 17-52). London: Routledge.

Grossman, P., Wineburg, S., \& Woolworth, S. (2001). Toward a theory of teacher community. Teachers College Record, 103(6), 942-1012.

Gurlitt, J., \& Renkl, A. (2010). Prior knowledge activation: How different concept mapping tasks lead to substantial differences in cognitive processes, learning outcomes, and perceived self-efficacy Instructional Science, 38(4), 417-434.

Guskey, T. R. (2000). Evaluating professional development. Thousand Oaks: Corwin Press.

Guskey, T. R. (2002). Does it make a difference? Evaluating professional development. Educational Leadership, 59(6), 45-51.

Guskey, T. R. (2012, March). Evaluating professional development. Paper presented at the Association for Supervision and Curriculum Development (ASCD), A collective call to action, Philadelphia.

Hall, G. E., \& Loucks, S. (1978). Teacher concerns as a basis for facilitating and personalizing staff-development. Teachers College Record, 80(1), 36-53.

Hammerness, K., Darling-Hammond, L., \& Bransford, J. (2005). How teachers learn and develop. In L. Darling-Hammond, \& J. Bransford (Eds.), Preparing teachers for a changing world. What teachers should learn and be able to do (pp. 358-390). San Francisco: Jossye-Bass.

Hargreaves, D. H. (1994). The new professionalism: The synthesis of professional and institutional development. Teaching and Teacher Education, 10(4), 423-438.

Harris, A., Leithwood, K., Day, C., Sammons, P., \& Hopkins, D. (2007). Distributedleadership and organizational change: Reviewing the evidence. Journal of Educational Change, 8(4), 337-347. doi: 10.1007/s10833-007-9048-4

Hattie, J. (2003, October). Teachers make a difference: What is the research evidence? Paper presented at the Australian Council for Educational Research Annual on Building teacher quility, Melbourne.

Henze, I. (2006). Science teachers' knowledge development in the context of educational innovation. Doctoral dissertation: Univeriteit Leiden, The Netherlands.

Herrington, J., Reeves, T. C., \& Oliver, R. (2010). A guide to authentic e-learning. New York: Routledge. 
Heus de, P., van der Leeden, R., \& Ganzendam, B. (1995). Toegepaste data-analyse: Technieken voor niet-experimenteel onderzoek in de sociale wetenschappen [Applied data-analysis. Methods for non-experimental research in social sciences]. Utrecht: Lemma.

Hewson, P. (2007). Teacher professional development in science. In S. K. Abell, \& N. G. Lederman (Eds.), Handbook of research on science education (pp. 1179-1203). Mahwah: Lawrence Erlbaum.

Hill, H., \& Cohen, D. K. (2005). Teaching teachers: Professional development to improve student achievement. Research Points, 3(1), 1-4.

Hoekstra, A., Brekelmans, M., Beijaard, D., \& Korthagen, F. (2009). Experienced teachers' informal learning: Learning activities and changes in behavior and cognition. Teaching and Teacher Education, 25(5), 663-673. doi: 10.1016/j.tate.2008.12.007

Hofstein, A., \& Kesner, M. (2006). Industrial chemistry and school chemistry: Making chemistry studies more relevant. International Journal of Science Education, 28(9), 10171039.

Hoyle, E., \& John, P. D. (1995). Professional knowledge and professional practice. London: Cassell.

Hunzicker, J. (2011). Effective professional development for teachers: A checklist. Professional Development in Education, 37(2), 177-179. doi: 10.1080/19415257.2010.523955

Jeanpierre, B., Oberhauser, K., \& Freeman, C. (2005). Characteristics of professional development that effect change in secondary science teachers' classroom practices. Journal of Research in Science Teaching, 42(6), 668-690.

Jones, C., Asensio, M., \& Goodyear, P. (2000). Networked learning in higher education: Practitioners' perspectives. The Association for Learning Technology Journal, 8(2), 18-28.

Keys, C. W., \& Bryan, L. A. (2001). Co-constructing inquiry-based science with teachers: Essential research for lasting reform. Journal of Research in Science Teaching, 38(6), 631645. doi: 10.1002/ tea.1023

Kezar, A. (2012). The path to pedagogical reform in the sciences: Engaging mutual adaptation and social movement models of change. Liberal Education, 98(1). Retrieved from http:// www.aacu.org/liberaleducation/le-wi12/kezar.cfm

Kwakman, K. (1999). Leren van docenten tijdens de beroepsloopbaan. Studies naar de professionaliteit op de werkplek in het voortgezet onderwijs. Doctoral dissertation: Katholieke Universiteit Nijmegen, The Netherlands.

Kwakman, K. (2003). Factors affecting teachers' participation in professional learning activities. Teaching and Teacher Education, 19(2), 149-170.

Leliveld, M. J., Van Tartwijk, J., Verloop, N., \& Bolk, J. (2008, June). Characteristics of effective professional development: A research in the medical faculty. Paper presented at the Onderwijs Research Dagen "Licht op Leren", Eindhoven.

Lepper, M. R., Corpus, J. H., \& Iyengar, S. S. (2005). Intrinsic and extrinsic motivational orientations in the classroom: Age differences and academic correlates. Journal of Educational Psychology, 97(2), 184-196.

Lieberman, A. (1995). Practices that support teacher development - transforming conceptions of professional learning. Phi Delta Kappan, 76(8), 591-596.

Lieberman, A., \& Pointer Mace, D. H. (2008). Teacher learning: The key to educational reform. Journal of Teacher Education, 59(3), 226-234 doi: 10.1177/0022487108317020 
Lieberman, A., \& Pointer Mace, D. H. (2010). Making practice public: Teacher learning in the 21st century. Journal of Teacher Education, 61(1-2), 77-88. doi: $10.1177 / 0022487109347319$

Little, J. W. (2003). Inside teacher community: Representations of classroom practice. Teachers College record, 105(6), 913-945.

Lohman, M. C. (2005). A survey of factors influencing the engagement of two professional groups ininformal workplace learning activities. Human Resource Development Quarterly, 16(4), 501-527. doi: 10.1002/hrdq.1153

Lotan, R. A., \& Navarrete, C. (1986, April). The process of mutual adaptation: A study of an innovative program. Paper presented at the The annual meeting of the American Educational Reseach Association, San Fransisco.

Loucks-Horsley, S., Love, N., Stiles, K. E., Mundry, S., \& Hewson, P. W. (2003). Designing professional development for teachers of science and mathematics (2nd ed.). California: Corwin Press.

Lowden, C. S. (2005). Evaluating the impact of professional development. The Journal of Research in Professional Learning. Retrieved from http://institute.nsta.org/learningcenter/pdp/NSDC_Evaluating_Impact_PD.pdf

Luft, J. A. (2001). Changing inquiry practices and beliefs: The impact of an inquiry-based professional development programme on beginning and experienced secondary science teachers. International Journal of Science Education, 23(5), 517-534.

Lumpe, A. T. (2007). Research-based professional development: Teachers engaged in professional learning communities. Journal of Science Teacher Education, 18(1), 125-128.

Margalef Garcia, L., \& Pareja Roblin, N. (2008). Innovation, research and professional development in higher education: Learning from our own expertise. Teaching and Teacher Education, 24(1), 104-116. doi: 10.1016/j.tate.2007.03.007

Marsh, C. J., \& Willis, G. (2003). Curriculum, alternative approaches, ongoing issues. Upper Saddle River, NJ: Pearson Education.

McKenney, S., \& Reeves, T. C. (2012). Conducting educational design research. London: Routledge.

McLaughlin, M. W. (1976). Implementation as mutual adaptation: Change in classroom organization. Teacher College Record, 77(3), 339-351.

Meirink, J. A. (2007). Individual teacher learning in a context of collaboration in teams. Doctoral dissertation: University of Leiden, The Netherlands.

Meirink, J. A., Imants, J. G. M., Meijer, P., \& Verloop, N. (2010). Teacher learning and collaboration in interdisciplinary teams. Cambridge Journal of Education, 40(2), 161-181.

Mitchell, I., \& Mitchell, J. (2005). What do we mean by career-long professional growth and how can we get it? In D. Beijaard, P. C. Meijer, G. Morine-Dershimer, \& H. Tillema (Eds.), Teacher professional development in changing conditions (pp. 291-307). Dordrecht: Springer.

National Research Council. (2012). A framework for K-12 science education: Practices, crosscutting concepts, and core ideas. Washington DC: The National Academies Press.

Newswander, L. K., \& Borrego, M. (2009). Engagement in two interdisciplinary graduate programs. Higher Education, 58(4), 551-562. doi: 10.1007/s10734-009-9215-z

Nieveen, N. (2009). Formative evaluation in educational design rerearch. In T. Plomp \& N. Nieveen (Eds.), An introduction to educational design rereach. Shanghai: Retrieved 15 May, 2012 from www.slo.nl/organisatie/international/publications. 
Oers van, B. (1998). From context to contextualising. In E. Forman, \& B. van Oers (Eds.), Mathematics learning in sociocultural contexts. Special issue of Learning and Instruction (Vol. 8, pp. 473-488).

Onderwijsraad. (2005). Bijdragen van onderwijs aan het Nederlnds innovatiesysteem [Contributions of education to the Dutch innovationsystem]. Retrieved 15 May, 2012 from http://onderwijsraad.nl/publicaties/2005/item344.

Ogborn, J. (2002). Ownership and transformation: Teachers using curriculum innovations. Physics Education, 37(2), 142-146.

Oha, E., \& Reeves, T. C. (2010). The implications of the differences between design research and instructional systems design for educational technology researchers and practitioners. Educational Media International, 4(47), 263-275. doi: 10.1080/09523987.2010.535326

Oliver, R. L. (2006). Customer satisfaction research. In R. Grover, \& M. Vriens (Eds.), The handbook of marketing research: Uses, misuses, and future advances (pp. 569-587). Thousand Oaks: SAGE Publications.

Owston, R. D., Sinclair, M., \& Wideman, H. (2006, April). Evaluation of a blended learning professional development program for middle-school mathematics ans science teachers. Paper presented at the Annual meeting of the American Educational Research, San Francisco.

Pajares, M. (1992). Teachers beliefs and educational research: Cleaning up a messy construct. Review of Educational Research, 62(3), 307-332.

Parchmann, I., Gräsel, C., Baer, A., Nentwig, P., Demuth, R., \& Ralle, B. (2006). “Chemie im Kontext": A symbiotic implementation of a context-based teaching and learning approach. International Journal of Science Education, 28(9), 1041-1062.

Penuel, W. R., Fishman, B. J., Yamaguchi, R., \& Gallagher, L. P. (2007). What makes professional development effective? Strategies that foster curriculum implementation. American Educational Research Journal, 44(4), 921-958. doi: 10.3102/0002831207308221

Pintrich, P. R. (2003). A motivational science perspective on the role of students' motivation in learning and teaching contexts. Journal of Educational Psychology, 95(4), 667-686.

Plomp, T. (2009). Educational design research: An introduction. In T. Plomp \& N. Nieveen (Eds.), An introduction to educational design research. Shanghai: Retrieved 15 May, 2012 from www.slo.nl/organisatie/international/publications.

Prins, G. (2011). Teaching and learning of modelling in chemistry education. Authentic practices as contexts for learning. Doctoral dissertation: Utrecht University, The Netherlands.

Putnam, R., \& Borko, H. (2000). What do new views of knowledge and thinking have to say about research on teacher learning? Educational Reseacher, 29(1), 4-15.

Rebar, B. (2010). Evidence, explanations, and recommandations for teachers'field trip strategies. Doctoral dissertation: Oregon State Univerisity.

Reeves, T. C. (2006). Design research from a technology perspective. In J. J. H. van den Akker, K. Gravemeijer, S. McKenney, \& N. Nieveen (Eds.), Educational design research (pp. 52-66). Abington Oxon: Routledge.

Rice, J. K., Croninger, R. G., \& Roellke, C. F. (2002). The effect of block scheduling high school mathematics courses on student achievement and teachers' use of time: Implications for educational productivity. Economics of Education Review, 21(6), 599-607. 
Richter, D., Kunter, M., Klusmann, U., Lüdtke, O., \& Baumert, J. (2011). Professional development across the teaching career: Teachers' uptake of formal and informal learning opportunities. Teaching and Teacher Education, 27(1), 116-126. doi: 10.1016/j.tate.2010.07.008

Rousseau, C. K. (2004). Shared beliefs, conflict, and a retreat from reform: The story of a professional community of high school mathematics teachers. Teaching and Teacher Education, 20(8), 783-796.

Rovai, A. P. (2003). A practical framework for evaluating online distance education programs. Internet and Higher Education, 6, 109-124.

Sa, C. M. (2008). Interdisciplinary strategies' in U.S. research universities. Higher Education, 55, 537-552. doi: 10.1007/s10734-007-9073-5

Şahin, F., Sarı, A., Demir, S., Demirci, N., \& Usta, S. (2010). Intersection of different disciplines: Elements. Social and Behavioral Sciences, 2(2), 2992-2996.

Schneider, R. M., Krajcik, J., \& Blumenfeld, P. (2005). Enacting reform-based science materials: The range of teacher enactments in reform classrooms. Journal of Research in Science Teaching, 42(3), 283-312.

Schwab, J. J. (1973). The practical 3: Translation into curriculum. The school review, 81(4), 501-522.

Shulman, S. (1987). Knowledge and teaching: Foundations of the new reform. Harvard Educational Review, 57(1), 1-22.

SLO. (2007). Programma PPO-project 'Discobizz' TCC de Thij: Retrieved 25 June, 2012 from http://www.slo.nl/voortgezet/onderbouw/themas/lrjr3/ppo/EenM/discobizz_lln mat.doc/.

Steering Committee NLT. (2007). Outline of a new subject in the sciences. A vision of an interdisciplinary subject: Advanced Science, Matematics and Technology (ASMaT) [Contouren van een nieuw bètavak. Visie op een interdisciplinair vak: Natuur, Leven en Technologie (NLT)], from

http://betavak-nlt.nl/Landelijk/Invoerscholen/Criteria/

Steering Committee NLT. (2010). Advies beproefd examenprogramma NLT; eindrapportage Stuurgroep NLT [Tested NLT examinationprogramme; final report Steering Committee NLT].

Stolk, M. J., Bulte, A. M. W., de Jong, O., \& Pilot, A. (2009). Strategies for a professional development programme: Empowering teachers for context-based chemistry education. Chemistry education research and practice, 10(2), 154-163. doi: $10.1039 / \mathrm{b} 908252 \mathrm{~m}$

Stolk, M. J., De Jong, O., Bulte, A. M. W., \& Pilot, A. (2011). Exploring a framework for professional development in curriculum innovation: Empowering teachers for designing context-based chemistry education. Research in Science Education 41(3), 369388. doi: $10.1007 /$ s11165-010-9170-9

Teaching and Learning Research Programme. (2006). Science education in schools issues, evidence and proposals, from http://www.tlrp.org/pub/documents/TLRP_Science_Commentary_FINAL.pdf

Terlouw, C. (2009). Leren door te stromen en aan te sluiten (Lectorale rede). Enschede, The Netherlands: Saxion Kenniscentrum Onderwijs \& Innovatie. 
Van den Akker, J. J. H. (1998). The implementation of teaching materials in educational practice [De implementatie van onderwijsleermiddelen in de onderwijspraktijk]. In B. P. M. Creemers (Ed.), Onderwijskundig lexicon editie III (pp. 49-58). Alphen aan den Rijn: Kluwer.

Van den Akker, J. J. H. (1999). Principles and methods of development research. In J. J. H. Van den Akker, R. Maribe Branche, K. Gustafson, N. Nieveen, \& T. Plomp (Eds.), Design approaches and tools in education and training (pp. 1-14). Dordrecht, the Netherlands: Kluwer Academic Publishers.

Van den Akker, J. J. H. (2003). Curriculum perspectives: An introduction. In J. J. H. van den Akker, W. Kuiper, \& U. Hameyer (Eds.), Curriculum landscape and trends. Dordrecht: Kluwer Academic Publishers.

Van den Akker, J. J. H., Gravemeijer, K., McKenney, S., \& Nieveen, N. (2006). Educational design research. Abingdon, Oxon: Routledge.

Van Driel, J. H., Beijaard, D., \& Verloop, N. (2001). Professional development and reform in science education: The role of teachers' practical knowledge. Journal of Research in Science Teaching, 38(2), 137-158.

Van Rooijen, E., Kalders, P., \& Van den Hout, E. (2004). Onderwijs en innovatie. Quick scan en case studie. Den Haag: B\&A Groep Beleidsonderzoek \&- Advies.

Van Veen, K., \& Sleegers, P. (2006). How does it feel? Teachers' emotions in a context of change. Journal of Curriculum Studies, 38(1), 85-111.

Van Veldhuizen, G. (2011). Learning at work, working to learn; Professional development of teachers from the personal and organizational perspective. Docteral dissertation: University of Utrecht; The Netherlands.

Van Wessum, L. (1997). The subject matter departments as unity: Collaboration and conceptions of professionalism in secondary education [De sectie als eenheid: Samenwerking en professionaliteitsopvattingen van docenten in het voortgezet onderwijs]. Doctoral dissertation: Utrecht University, The Netherlands.

Verhagen, P. W., Kuiper, W., \& Plomp, T. (1999, February). Educating educational designers: The case of a generic model. Paper presented at the Association for Educational Communications and Technology convention, Houston, Texas.

Vermunt, J. D. (2006). Docent van deze tijd: Leren en laten leren. Oratie: Universiteit Utrecht, The Netherlands.

Vescio, V., Rossa, D., \& Adams, A. (2008). A review of research on the impact of professional learning communities on teaching practice and student learning. Teaching and Teacher Education, 24(1), 80-91. doi: 10.1016/j.tate.2007.01.004

Visscher-Voerman, I. (1999). Design approaches in training and education: A reconstructive study. Doctoral dissertation: University of Twente, The Netherlands.

Visscher-Voerman, I., \& Gustafson, K. L. (2004). Paradigms in the theory and practice of education and training design. Educational Technology Research and Development, 52(2), 69-89.

Visser, T. C., Coenders, F. G. M., Terlouw, C., \& Pieters, J. M. (2010). Essential characteristics for a professional development program for promoting the implementation of a multidisciplinary science module. Journal of Science Teacher Education, 21(6), 623-642. doi: 10.1007/s10972-010-9212-1

Visser, T. C., Coenders, F. G. M., Terlouw, C., \& Pieters, J. M. (2012a). Design of a model for a professional development programme for a multidisciplinary science subject in the Netherlands. Professional Development in Education, 1-4. doi: $10.1080 / 19415257.2012 .669393$ 
Visser, T. C., Coenders, F. G. M., Terlouw, C., \& Pieters, J. M. (2012b). Evaluating teachers' satisfaction about a professional development programme for a multidisciplinary science subject. Submitted.

Visser, T. C., Coenders, F. G. M., Terlouw, C., \& Pieters, J. M. (2012c). Evaluating teachers' satisfaction about a professional development programme for implementation of a multidisciplinary science subject. Submitted.

Voogt, J., Fisser, P., Pareja Roblin, N., Tondeur, J., \& van Braak, J. (2012). Technological pedagogical content knowledge - a review of the literature. Journal of Computer Assisted Learning. doi: 10.1111/j.1365-2729.2012.00487.x

Voogt, J., Westbroek, H., Handelzalts, A., Walraven, A., McKenney, S. E., Pieters, J. M., \& De Vries, B. (2011). Teacher learning in collaborative curriculum design. Teaching and Teacher Education, 28(8), 1235-1244. doi: 10.1016/j.tate.2011.07.003

Wang, P.-Y., \& Yang, H.-C. (2012). Using collaborative filtering to support college students' use of online forum for English learning. Computers $\mathcal{E}$ Education, 59(2), 628-637. doi: 10.1016/j.compedu.2012.02.007

Waslander, S. (2007). Learning about innovation. Review of scientific research on sustained innovation in secondary education [Leren over innoveren]. VO-project Innovatie Expeditie durven, delen, doen, Utrecht.

Wikeley, F. (2005). Evaluating effective school improvement. School Effectiveness and School Improvement, 16(4), 387-406.

Witziers, B., Sleegers, P., \& Imants, J. (1999). Departments as teams: Functioning, variations and alternatives. School Leadership and Management, 19(3), 293-304.

Yin, R. K. (2003). Case study research, design and methods. (3rd ed.). London: Sage. 


\section{ENGLISH SUMMARY}

Schoolteachers must deal with curriculum innovations during their teaching careers. In 2005, the Dutch Ministry of Education, Culture and Science introduced committees to develop and redesign the curricula for chemistry, biology, physics, and mathematics in secondary education. The purpose of redesigning the curricula was to increase the attractiveness of science education and attract more students for science studies, which is consistent with the Government's efforts to strengthen the Dutch knowledge-based economy. Another important motive was to increase the coherence between the traditional science subjects. In addition, a national steering committee was installed in 2006 with the task of developing a new multidisciplinary subject 'Nature, Life, and Technology (NLT)', also known as Advanced Science, Mathematics, and Technology (ASMaT).

NLT was introduced into the science curriculum of the upper level of secondary education in August 2007. NLT is an optional science subject, in which the curriculum is contextually based and has a modular structure. A teaching module consists of a professional or situated practice from everyday life (for example, Forensic research or MP3-players) in which specific concepts traditionally belonging to physics, chemistry, biology, mathematics, and physical geography are explored. At the school level, the implementation of NLT has four specific features outlined by the NLT Steering Committee: a) Teachers from the different science disciplines cooperate in a multidisciplinary team; b) Teachers of NLT have a degree in one of the five relevant mono-disciplinary subjects; c) The multidisciplinary team of teachers at the school has the freedom to select the modules and decides on the order in which the modules will be taught; d) The school administration, in close consultation with the team of teachers, determines which and how many teachers will be teaching a specific module. 
At the class level, NLT has five particular characteristics defined by the NLT Steering Committee: a) Given the specific character of NLT, instructional strategies are more diverse than those used in the mono-disciplines; b) Students are not obliged to take biology, physics or geography; c) Teachers have the freedom to make changes to the subject content; d) The assessment methods and instruments are more diverse; e) Students are brought into contact with a broad range of higher education studies and possible careers through organizing field trips and guest lectures.

The specific features of NLT and its characteristics mean that it has the nature of a curriculum innovation. Teachers can be prepared for this by a professional development programme. The general goal of this study was to determine what kind of professional development strategy would result in a successful implementation of NLT in schools and classrooms. We focused on identifying the essential characteristics for developing a professional development programme to improve the implementation of a multidisciplinary module, and to design and implement such a professional development programme, followed by the evaluation of this programme.

This dissertation was inspired by design-based research, with the following general research question:

'What is the effectiveness of a professional development programme as a strategy for improving the implementation of a multidisciplinary science curriculum?'

The general question is addressed by three sub-studies. The empirical and theoretical literature, questionnaires, and interviews were used in the different sub-studies to answer the research question.

Sub-study one, reported in chapter 2 , describes the essential characteristics for a professional development programme that promotes the acquisition of teacher competences required for the implementation of a multidisciplinary science module. Three data sources were used to identify these characteristics: Empirical evidence from the classroom settings of the schools, specific curriculum features of the NLT subject, and theoretical and empirical evidence generated by curriculum implementation literature. Analysis of the data identified five characteristics as essential for incorporation into such a professional development programme. The essential characteristics are: (a) Teachers should develop their knowledge, (b) teachers should cooperate with 
colleagues, (c) teachers should network, (d) the module should be made relevant and attractive for students, and (e) teachers should be well prepared and organized for their lessons.

Sub-study two, reported in chapter 3, describes the design of a generic model for a professional development programme to prepare and assist teachers for a multidisciplinary science module. The generic model is translated into a programme suitable for the specific NLT module, called 'The hydrogen car'. The generic model consists of three phases and four stages: The before teaching phase consisting of individual preparation and a collaborative preparation seminar; the during teaching phase consisting of online support; and the after teaching phase consisting of a collaborative reflection meeting.

In sub-study three, the implemented professional development programme is evaluated. Eleven teachers from four different schools participated in two professional development programmes, six teachers in the first professional development programme and five teachers in the subsequent module. The selected NLT-modules were new for all teachers.

The evaluation of Level 1 'participants' reaction' from Guskey's five-level evaluation model is reported in chapter 4. Overall, the participating teachers positively appreciated this professional development programme; several elements of the programme stages ensured teacher satisfaction.

In chapter 5, the remaining four levels of Guskey's model are used to evaluate the professional development programme in terms of its effectiveness. Levels 2 through 5 are: participants' learning, organizational support, participants' use of new knowledge and skills, and student learning outcomes. Throughout the designed professional development programme, the focus was on the following seven learning areas: (a) instructional strategies, (b) differences in students' prior knowledge, (c) adjustments to the module, (d) assessment methods and instruments, (e) field trips and guest lectures, (f) collaboration with colleagues, and (g) content knowledge. The effects are described for these seven learning areas. The findings show that the professional development programme is a useful venture for teachers' professional growth in different learning areas. All teachers but one learned for more than half of the learning areas. Teacher learning outcomes showed that the professional development programme was more successful when it was directly linked to immediate school practice and to teachers' prior knowledge. 
In chapter 6, we reflect on the different phases of design-based research and its outcomes. In this chapter we also describe the difficult elements of this programme, and suggest how these difficulties can be handled.

This dissertation ends with design principles comprising heuristics that can inform future efforts at designing a professional development programme. Should future designers seek to develop a specific programme to prepare and assist teachers for a multidisciplinary (science) module and have teachers learn in the seven learning fields based on a generic model for a professional development programme, they can use the design principles that have been generated from this research. 


\section{NEDERLANDSE SAMENVATTING}

Docenten komen regelmatig in aanraking met curriculumvernieuwingen. In 2005 heeft het ministerie van Onderwijs, Cultuur en Wetenschap vernieuwingscommissies voor de verschillende bètavakken (biologie, natuurkunde, scheikunde en wiskunde), ingesteld. De commissies moeten de curricula herontwerpen, met als doel om vooral de inhoud te moderniseren, om zo meer belangstelling van leerlingen voor bèta- en techniekstudies te wekken. Dat sloot aan bij het streven van de regering om Nederland als kenniseconomie te versterken. Een belangrijk motief was echter ook meer samenhang tussen de bètavakken aan te brengen. Als aanvulling daarop werd in 2006 een extra commissie ingesteld met het doel om een nieuw multidisciplinair bètavak te ontwikkelen: Natuur, Leven en Technologie (NLT).

NLT is geïntroduceerd in augustus 2007 als profielkeuzevak voor leerlingen in de natuurprofielen van havo en vwo en wordt met een schoolexamen afgesloten. NLT is een optioneel multidisciplinair bètavak waarbij het curriculum is gebaseerd op contexten en het heeft een modulaire structuur. Een module bestaat uit een bestaande praktijk (bijvoorbeeld: forensische technieken of mp3-speler) waarin verschillende concepten uit de geïntegreerde bètavakken aan de orde komen. Op schoolniveau heeft de implementatie van NLT vier specifieke kenmerken, beschreven door de NLT stuurgroep: a) docenten natuurkunde, scheikunde, biologie, wiskunde en fysische geografie werken samen in een multidisciplinaire sectie; b) docenten die NLT geven hebben een eerstegraadsopleiding in een van de bovengenoemde monodisciplines; c) de sectie heeft de vrijheid modules te selecteren voor elk examendomein en bepaalt in welke volgorde die modules worden gegeven; en d) het management van de school bepaalt samen met de sectie welke en hoeveel docenten de specifieke modules zullen geven.

Op klassenniveau heeft NLT vijf specifieke karakteristieken: a) Gezien de multidisciplinariteit zijn de werkvormen meer divers dan bij de 
monodisciplines; b) niet alle leerlingen hebben alle bètavakken die deel uit maken van NLT in hun vakkenpakket; c) docenten hebben de vrijheid om veranderingen aan te brengen in de inhoud van het vak; d) ook de toetsvormen zijn meer divers; en e) leerlingen komen in aanraking met opleidingen en beroepen door excursies en gastcolleges.

Genoemde specifieke NLT-kenmerken impliceren een curriculumvernieuwing en docenten kunnen hierop worden voorbereid door middel van een professionaliseringsprogramma. Het algemene doel van deze studie was: Het bepalen van essentiële kenmerken voor een professionaliseringsprogramma. Deze essentiële kenmerken verbeteren de implementatie van een multidisciplinaire bètamodule. Met behulp van onder andere deze kenmerken werd een dergelijk professionaliseringsprogramma ontwerpen. Vervolgens werd het professionaliseringsprogramma geïmplementeerd voor twee specifieke NLT- modules, geëvalueerd en de effecten werden bepaald.

Dit proefschrift kan worden gekarakteriseerd als een ontwerp-gericht onderzoek, met als algemene onderzoeksvraag:

"Wat is de effectiviteit van een professionaliseringsprogramma, als strategie om de implementatie van een multidisciplinair bètacurriculum te verbeteren."

De beantwoording van de algemene onderzoeksvraag geschiedt door middel van drie deelstudies. Daarbij wordt gebruik gemaakt van literatuur, vragenlijsten en interviews.

In de eerste deelstudie, weergegeven in hoofdstuk 2, staat beschreven wat de essentiële kenmerken zijn voor een professionaliseringsprogramma dat de implementatie van een multidisciplinaire bètamodule bevordert. Drie bronnen worden gebruikt om deze kenmerken te identificeren: empirische gegevens vanuit het klaslokaal, kenmerken van het nieuwe vak NLT en theoretische en empirische gegevens van curriculum implementatiestudies. De analyse van data laat zien dat er vijf kenmerken zijn die speciaal aandacht nodig hebben in een dergelijk professionaliseringsprogramma. Deze essentiële kenmerken zijn: (a) docenten moeten hun kennis ontwikkelen, (b) docenten moeten samenwerken met collega's, (c) docenten moeten netwerken, (d) de module moet relevant en aantrekkelijk gemaakt worden voor de leerlingen en (e) docenten moeten goed voorbereid zijn voor de lessen. 
In deelstudie twee, beschreven in hoofdstuk 3, wordt een ontwerp beschreven van een generiek model voor een professionaliseringsprogramma dat docenten voorbereidt en helpt met de implementatie van een multidisciplinaire bètamodule. Vervolgens wordt dit generieke model toegepast op een specifieke NLT-module, genaamd "De waterstof auto". Het generieke model is opgebouwd uit drie periodes en vier fasen: de periode vóór het lesgeven bestaat uit een individuele voorbereiding en een gezamenlijke voorbereidingsbijeenkomst. De periode tijdens het lesgeven bestaat uit een online ondersteuning. De periode na het lesgeven bevat een gezamenlijke reflectiebijeenkomst.

In de derde deelstudie wordt het geïmplementeerde professionaliseringsprogramma geëvalueerd en worden de effecten bepaald. Elf docenten van vier verschillende scholen hebben deelgenomen aan twee professionaliseringsprogramma's; zes docenten namen deel aan het eerste professionaliseringsprogramma en vijf docenten aan het daaropvolgende programma. De geselecteerde NLT-modules waren nieuw voor alle docenten.

In hoofdstuk 4 wordt de evaluatie beschreven aan de hand van het eerste niveau "reacties van deelnemers" van Guskeys five-level evaluatiemodel. In het algemeen waren de docenten positief over het professionaliseringsprogramma en gaven ze aan dat verschillende onderdelen uit het programma, zoals inrichting van het programma en bespreken van eigen ingebrachte punten, zorgen voor voldoening.

In hoofdstuk 5 worden de effecten van het geïmplementeerde professionaliseringsprogramma beschreven aan de hand van de overgebleven vier niveaus van Guskeys evaluatiemodel. De niveaus twee tot en met vijf zijn respectievelijk: leerresultaten van de deelnemers, organisatorische ondersteuning, gebruik van geleerde kennis en vaardigheden door de deelnemers en leeropbrengst van de leerlingen. Gedurende het professionaliseringsprogramma lag de focus op zeven leergebieden: (a) werkvormen, (b) verschil in voorkennis van leerlingen, (c) aanpassingen aan de module, (d) toetsvormen, (e) excursies en gastcolleges, (f) samenwerking met collega's en (g) vakinhoudelijke kennis. De effecten zijn voor deze zeven leergebieden in kaart gebracht. Geconcludeerd kan worden dat over het algemeen het professionaliseringsprogramma heeft bijgedragen aan de professionele groei van de docenten op de verschillende leergebieden. De leerresultaten van docenten in dit onderzoek laten onder andere zien dat een 
professionaliseringsprogramma dat aansluit bij de dagelijkse schoolpraktijk en bij de voorkennis van docenten succesvoller is.

In hoofdstuk 6 wordt gereflecteerd op de verschillende fasen van het ontwerpgerichte onderzoek en op de uitkomsten. In dit hoofdstuk wordt ook beschreven wat de moeilijke elementen zijn voor een dergelijk professionaliseringsprogramma en hoe hier mee omgegaan kan worden.

Als afsluiting van dit proefschrift zijn ontwerpprincipes ontworpen als handvatten voor toekomstige ontwerpers. Wanneer een toekomstige ontwerper een specifiek programma wil ontwerpen om docenten voor te bereiden en te assisteren voor een multidisciplinaire (bèta)module en deze docenten wil laten leren in de zeven leergebieden. Dan kunnen de beschreven ontwerpprincipes gebaseerd op een generiek model voor een professionaliseringsprogramma dienen als handvatten in het ontwerp. 


\section{DANKWOORD}

Eindelijk ligt het er dan, mijn proefschrift. Mijn promotieonderzoek is gestart in september 2007 en na vijf intensieve, afwisselende, onstuimige, drukke, mooie en leerzame jaren ben ik blij dat ik deze kans heb gegrepen, maar ben ik ook opgelucht dat het $\mathrm{nu}$ is afgerond. Tijd dus voor een niet verplicht, maar wel zeer gemeend woord van dank.

Dank omdat -zoals zo vaak gezegd- je een proefschrift niet alleen schrijft en naast enkele instanties waarzonder dit proefschrift nooit tot stand had kunnen komen er ook een groot aantal mensen bij betrokken is geweest van wie ik er hier een aantal met naam en toenaam wil noemen.

Dit proefschrift was niet tot stand gekomen zonder de medewerking van zowel het Platform Bèta Techniek, dat met steun van het ministerie van OCW het programma DUDOC (Didactisch Universitair onderzoek van DOCenten naar vernieuwing van de bètavakken) heeft ingesteld als wel de medewerking van mijn school CSG Het Noordik en de Universiteit Twente. Hierdoor kreeg ik als docent de mogelijkheid om op mijn school voor drie dagen vrijgesteld te worden van lestaken. Ik kreeg de gelegenheid om drie dagen in een onderzoeksomgeving op de Universiteit Twente bij ELAN onderzoek te verrichten en toch ook nog enkele dagen op mijn eigen school in de praktijk waar mijn onderzoek betrekking op heeft - werkzaam te blijven. Platform Bèta Techniek; CSG Noordik en Universiteit Twente: dank voor deze kans die jullie mij geboden hebben.

Naast de organisaties zoals hierboven genoemd, zijn het natuurlijk vooral de personen die ik expliciet wil noemen. Met veel mensen heb ik de afgelopen jaren persoonlijk of virtueel contact gehad en ik mag stellen dat alle op hun eigen wijze hebben bijgedragen aan dit proefschrift en vanwege hun persoonlijke betrokkenheid ook vaak nog aan mijn persoonlijke motivatie. Aan 
het einde van dit proces, aan het einde van dit speciaal stukje levenservaring wil ik - in willekeurige volgorde - hen allen hiervoor bedanken.

Mijn promotoren Jules Pieters, Cees Terlouw en Fer Coenders van de Universiteit Twente wil ik bedanken voor hun vertrouwen en support in de afgelopen jaren, maar ook voor het begrip dat alle drie in de voor mij soms lastige tijden ten toon hebben gespreid. Cees: bedankt dat je in het begin, voordat er zelfs een promotor aanwezig was, me al hebt willen helpen bij het opstarten van het onderzoek. Wat fijn dat je ook nog bij het onderzoek betrokken wilde blijven toen er een promotor kwam en je elders ging werken. Je precieze commentaar, het aandragen van literatuursuggesties en je creatieve ideeën bezorgden mij vaak nieuwe inzichten. Zo zal ik me nog lang de verhelderende tabellen en matrixen die refereerden naar Miles and Huberman blijven herinneren als een eye-opener en prima suggestie. Fer: je was mijn zo genoemde dagelijks begeleider. Dank en lof voor je wekelijkse belangstelling, je veelvuldige en vaak heel specifieke suggesties en niet in de laatste plaats dank voor je immers voortdurende kritische blik. Jules, bedankt dat je je na een jaar bij het onderzoek hebt aangesloten als promotor. Je constructieve commentaar en overkoepelende blik op het geheel gaf vaak een verhelderende kijk op waar ik stond, zodat ik weer verder kon gaan. Samen met de toegankelijkheid en vaak snelle reacties zorgde dit voor een goede basis voor dit proefschrift.

Het was heel plezierig om met een dergelijk gevarieerd begeleidersteam te werken. Ondanks jullie soms ogenschijnlijke overdosis aan opmerkingen en commentaar slaagden jullie in de opzet ervoor te zorgen dat de sfeer positief bleef en ik (bijna elke keer) positief uit onze gezamenlijke gesprekken kwam zodat ik met frisse moed en vol enthousiasme door ging. Niet in de minste plaats zijn het ook jullie belangstellende en waarderende telefoontjes en mailtjes geweest die mij vaak net weer dat extra zetje gaven. Bedankt voor deze plezierige en goede begeleiding; deze heeft me enorm gesteund en geholpen en ervoor gezorgd dat er niet alleen een mijns inziens geweldig proefschrift ligt maar ook dat ik me de afgelopen jaren daardoor enorm persoonlijk heb ontwikkeld en in vele opzichten ben gegroeid.

Al hoewel CSG Het Noordik als organisatie hier reeds al is genoemd wil ik expliciet de toenmalige directeur Wim Diepeveen bedanken voor de mogelijkheid die ik heb gekregen om aan dit uitzonderlijke programma mee te doen. Niet in de laatste plaats wil ik - wanneer ik het hier over mijn geweldige school heb- mijn collega's bedanken voor de enorme support. Aukje Hoogwijk 
en Leontine de Graaf; jullie hebben er voor gezorgd dat het werk op school altijd door kon gaan. Jullie hebben werk voor me uit handen genomen op een wijze dat zelfs leerlingen nooit last hebben ondervonden van het feit dat ik slechts twee dagen op school was. In dit kader wil ik ook geenszins vergeten om Merlin Swart en Nienke Velthuis voor het meenemen van werk en regelen van situaties op school te noemen. Annelies, Ellis, Jeanette en Petra van de administratie; bedankt voor de flexibiliteit die ik soms van jullie vroeg en die er altijd bleek te zijn. Ook wil ik de natuurkunde-scheikunde sectie bedanken voor hun steun en belangstelling. Wanneer het om CSG Het Noordik gaat last but not least de collega's van het zogenoemde 'Rokershok'. Een ieder bedankt voor de steun, belangstelling maar vooral de gezelligheid tijdens de pauzes en uitjes. Ik kreeg er altijd weer energie van om door te gaan wanneer ik jullie weer drie dagen moest verlaten.

Ik wil Pauline Teppich, Marion Meenink en Paula Krupers bedanken voor de hulp van het organiseren en afronden van allerlei zaken de afgelopen jaren. Sandra Schele voor de laatste afrondende fase van mijn proefschrift. Mijn kamergenoten Ellen Donkers en Andrea Scholz voor de steun tijdens het begin van mijn promotie en Nico Rutten en Daan van Smaalen voor de steun tijdens de laatste jaren van mijn promotie. Daarnaast natuurlijk ook alle andere (ex)collega's van ELAN voor de steun, de interessante gesprekken en de fijne samenwerking de afgelopen jaren.

Het mag duidelijk zijn dat ook de bereidheid van de docenten die mee hebben gewerkt in mijn onderzoek zeer door mij op prijs is gesteld. Ik weet ondanks de (te) hoge werkdruk die er in het onderwijs is en de grote hoeveelheid verzoeken voor medewerking die er op de gemiddelde docent afkomen jullie bereidheid op de door mij gedane verzoeken tot medewerking groot was. Anneke, Carla, Eltjo, Harry, Jan S., Jan de W., Jell, Jos, Peter en Richard: bedankt. Ik vertrouw er op dat ik met dit proefschrift hier iets tegenover heb kunnen stellen en dat de uitslag van dit onderzoek voor jullie en voor de experts Hanna, Jan-Jaap en Leontine op termijn van waarde zal zijn in jullie schoolpraktijk. Ik hoor het graag.

Binnen de DUDOC-community wil ik de leden van de programmaraad bedanken. Maar ook mijn mede DUDOC-ers van tranche 2007 en tranche 2008 voor de gezelligheid en inhoudelijke bijdrage tijdens onze bijeenkomsten. 
Voor wat betreft de tekstuele en stylistische aspecten van dit proefschrift wil ik Emily Fox en Marjan Soenveld bedanken voor de verbeteringen, opmerkingen en suggesties die jullie mij hebben gegeven. Emily: thank you for making suggestive edits and questions.

Omdat naast het vele werk ook de nodige ontspanning nodig is om de zaag scherp te houden, dank ik de meiden en coach van volleybal. Ook naaste vrienden bedank ik graag voor het begrip en de noodzakelijke afleiding en het onontbeerlijke plezier dat jullie mij hebben gegeven.

Papa \& Mama, Jeanine \& Jan Kees, Elvira \& Koen, Jan \& Akkie, Rob \& Leonie, Eric \& Caja en alle andere familieleden: bedankt voor de steun en support al die jaren.

Merle - lieve dochter - ook jij zult voor mij verbonden blijven met dit proefschrift. Halverwege het promotietraject raakte ik in verwachting van jou. Door jou en door mijn niet eenvoudig verlopen zwangerschap, ben ik een stuk rustiger geworden en kan ik nog meer genieten van de belangrijke momenten van het leven. Bedankt!

Ter afsluiting wil ik mijn lieve man Peter bedanken. De steun die je als promovendus ondervindt van je partner lijkt vanzelfsprekend, maar is dit natuurlijk niet altijd. Het werken aan mijn promotieonderzoek en het schrijven van mijn proefschrift was slechts mogelijk bij de gratie van veel uithoudings- en incasseringsvermogen. Hoogte- en dieptepunten hebben we samen meegemaakt: een trouwerij, twee niet altijd even eenvoudige zwangerschappen, een kind en een promotie. Hopelijk breken na de komst van onze tweede dochter iets rustigere tijden aan waarin we nog meer van elkaars gezelschap kunnen genieten zonder dat we aan een project bezig zijn.

Tenslotte bedank ik allen die ik vergeten zou kunnen zijn, die op enigerlei wijze een steentje hebben bijgedragen aan de totstandkoming van het resultaat.

Dank, dank, dank .... Ik ga uitrusten, bevallen en genieten.

\section{Talitha Visser}




\section{APPENDIX \\ Questionnaire used for the expert appraisal}

\section{Questions}

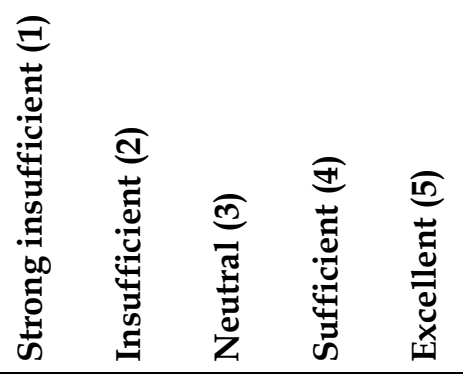

1. Teachers have different Master's degree for at least one subject.

Do you think the generic model adequately takes this fact into account?

2. Professional development culture of Dutch school. Do you think the generic model adequately takes this fact into account?

3. Students haven't acquired similar prior knowledge. Do you think the generic model adequately takes this fact into account?

4. Possibility to change parts in subject matter. Do you think the generic model adequately takes this fact into account?

5. Assessment methods. Do you think the generic model adequately takes this fact into account?

6. Do you think the generic model adequately takes the module selection and preparation phase into account?

7. Do you think the generic model adequately takes the module teaching and effect phase into account?

8. Do you think the generic model adequately takes the reflection on the module into account?

9. Do you think the generic model gives teachers ample opportunities to acquire new knowledge and skills?

10. Do you think the generic model gives teachers opportunities to make the module relevant and attractive for students?

11. Do you think the generic model adequately prepares and organizes teachers for their lessons?

12. Teachers should cooperate with colleagues. Do you think the generic model gives teachers opportunities to exchange and discuss experiences and ideas with colleagues?

13. Do you think applying the generic model could lead to a wellorganized network in which teachers from different schools participate? 


\section{CURRICULUM VITAE}

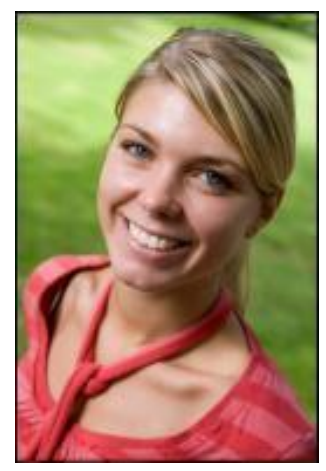

Talitha Visser-Veenhoven was born on December 24 in 1980 in Dronten, The Netherlands. In 2003 she obtained her bachelor degree magna cum laude, for her teacher qualification at HAN University of applied scientist in Nijmegen. She combined her study with working as a laboratory employee at Levensmiddelen Analyse Bureau Flevolab in Zeewolde. After traveling for ten months around the world she started working on a freelance- base for the SLO the Dutch institute for curriculum development. In 2004, she began working toward her Master's degree at the Institute for Teacher Education, Science Communication \& School Practices at the University of Twente, from which she graduated in 2006. She started working as a chemistry teacher at the CSG Het Noordik in Almelo in August 2006 and from 2007 also as a Nature, Life and Technology teacher. In September 2007 she started her PhD-studies at the University of Twente funded by the DUDOC-programme combined with her job in Almelo.

Talitha is married to Peter in July 2008, they have a daughter Merle from March 2010 and they expect a daughter in November 2012. 


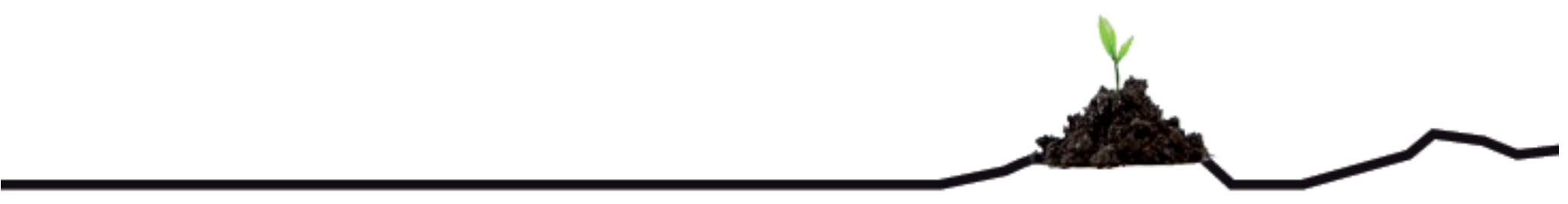

